\title{
The Enduring Effects of Earlier Trauma on Seniors' Well-Being
}

by

Jacqueline M. Wickett, B.A.

\author{
A thesis submitted to the \\ Faculty of Graduate Studies and Research \\ in partial fulfillment of the requirements for the degree of \\ Masters of Arts
}

Department of Psychology

\author{
Carleton University \\ Ottawa, Ontario
}

September, 2005 


$\begin{array}{ll}\begin{array}{l}\text { Library and } \\ \text { Archives Canada }\end{array} & \begin{array}{l}\text { Bibliothèque et } \\ \text { Archives Canada }\end{array} \\ \begin{array}{l}\text { Published Heritage } \\ \text { Branch }\end{array} & \begin{array}{l}\text { Direction du } \\ \text { Patrimoine de l'édition }\end{array} \\ \begin{array}{l}\text { 395 Wellington Street } \\ \text { Ottawa ON K1A ON4 }\end{array} & \begin{array}{l}\text { 395, rue Wellington } \\ \text { Ottawa ON K1A ON4 } \\ \text { Canada }\end{array}\end{array}$

Your file Votre référence

ISBN: 0-494-10076-1

Ourfile Notre référence

ISBN: 0-494-10076-1

NOTICE:

The author has granted a nonexclusive license allowing Library and Archives Canada to reproduce, publish, archive, preserve, conserve, communicate to the public by telecommunication or on the Internet, loan, distribute and sell theses worldwide, for commercial or noncommercial purposes, in microform, paper, electronic and/or any other formats.

The author retains copyright ownership and moral rights in this thesis. Neither the thesis nor substantial extracts from it may be printed or otherwise reproduced without the author's permission.
AVIS:

L'auteur a accordé une licence non exclusive permettant à la Bibliothèque et Archives Canada de reproduire, publier, archiver, sauvegarder, conserver, transmettre au public par télécommunication ou par l'Internet, prêter, distribuer et vendre des thèses partout dans le monde, à des fins commerciales ou autres, sur support microforme, papier, électronique et/ou autres formats.

L'auteur conserve la propriété du droit d'auteur et des droits moraux qui protège cette thèse. $\mathrm{Ni}$ la thèse ni des extraits substantiels de celle-ci ne doivent être imprimés ou autrement reproduits sans son autorisation.
In compliance with the Canadian

Privacy Act some supporting forms may have been removed from this thesis.

While these forms may be included in the document page count, their removal does not represent any loss of content from the thesis.
Conformément à la loi canadienne sur la protection de la vie privée, quelques formulaires secondaires ont été enlevés de cette thèse.

Bien que ces formulaires aient inclus dans la pagination, il n'y aura aucun contenu manquant.

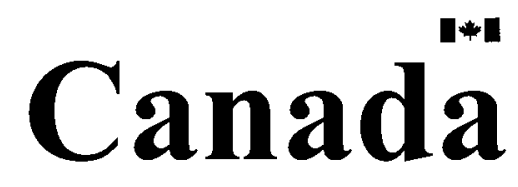




\begin{abstract}
The present study examined the effects of earlier exposure to interpersonal and non interpersonal trauma on seniors' psychological, physical and social well-being and the processes by which these effects occur. A community sample of 310 senior men and women age 60 and over completed a survey with measures of their experiences of trauma, well-being and measures of coping, reminiscence, current stress, and exposure to the traumagenic dynamics. Correlational analyses indicated that senior survivors of interpersonal trauma had poorer psychological and physical well-being and path analyses revealed that negative reminiscence, current stress and the traumagenic dynamics mediated this relation. In contrast, senior survivors of noninterpersonal trauma had poorer physical well-being and a hierarchical regression analysis indicated this relation was moderated by current stress. The strengths and limitations of this research, as well as the implications of these findings for interventions designed to enhance senior trauma survivors' well-being and research, are discussed.
\end{abstract}




\section{Acknowledgements}

I'd like to thank my advisor Dr. Connie Kristiansen for her knowledge, expertise, guidance, support and encouragement. I'd also like to thank my friends and family for their support and encouragement. 


\section{Contents}

Effects of Earlier Trauma on Seniors Well-Being 1

Effects of trauma on seniors' psychological well-being 2

Effects of trauma on senior's physical well-being $\quad 10$

Exacerbated, Re-emergent and Delayed PTSD among Senior Trauma Survivors $\quad 14$

Age- and trauma-related declines in coping and PTSD 16

The synergistic processes of trauma and aging $\quad 21$

The Present Study 31

Method

$\begin{array}{ll}\text { Procedure } & 35\end{array}$

$\begin{array}{ll}\text { Participants } & 36\end{array}$

$\begin{array}{ll}\text { Measures } & 41\end{array}$

Results

Preliminary analyses $\quad 54$

$\begin{array}{ll}\text { Main analyses } & 67\end{array}$

$\begin{array}{lr}\text { Additional analyses } & \mathbf{8 0}\end{array}$

$\begin{array}{lr}\text { Discussion } & 82\end{array}$

$\begin{array}{ll}\text { References } & 105\end{array}$

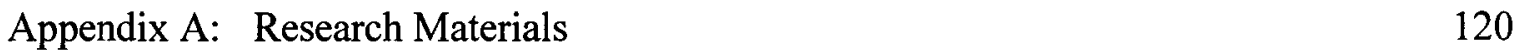

Appendix B: Tables and Figures $\quad 153$ 


\section{List of Tables}

Table 1: $\quad$ Results of the Factor Analysis of the Brief COPE 155

Table 2: $\quad$ Results of Item Analyses and Descriptive Statistics for the Potential 157 Mediating/Moderating Variables

Table 3: $\quad$ Results of the Factor Analysis of the Measure of

Reminiscence

Table 4: $\quad$ Results of the Principal Components Analysis of the

Measure of Exposure to the Traumagenic Dynamics

Table 5: Descriptive Statistics for the Measures of Psychological Well-Being

Table 6: $\quad$ Correlations Among TSI-A Scale Scores

Table 7: $\quad$ Item Loadings for the Principal Components Analysis of the Measure of Physical Health

Table 8: $\quad$ Descriptive Statistics for the Measures of Well-Being

Table 9: $\quad$ Results of the Principal Components Analysis of the Measure of Social Well-Being

Table 10: $\quad$ Frequency of Participants' Experiences of Different Types of Trauma by Gender

Table 11: Descriptive Statistics for Participants' Responses to Questions Regarding their 'Worst' Stressful Experience

Table 12: $\quad$ Frequency of Participants' Experiences of Current Stressors

Table 13: Correlations Between the Potential Mediating/Moderating Variables

Table 14: $\quad$ Simple and Partial Correlations of Measures of Trauma with

Table 15: Correlations of Well-Being with Potential Mediating/Moderating Variables

Table 16: Results of Simultaneous Regression of the Measure of Psychological Well-Being onto the Potential Mediating Variables and Interpersonal Trauma

Table 17: Results of Simultaneous Regression of the Measure of Psychological Well-Being onto the Potential Mediating Variables and Noninterpersonal Trauma

Table 18: Correlations Between Participants Demographic Characteristics and the Trauma, Potential Mediating/Moderating and Well-Being Measures 


\section{List of Figures}

Figure 1: $\quad$ A Model of the Variables Mediating the Impact of Earlier Trauma on Seniors' Well-Being

Figure 2: $\quad$ Results of the Path Analysis Examining Variables Mediating the Effects of Interpersonal Trauma on Well-Being

Figure 3: $\quad$ Results of the Path Analysis Examining Variables Mediating The Effects of Noninterpersonal Trauma on Well-Being

Figure 4: $\quad$ Predicted Scores Associated with the Interactive Effect of 176 Noninterpersonal Trauma and Current Stress on Physical Health

Figure 5: $\quad$ Predicted Scores Associated with the Interactive Effect of Negative Reminiscence and Current Stress on Physical Health

Figure 6: $\quad$ Predicted Scores Associated with the Interactive Effect of 178 Traumagenic Dynamics and Current Stress on Physical Health 


\section{The Enduring Effects of Earlier Trauma on Seniors' Well-Being}

According to Canadian census data, the number of seniors aged 65 and older increased 10\% between 1996 and 2001 (Statistics Canada, 2002a) and the population aged 45 to 64 increased 36\% between 1991 and 2001 (Statistics Canada, 2002b). This increase in the number of seniors poses a number of research challenges, one of which pertains to our understanding of the long-term effects of trauma on seniors' well-being. Seniors' experiences of trauma are far from rare. Norris (1992), for example, interviewed 1000 adults in North and South Carolina about their experiences of ten potentially traumatic events. Of the 321 participants who were sixty years of age or older, $69 \%$ had experienced at least one of the traumatic events. The tragic death of a friend or relative was experienced most often $(25.9 \%)$, followed by robbery $(24.1 \%)$, combat $(20.4 \%)$, and a motor vehicle accident (19.8\%). In addition, $11.7 \%$ had experienced a fire, $8.6 \%$ had been physically assaulted and $1.9 \%$ had been sexually assaulted, while $12.3 \%$ had experienced some other disaster and $12 \%$ had experienced some other hazard. Taken together, the increasing population of seniors and the likelihood that many seniors have experienced some type of trauma form the impetus of this research. Specifically, this research is designed to examine the effects of earlier experiences of trauma on seniors' well-being and the processes by which such effects occur.

\section{Effects of Earlier Trauma on Seniors' Well-Being}

Trauma has diverse and profound effects on people, including effects on people's psychological and physical well-being. Moreover, these effects may last throughout the lifespan, particularly in the case of interpersonal traumas (i.e., those perpetrated 
intentionally by another person) relative to noninterpersonal traumas (i.e., accidents and disasters) (e.g., Higgins, 1999; Higgins \& Follette, 2002).

Effects of trauma on seniors' psychological well-being. One of the most clearly documented psychological consequences of trauma is Posttraumatic Stress Disorder (PTSD), which is characterized by three groups of symptoms (American Psychiatric Association [APA], 1994). These symptoms include a) intrusive and distressing reexperiencing of the trauma in the form of recurrent dreams and flashbacks and being oversensitive to cues that resemble the trauma; b) avoidance of trauma-related stimuli and emotional numbing, including loss of interest in people and activities, feelings of detachment and a restricted range of emotions; and c) hyperarousal, as indicated by hypervigilance, sleep disturbances, problems concentrating, irritability and anger.

The symptoms of avoidance and arousal are not unique to PTSD. In particular, hyperarousal and avoidance are found in phobic disorders, detachment, loss of interest and helplessness are found in depression, and hypervigilance also characterizes generalized anxiety disorder. However, PTSD is a distinct disorder in that intrusive and distressing reexperiencing of the trauma in the form of flashbacks is extremely rare in conditions other than PTSD (Brewin, 2003). The neurobiology of PTSD is also distinct from that of other disorders. For example, increased levels of norepinephrine have been found in combat veterans with PTSD compared to combat veterans with other disorders. Further, while depression is associated with increased activity in the hypothalamic-pituitary-adrenal (HPA) axis and, as a result, increased levels of cortisol, PTSD is associated with decreased HPA activity and reduced levels of cortisol (Brewin, 2003). 
While PTSD is often sufficient to capture the aftereffects of acute nonhuman traumas such as car accidents or natural disasters, more chronic interpersonal traumas such as child abuse, partner abuse, and being held captive are often associated with additional symptoms (APA, 1994; Cloitre, Koenen, Gratz, \& Jakupcak, 2002; Herman, 1992). These symptoms include impaired affect modulation (e.g., impulsiveness and risk-taking, selfdestructive and suicidal behavior, difficulty regulating anger), alterations in attention and consciousness (e.g., amnesia, dissociation), somatization, chronic changes in character that include changes in self-perceptions (e.g., chronic guilt and shame, self-blame, feeling ineffective and damaged) and changes in relations with others (e.g., inability to trust or maintain relationships, being revictimized or victimizing others), and alterations in systems of meaning (e.g., loss of previously sustaining beliefs, depression). Taken together, these symptoms are often referred to as Complex PTSD or Disorders of Extreme Stress (e.g., Briere, 1995; Herman, 1992; Roth, et al., 1997; van der Kolk, 1996; van der Kolk et al., 1996).

Symptoms of PTSD and Complex PTSD have been regularly observed since the $19^{\text {th }}$ century, being referred to by various names such as "soldiers heart," "shell shock" and "battle fatigue." Only after WWI were the symptoms of PTSD regarded as psychological. Prior to then the symptoms of "shell shock," which included blindness, deafness, amnesia and overall maladjustment, were attributed to the effects of shrapnel, air pressure, noise and poison associate with proximity to an explosion (Brewin, 2003). It became clear, however, that the term "shell shock" was unsuitable because soldiers not exposed to explosions experienced fear, terror, constant intrusions of battle field memories, irritability, apprehensiveness, nightmares, anxiety, avoidance and dissociative states. During WWII the 
expression "combat or battle fatigue" was adopted to describe soldiers' PTSD symptoms. Veterans of WWII, also known as the heroes of the 'good war,' received a warm welcome home and help adjusting to civilian life. Soldiers' participation in the Vietnam War, in contrast, was regarded as pointless and meaningless. Because these soldiers came home feeling guilty and lonely rather that proud, their symptoms of PTSD were not recognized and taken seriously. However, as a result of the lobbying of veterans and therapists, PTSD was recognized and included in the diagnostic manual of psychiatric disorders (DSM-III) in 1980.

Both PTSD and Complex PTSD have been observed in senior trauma survivors. In Norris' (1992) study of people's exposure to a range of traumas, for example, $4 \%$ of the seniors exposed to trauma had PTSD. More specifically, 3.3\% of the seniors who had experienced a crime (i.e., robbery, physical or sexual assault), $4.1 \%$ of those exposed to a hazard (i.e., fire, natural disaster), $3.9 \%$ of those exposed to an accident (tragic death, motor vehicle crash), and $2 \%$ of the combat veterans satisfied the diagnostic criteria for current PTSD.

Even higher rates of PTSD have been observed in studies of seniors' exposed to particular types of interpersonal traumas, such as studies of senior war veterans, prisoners of war (POWs), concentration camp survivors and victims of violence toward women and children (for a review see Green, 1993). Studies of combat veterans, for example, report rates of PTSD ranging from $14 \%$ to $67 \%$ (e.g., Jongedijk, Carlier, Schreuder, \& Gersons, 1996; Sutker \& Allain, 1996; Weintraub \& Ruskin, 1999). Similarly, PTSD rates range from $42 \%$ to $88 \%$ in studies of now-senior POWs (e.g., Sutker \& Allain, 1996; Weintraub \& Ruskin, 1999) and from $22 \%$ to $65 \%$ in senior Holocaust survivors (e.g., Joffe, Brodaty, 
Luscombe, \& Ehrlich, 2003; Kutch \& Cox, 1992). The variation in the rates of PTSD across studies is likely due to differences in the severity of the trauma, the nature of the sample (e.g., clinical vs. nonclinical) and the way of measuring trauma and PTSD.

Complex PTSD has also been observed in now-senior combat veterans. In Jongedijk et al's (1996) study of 21 Dutch war veterans ( $M$ age $=66$ years), $38 \%$ met the diagnostic criteria for Complex PTSD. High rates of Complex PTSD have also been found among senior Holocaust survivors. For example, Joffe, Brodaty, Luscombe, and Ehrlich (2003) compared the psychological functioning of 100 Holocaust survivors with that of 50 refugees who had not experienced the Holocaust and 50 English-born Australians ( $M$ age $=$ 75 years). Compared to the refugees and the Australians, the Holocaust survivors were almost twice as likely to experience troubles with depression and 'nerves,' to suffer from anxiety, insomnia and somatic symptoms, and to rate their emotional health as 'bad' to 'fair.' Indeed, according to Brom et al. (2002, p. 199), "PTSD is not and has never been suitable to describe the complex constellation of symptoms that have been observed in Holocaust survivors. The deep-seated injury and lack of basic trust, the extreme restriction of emotions and characterological difficulties ... are not adequately accounted for by the criteria for PTSD." Consistent with this, Krystal (1981) observed life patterns of masochistic behaviour, chronic depression and anxiety, and anhedonia in the course of his clinical work with approximately 1000 Holocaust survivors. These Holocaust survivors also experienced feelings of shame and guilt, aggressiveness, and the destruction of basic trust. They also had difficulty recognizing and verbalizing their emotions and experienced their feelings and emotions in the form of somatic complaints, such as heart palpitations, pain and insomnia. 
Other researchers have documented both PTSD and the symptoms associated with Complex PTSD in samples of senior survivors of violence toward women and children. In one of the first systematic studies in this area, Gentlewarrior (1997) used a two-stage selfadministered postal survey to collect information from a stratified national sample of 3000 professional women. Fifty-nine percent responded to the initial questionnaire, $16 \%(n=$ 294) of whom identified as survivors of child sexual abuse. Although this rate of child sexual abuse is lower than the $30 \%$ observed in more representative samples (e.g., Finkelhor, Hotaling, Lewis, \& Smith, 1990), it is consistent with the professional status of these women. Of these 294 women, $125(42.5 \%)$ responded to a subsequent survey assessing their experiences of other interpersonal traumas since the age of 17 (i.e., rape, partner abuse, non-intimate physical assault and witnessing someone being assaulted, injured or killed) and their trauma-related symptoms. Thirty-nine percent reported adult experiences of rape, partner abuse, non-intimate physical assault and/or witnessing another person being assaulted, injured or killed. Comparing the 67 middle-aged (29 - 59 years) and 58 senior (60 - 90 years) women who had experienced childhood sexual abuse revealed no differences in the rates of other forms of trauma or trauma symptoms (e.g., anxiety, dissociation, depression). Given these findings, Gentlewarrior (1997, p. 108) concluded that, "even with extensive sociocultural privilege in adult life, the traumatic effects of child sexual abuse can linger across the lifespan."

Similar findings were observed in Higgins and Follette's (2002) study of 102 San Francisco-based women over the age of 60 ( $M$ age $=70$ years), of whom $72 \%$ reported experiences of at least one type of interpersonal trauma. In particular, $28 \%$ reported experiencing child physical abuse, $30 \%$ child sexual abuse, $18 \%$ adolescent sexual abuse, 
$24 \%$ adult rape and $49 \%$ partner abuse. These rates of interpersonal trauma are comparable to those observed in representative samples of the American population (e.g., Briere, 1995; Finkelhor et al., 1990; Green, 1993; Kilpatrick \& Resnick, 1993; Resnick, Kilpatrick, Dansky, Saunders, \& Best, 1993). In addition, 69\% reported experiencing a natural disaster, $48 \%$ had experienced a life threatening illness, $39 \%$ had been involved in a serious accident, $28 \%$ had witnessed a violent death, $22 \%$ had close friend or family member who was killed and $7 \%$ had been physically assaulted by a stranger. Interestingly, these women rated their experiences of interpersonal traumas as more stressful than their experiences of noninterpersonal traumas, with the exception of sexual abuse during adolescence, which was rated between 'a little stressful' and 'stressful.' The frequency of these older women's experiences of physical and sexual assault, along with the stress associated with these traumas, clearly suggest the need for more research examining the long, long-term effects of violence toward women and children.

Other analyses of Higgins and Follette's (2002) data highlight the long lasting negative effects of violence toward women and children. In particular, women who experienced at least two types of interpersonal trauma, as opposed to one or no interpersonal traumas, were more depressed, exhibited more global distress, and had more trauma-related symptoms (e.g., anxiety, intrusive thoughts, etc.). Unfortunately, Higgins and Follette (2002) did not report the correlations of noninterpersonal trauma with the various measures of psychological well-being. Nor did they examine the extent to which these women's distress was a function of other current stressors in their lives as opposed to trauma, and the moderating or mediating role of social support (which they measured using six items). 
A study of a community sample of 194 Dutch elders between the ages of 65 and 94 also uncovered long-lasting effects of abuse (Kraaij \& De Wilde, 2001). In interviews, $15 \%$ of the seniors reported having been sexually abused, usually during adulthood (11\%), followed by late adulthood (5\%) and childhood (3\%), and 7\% reported physical abuse, typically during childhood (5\%) and adulthood (3\%). After controlling for age and gender, ${ }^{1}$ lifetime experiences of sexual abuse (e.g., by parent, partner; $\beta=.174$ ), relational stress (e.g., divorce from partner, broken relationship with child; $\beta=.216$ ) and the death of significant others (e.g., father, child; $\beta=.167$ ) accounted for $27 \%$ of the variance in respondents' depression scores. Lifetime experiences of physical abuse, emotional abuse/neglect, crime/disaster/war, the problem behaviour of significant others (e.g., suicide, addiction), severe illness (on the part of the self or others), and poor socioeconomic circumstances did not contribute to the equation predicting depression. In addition, and after controlling for age and gender, the number of negative life events experienced during adulthood (i.e., between the ages of 16 and $49 ; \beta=.251$ ), late adulthood (i.e., after the age of $49 ; \beta=.294)$ and the childhood by adulthood interaction term $(\beta=.156)$ explained $34 \%$ of the variance in depression scores. The latter interaction occurred because the relation between the number of negative life events experienced in adulthood was more strongly tied to current depressive symptoms for those who experienced more, rather than fewer, negative life events as a child. Thus, experiences of childhood trauma appear to make

\footnotetext{
' Given that both sexual abuse (e.g., Finkelhor et al., 1990) and depression (Mazure, Keita, \& Blehar, 2002) are more common among women than men, controlling for participants' gender may have minimized the impact of earlier experiences of sexual abuse on seniors' depression.
} 
seniors vulnerable to the continuing negative effects of trauma experienced earlier during middle-age.

Although no systematic studies have examined the rates of PTSD in senior survivors of violence against women and children, a growing number of case studies also point to the long-lasting effects of violence toward women and children on seniors' psychological health (Allers, Benjack, \& Allers, 1992; Delorey \& Wolf, 1993; Gagnon \& Hersen, 2000;

McInnis-Dittrich, 1996; Walter, 1992). In one of three case studies, Allers et al. (1992) described a 66-year-old woman who sought couples' counselling for difficulties associated with her "manic depression." Her physician also believed she was beginning to experience the early onset of Alzheimer's because of memory difficulties and motor problems. After five weeks of couple's counseling she disclosed a history of child abuse perpetrated by her uncle and was referred for individual therapy. A psychiatrist familiar with the psychological aftereffects of child abuse diagnosed her with PTSD and, after treatment for PTSD, her symptoms abated and a follow-up assessment indicated no problems with dementia. In one of four case studies, McInnis-Dittrich (1996) described a 68-year-old woman who was sexually abused as a child by her father and grandfather. As a senior, this woman suffered from a number of the symptoms associated with Complex PTSD, namely self-mutilation, suicidal ideation, frequent accidents, severe depression, isolation, and difficulty concentrating. Wolkenstein and Sterman (1998) described similar psychological difficulties on the part of two older women with histories of abuse who presented to a community mental health center "with depressive and anxious symptoms, poor family relationships, multiple health problems, alcohol dependence (in themselves, their former spouses, and their children), and economic difficulties" (Wolkenstein \& Sterman, 1998, p. 
341). Similarly, Osgood and Manetta (2002) described three senior women who had been physically or sexually abused as a child or adult, each of whom had symptoms of PTSD, including substance abuse and suicidal ideation.

In sum, then, both war-related trauma and experiences of violence toward women and children appear to have long-lasting detrimental effects on senior's psychological wellbeing, contributing to the symptoms of PTSD and Complex PTSD.

Effects of earlier trauma on seniors' physical well-being. Trauma also has profound effects on physical well-being. This is perhaps most evident in the mortality, morbidity and disability rates observed among POWs. Keehn (1980), for example, found increased mortality due to accidental injury, suicide and tuberculosis among Pacific and Korean POWs. Keehn also noted that, "The finding of increased mortality due to trauma, both accidental (including cases of masked suicide) and suicide, in former prisoners of war is not surprising. Increased feelings of frustration, anger, and tension lead to impatience and impulsive actions which are likely to contribute to both the risk of and the severity of accidental and self-inflicted injury" (p. 209). Similarly, Beebe (1975) reported higher hospitalization and Veterans Affairs medical care utilization rates on the part of European, Pacific and Korean POWs relative to non-POW controls.

Studies of trauma survivors also point to the long-lasting negative effects of trauma on physical health. In a 35 year prospective study, Schnurr, Spiro, Aldwin, and Stukel (1998) had 1079 older male veterans complete measures of their combat exposure, exposure to noncombat trauma (e.g., serious accidents, violent crimes, natural disasters) and physical health symptoms every three to five years, beginning when they were aged 30 until they were aged 75 . Analyses of these data revealed that, while the experience of combat trauma 
and noncombat trauma were not, in themselves, associated with symptom reports, men who experienced both combat and noncombat trauma reported $16 \%$ more physical symptoms across all ages than men who had experienced no type of trauma. In addition, veterans who had experienced both combat and noncombat trauma had more PTSD symptoms than men who had experience either no trauma or noncombat trauma only.

Creasey et al. (1999) reported similar findings in their comparison of the physical health and functional performance of 101 Australians who had been held captive by the Japanese during WWII with that of 107 non-POWs who experienced combat in the same theatre of war. Relative to the combat veterans, the POWs reported significantly more somatic symptoms (5.4 vs. 7.4 , respectively), more medical diagnoses ( 7.7 vs. 9.4 , respectively), including gastrointestinal, musculoskeletal and cognitive disorders, took a greater number of different medications ( 3.4 vs. 4.5 , respectively), and had more difficulty performing the basic activities of daily living (e.g., doing housework, laundry, preparing meals, managing money). However, there were no group differences in the number of hospital visits, length of stay in hospital and subjective health status.

The physical health of senior Holocaust survivors also fares poorly compared to seniors who did not experience the Holocaust. In Joffe et al.'s (2003) study, described earlier, $23 \%$ of the Holocaust survivors rated their physical health as 'poor,' as compared to $8 \%$ of the refugees and $6 \%$ of the Australians. Further, relative to the refugee and Australian groups, who took an average of 4.6 and 4.7 medications in the last year, respectively, the Holocaust survivors consumed almost 6 medications, typically sedatives and sleeping pills. However, the groups did not differ in their ability to perform the basic activities of daily living. 
That earlier trauma affects senior Holocaust survivors' physical well-being was also reported by Landau and Litwin (2000), who compared the health of a community sample of 93 Holocaust survivors $(M$ age $=81$ years $)$ with that of 103 senior men and women who had not experienced the Holocaust. In this study, the female Holocaust survivors reported significantly more doctor visits, poorer physical functioning (i.e., they were less able to move large objects such as a sofa, lift their hand over their head or write) and poorer subjective health status than women who had not experienced the Holocaust. Female Holocaust survivors also tended to have slightly higher levels of depression, marginally higher rates of PTSD, and were less satisfied with life. The only difference between the two groups of men, in contrast, was in regard to PTSD. In particular, the rate of PTSD among the male Holocaust survivors (27.1\%) was eight times greater than that among men who had not experienced the Holocaust (3.8\%). Conceivably, the female Holocaust survivors may have experienced their psychological distress in the form of physical health problems (i.e., somatization) to a greater extent than the male Holocaust survivors.

Senior survivors of violence against women and children are also at risk for impaired physical health. Gentlewarrior (1997), for example, found that women who had experienced interpersonal trauma (i.e., childhood sexual abuse, rape, partner abuse and/or witnessing a person being assaulted, injured or killed) reported more physical health problems and more medication use in the last six months compared to women who had not experienced interpersonal trauma. The number of doctor's visits, however, was independent of these women's experiences of interpersonal trauma. Higgins (1999) also found that older women who experienced at least two types of interpersonal trauma had 
more physical health problems and took more medications compared to those who experienced one or no interpersonal traumas.

Overall, interpersonal traumas experienced earlier in life, be they war-related or associated with violence toward women and children, appear to have long lasting effects on older people's physical well-being, including effects on longevity, physical symptoms, medication use, and their ability to perform the activities of daily living. Interestingly, findings from studies with younger populations suggest that the impact of trauma on physical health is mediated by PTSD (for a review see Green \& Kimerling, 2004). Consistent with this possibility, Schnurr, Spiro and Paris' (2000) longitudinal study of 605 senior veterans of the Korean Conflict and WW II revealed that combat exposure predicted the onset of a number of physician-diagnosed disorders, including arterial, pulmonary and upper gastrointestinal disorders and other heart disorders. After controlling for age, smoking, body mass index and alcohol use, PTSD symptoms were also associated with a number of physical health problems, including arterial disorders, gastrointestinal disorders, dermatological problems and musculoskeletal disorders. When PTSD was controlled, only the relation between combat exposure and pulmonary disorders remained significant. Thus, PTSD mediated the relations between combat exposure and arterial, upper gastrointestinal and heart disorders.

\section{Exacerbated, Re-emergent and Delayed PTSD among Senior Trauma Survivors}

A number of studies have documented the exacerbation, re-emergence and delayed onset of PTSD in aging trauma survivors. In an early study, Zeiss, Dickman, and Nichols (1985, cited in Molinari \& Williams, 1995) found that almost $65 \%$ of 179 older WW II and Korean conflict POWs had symptoms consistent with PTSD. Of these, $22 \%$ had continuous 
symptoms, $17 \%$ had symptoms that gradually disappeared, $20 \%$ had re-emergent symptoms and 36\% had late-onset PTSD. Similarly, Op den Velde et al. (1993) found that 56\% of 147 WWII Dutch resistance veterans between the ages of 60 and 65 had current PTSD, 28\% had PTSD in remission and 16\% had never had PTSD. Most of these resistance fighters developed symptoms of PTSD within five years of the end of WW II. A striking 35\%, however, did not develop symptoms of PTSD for 25 or more years.

Port (1998) also observed a varied course and onset of PTSD in her four-year longitudinal study of 179 community dwelling WWII and Korean POWs $(M$ age $=76$ years). Among these POWs, 27\% met the diagnostic criteria for PTSD in the first year of the study, compared to $34 \%$ four years later. These POWs' PTSD scale scores also increased significantly over the four years of the study. Of those senior POWs with PTSD (34\%), most (29\%) reported symptoms shortly after the war and recovering fully by 1949. Others (17\%) reported symptoms for 30 years following the war and recovering fully by 1979. A comparable number of POWs (18\%) reported continuous symptoms of PTSD since the war and $11 \%$ reported intermittent symptoms that came and went over time. In addition, two percent reported PTSD symptoms that appeared for the first time when they were at least 55 years old. Overall, then, $13 \%$ of these older POWs experienced either reemergent or delayed PTSD in their elder years.

Although there are no systematic studies of exacerbated, re-emergent or delayed PTSD in survivors of violence against women and children, case studies suggest that senior abuse survivors are at risk. In this regard, Gagnon and Hersen (2000) described a 60-yearold woman who sought help for various symptoms associated with Complex PTSD, including depression, anhedonia, insomnia, suicidal ideation, feelings of worthlessness and 
anxious rumination, symptoms that had intensified after she and her husband retired and moved to another city two years earlier. As a child, this woman suffered physical and verbal abuse from both parents and sexual abuse by her father and older sister. As an adult she escaped her abusive family by entering into a 41 -year marriage in which her husband sexually, physically and verbally abused her. During therapy, she revealed feelings of badness that made her believe she deserved her childhood abuse, her subsequent revictimization by her husband and her son's death. She also reported feeling incompetent and incapable of living on her own, feelings that she believed kept her in the abusive relationship with her husband. After two years of therapy, which included fostering safety and coping skills, altering maladaptive cognitions and assertiveness training, she was happier, less angry, developed a more positive view of herself and was considering leaving her husband.

Similarly, Walter (1992) described an elderly widow who, after the death of her parents, was sexually abused from the age of three to 16 by a caregiver. This woman, who frequently ruminated about her childhood abuse, was admitted to a geriatric psychiatry unit for exacerbated symptoms of PTSD and Complex PTSD that included panic attacks, severe anxiety, depression, anhedonia and dependent personality features. These symptoms were triggered by overwhelming feelings of loneliness after returning from an out-of-state visit with her children and grandchildren. Her feelings of loneliness also provoked an intense review of her life in which she began to question the purpose and meaning of her life. After eight weeks of therapy and antidepressant medication, her symptoms and energy levels improved, she developed an interest in helping others and was sent home with psychiatric follow-up, a referral to a local senior centre and an opportunity to work as a volunteer. 
As evidenced above, re-emergent, exacerbated and delayed PTSD have been observed following a variety of interpersonal traumas, including those associated with war and violence against women and children. Several processes have been held responsible for the PTSD observed in these studies, including age- and trauma-related declines in coping capacities and the synergy between the processes associated with trauma and aging.

Age- and trauma-related declines in coping and PTSD. The 'deficiency model' of aging (Schmid, 1991) suggests that senior trauma survivors may be vulnerable to exacerbated, re-emergent and delayed onset PTSD because aging has rendered them too weak and frail to cope with their emotionally laden traumatic memories. Similarly, the 'differential vulnerability hypothesis' states that trauma has more negative effects on the psychosocial functioning of seniors relative to younger adults (Fields, 1996). As Aarts and Op den Velde (1996, p. 365) note, however, "although, indeed, the elderly often demonstrate an impairment of short-term memory and a decrease in physical and biological functionality, there is no empirical evidence whatsoever that coping mechanisms, cognitive faculties, and affect regulation necessarily deteriorate in the later stage of the life cycle." To the contrary, researchers examining the impact of natural disasters (Fields, 1996; Green, Gleser, Lindy, Grace, \& Leonard, 1996) report that "elderly disaster survivors appear to be at relatively low risk for developing long-term psychological problems following these events. Their coping strategies, and perhaps their cumulative past experience, seem to allow them to take changes brought on by the disaster events relatively in stride" (Green et al., 1996, p. 122). Thus, it seems unlikely that senior trauma survivors' experiences of PTSD and Complex PTSD arise as a result of age-related declines in their ability to cope with their traumatic pasts. 
Others have suggested that senior trauma survivors are vulnerable to exacerbated, re-emergent and delayed onset PTSD because their earlier traumatization has robbed them of their ability to cope with the stresses associated with aging, such as retirement, illness, and the loss of loved ones (for a review see Aarts \& Op den Velde, 1996; Snell \& PadinRivera, 1997). Along these lines, a number of studies have documented the negative impact of negative life events on senior trauma survivors. In Port's (1998) four-year longitudinal study of senior war veterans, for example, changes in physical health (e.g., declines in hearing, vision) were associated with increases in PTSD scores. However, experiences of other negative life events, such as moving, being a crime victim and the death of a significant other, were unrelated to their PTSD scores across time. Thus, senior trauma survivors do not appear to be vulnerable to all stressors.

Kaup, Ruskin, and Nyman (1994) also found evidence of exacerbated PTSD due to current life stressors in the records of 20 WWII veterans ( $M$ age $=63$ years). Of the 16 veterans who had either continuous PTSD or had recovered from PTSD since the war, 14 had exacerbated symptoms associated with their retirement, deterioration in health or the death of a loved one. Most commonly, these veterans had experienced both retirement and a decline in health concurrent with the exacerbation of their PTSD symptoms.

Similar vulnerability to the stressors of aging has been observed among Holocaust survivors. In a study of 72 community dwelling, non-treatment seeking Holocaust survivors (Yehuda et al., 1995), the 56\% with PTSD reported both more traumatic experiences in their lives and more stressful life events in the past year (e.g., institutionalization, widowhood, role loss, reduced income, impaired health) compared to those without PTSD and a control group not exposed to the Holocaust and without PTSD. Although participants' cumulative 
lifetime trauma scores and current stress scores were moderately correlated, the severity of their PTSD was independently related to their original trauma, lifetime exposure to other traumas and the number of current stressors in their lives. Yehuda et al. (1995, p. 1817) therefore concluded that, "the supplemental impact of events in addition to the trauma must be considered in explaining the onset, persistence, and severity of PTSD."

A number of case studies also illustrate changes in PTSD symptoms concurrent with the stressful life events of aging (Aarts \& Op den Velde, 1996; Hermann \& Eryavec, 1994; Kaiman, 2003). Kaimen (2003), for example, reported that each member of a group of 29 veterans at a Veterans Affairs health centre had PTSD at some point during their life. While some of these men had continuous PTSD since the war, most had latent or mild PTSD until their 60 s or 70 s, when their PTSD was exacerbated by the stressors of aging, including retirement, deteriorations in health and the loss of loved ones. For example, an 84-year-old veteran reported that he was not bothered seriously by PTSD until he retired at the age of 76. He then began to experience outbursts of anger, an exaggerated startled response, severe insomnia, nightmares of his combat experiences and daily intrusive memories of combat and the friends he lost during the war. Another case involved an 81-year-old veteran whose only symptom of PTSD in the years following the war was severe outbursts of anger. This man's declining health, surgery and retirement triggered PTSD symptoms that included frequent intrusive thoughts, nightmares, insomnia and an exaggerated startled response.

The contribution of hospitalization to re-emergent PTSD was conveyed by Aarts and Op den Velde's (1996) case study of Mr. K. who fought in a guerrilla war for three years, during which he witnessed his best friend die as they entered a booby-trapped building. 
Upon his return from combat Mr. K suffered flashbacks, nightmares and depression, although his complaints gradually diminished after five years. After 21 symptom-free years, he suffered for another three years when his son entered the military. At the age of $69 \mathrm{Mr} . \mathrm{K}$ was involved in a car accident that immobilized him in hospital, during which his PTSD re-emerged in the form of flashbacks and angry outbursts. After working with a psychiatrist and participating in a discussion group with fellow survivors of the Indonesian war, Mr. K's symptoms again subsided.

Another case study presented by Aarts and Op den Velde (1996) illustrates the contribution of the deaths of loved ones to delayed PTSD. This case involved an 83-year old Jewish woman who was referred for treatment because of suspected dementia. Mrs. E survived WWII by hiding in haystacks and the basement of a farmhouse, although German soldiers nearly found her many times. After the war, she discovered that none of her family had survived the Holocaust. She soon married, although her husband died of illness three years later. Nevertheless, Mrs. E was successful in mid-life as a social worker and had a close network of friends. At the age of $81 \mathrm{Mrs}$. E moved into a seniors' home and, when she eventually outlived her friends, she began to develop symptoms of PTSD such as nightmares, weight loss, isolation, and irritability. When referred to treatment because of suspected dementia, Mrs. E. was diagnosed with delayed-onset PTSD. During the course of psychotherapy she realized that the pain of losing her family was so severe that she had previously been unable to feel it. As Mrs. E became able to express her feelings of grief, guilt and loneliness, her somatic complaints diminished. According to the authors, Mrs. E's symptoms of delayed PTSD were triggered by the loneliness she experienced after the deaths of her friends and her relocation to a senior's home. 
In view of the above, it is clear that senior trauma survivors are adversely affected by the stressors associated with aging. Given this, one must ask why senior trauma survivors are particularly vulnerable to such stress. In this regard, Gagnon and Hersen (2000) suggested that child abuse contributes to the development of maladaptive coping strategies. Consistent with this, Higgins (1999) found that senior women who had experienced at least two interpersonal traumas were more likely to use less effective escapeavoidance coping strategies such as wishful thinking, behavioural efforts to escape or avoid the problem, and self-blame and criticism, relative to senior women who had experienced fewer interpersonal traumas. That trauma survivors use avoidance coping strategies is, perhaps, not surprising given that avoidance is one of the criteria for a diagnosis of PTSD (APA, 1994). Moreover, declining physical health may preclude the use of some avoidant coping strategies, making senior trauma survivors especially vulnerable to stress (Buffum \& Wolfe, 1995; Sadavoy, 1996). Ineffective coping with the stresses of aging, then, may well be responsible for the exacerbated, re-emergent and delayed PTSD experienced by some senior trauma survivors.

The synergistic processes of trauma and aging. Other researchers have suggested that aging may contribute to PTSD because the processes associated with aging recreate the feelings underlying interpersonal traumatization (Aarts \& Op den Velde, 1996; Higgins \& Follette, 2002; Kristiansen, 2003; Kristiansen \& Hay, 2000; Molinari \& Williams, 1995; Shmotkin et al., 2003). This may occur because the stressors of aging share the psychosocial dynamics that underlie trauma and/or because the life review process brings trauma survivors face-to-face with their traumatic experiences. 
In regard to the psychosocial dynamics of trauma, Kristiansen and Hay (2000; Kristiansen, 2003) suggested that the stressors of aging may replicate the feelings of powerlessness, stigmatization, and betrayal underlying childhood sexual abuse (Finkelhor \& Browne, 1985), rape and partner abuse (Kristiansen, 2003) and other traumas, including war-related trauma. Perhaps the most fundamental of these dynamics is powerlessness (Kristiansen, 2003). Indeed, the APA (2000, p. 463) defines a traumatic event as one where "the person's response to the event must involve intense ... helplessness." A victim of child abuse, for example, is rendered powerless by an adult abuser's relative age, status and physical prowess. Adult survivors of rape and battering may also be powerless given a male perpetrator's physical strength and threats (Heney \& Kristiansen, 1998). Similarly, soldiers drafted involuntarily may feel powerless to stay with their families or leave the military once enlisted (Granatstein, 1969) and, once in combat, powerless in the face of the enemy. The lack of freedom and maltreatment encountered by prisoners of war and those in concentration camps makes their powerlessness strikingly clear. The feelings of powerlessness associated with war-related trauma may also be amplified by watching friends and loved ones die (Weisaeth \& Eitinger, 1993).

Senior trauma survivors may encounter similar feelings of powerlessness as a result of their increasing frailty, declines in mental agility and increasing dependence on benevolent caregivers, and these feelings of powerlessness may contribute to symptoms associated with PTSD. Consistent with this, Molinari and Williams (1995) attributed the reemergent and delayed-onset PTSD observed among the POWs in Zeiss et al.'s study (1985, cited in Molinari \& Williams, 1995) "to the losses which are so often a part of aging, which can trigger long-repressed feelings of vulnerability and lack of personal control that 
occurred during captivity" (pp. 100-101). Along these lines, Allers, et al. (1992) observed impaired psychological functioning in a 79-year old woman who had been sexually and physically abused by her grandparents until she was 14 years old. She sought medical attention for chronic depression, difficulty sleeping, disorientation, poor appetite and an inability to maintain personal hygiene. The severity of these symptoms had increased when her husband's death threatened her ability to live independently. Similarly, Gagnon and Hersen (2000) described an 82-year-old woman who suffered from the sexual abuse that she experienced by an uncle between the ages of nine and 11. This woman reported that she felt anxious and helpless and was fearful of most men for many years following the abuse. As a result of her deteriorating vision and increasingly severe osteoarthritis, these feelings reappeared during her senior years when she became fearful of being attacked outside the home.

Perhaps the greatest risk of powerlessness is in nursing homes, where virtually every aspect of seniors' lives is controlled (Kristiansen, 2003; Kristiansen \& Hay, 2000; Peters \& Kaye, 2003), and such powerlessness has been noted to have profound effects on seniors' well-being. In one study (Langer \& Rodin, 1976), the senior residents of a nursing home who had been randomly assigned to assume responsibility over their daily lives (e.g., arranging the furniture in their rooms, selecting their own recreational activities) were happier, more active and alert, and generally felt better compared to the senior residents who had these decisions made for them. Interestingly, these effects were apparent after only three weeks. Moreover, a year and a half later the residents with personal control continued to be more active, more sociable, happier, and had half the mortality rate (i.e., 15 vs. 30\%, respectively) of their no-control counterparts (Langer, 1983). For seniors who are 
trauma survivors, the loss of control may also trigger memories, feelings and behaviours associated with seniors' earlier experiences of trauma. Indeed, Peters and Kaye (2003) point to this possibility in their review of the impact of childhood sexual abuse on older women entering residential care facilities.

Interpersonal trauma is also associated with stigmatization and shame (Finkelhor \& Browne, 1985; Kristiansen, 2003; Heney \& Kristiansen, 1998). During child sexual abuse feelings of stigma and shame are instilled by the abuser's negative messages (e.g., that hold the child responsible for the abuse) and the social secrecy shrouding sexual abuse (Finkelhor \& Browne, 1985; Summit, 1983). Such secrecy and shame are also associated with adult women's experiences of rape and partner abuse (Kristiansen, 2003), while combat veterans may be stigmatized for participating in unpopular wars (Aarts \& Op den Velde, 1996; Port, 1998) such as the Korean conflict or the Vietnam war, and war veterans, POWs and concentration camp survivors may be shamed by the things they did to survive.

Senior trauma survivors may experience comparable stigmatization and shame as a result of society's ageism (Friedan, 1993; Pearlman, 1993). Palmore (2001), for example, found that over $77 \%$ of 84 respondents aged 60 to 93 reported experiencing at least one incident of ageism, such as being called insulting names or being patronized. Moreover, Hausdorff, Levy, and Wei (1999) found that ageism affects seniors' behaviour. In their study, 47 healthy women and men aged 63 to 82 years were randomly and blindly assigned to view words associated with either a positive or negative stereotype of aging that were displayed subliminally on a computer screen. Those who viewed words associated with a positive stereotype of aging subsequently walked faster and displayed greater gait speed (time spent with one foot in the air during walking) than at baseline. No change in walking 
was evident on the part of participants who had been primed with words associated with a negative stereotype of aging, conceivably because exposure to negative stereotypes of aging was a normative experience for these seniors. In the present context, these findings suggest that it is not unreasonable to suggest that senior trauma survivors may be particularly vulnerable to the effects of ageism to the extent that ageism induces the feelings of shame that they experienced during their original traumatization. Such ageism may also extend to the health care sector where seniors' symptoms may be minimized or neglected because they are misattributed to 'normal aging' (Reich, 1996; Robb, Chen, \& Haley, 2002; Somer, 2000).

The third dynamic associated with interpersonal trauma is betrayal. A child feels betrayed when a trusted person harms them, when others fail to protect them, and when their disclosures of abuse are disbelieved (Summit, 1983). An adult woman may feel betrayed when she is assaulted by her partner and when the police or courts leave her feeling revictimized (Kristiansen, 2003). War veterans and POWs may feel betrayed by physicians who misattribute their symptoms of PTSD to psychiatric illnesses, such as schizophrenia and autism (Buffum \& Wolfe, 1995; Weisaeth \& Eitinger, 1993), or to cowardice and weakness (Buffum \& Wolfe, 1995). POWs may feel betrayed when no one comes to their rescue. Similarly, Holocaust survivors may have felt betrayed by friends who refused to help them, by family members who were unable to save them, and by a society that allowed the Holocaust to happen. Senior trauma survivors' feelings of betrayal may be rekindled in a number of ways, such as by the ageism they encounter, the decline of their physical bodies or minds, by people who fail to live up to their expectations (e.g., 
family members who put them in residential care) and by people who exploit them or convince them to do things that are not in their best interests.

The reinstatement of these psychosocial dynamics is important because once feelings reminiscent of trauma are triggered, a person may "experience the emotional intensity of the trauma without conscious awareness of the historical reference" (JanoffBulman, 1992, p. 103) or source of these feelings. As a result, trauma survivors' well-being varies as a function of the extent to which they experience these dynamics in their current lives. For example, in a test of Finkelhor and Browne's (1985) traumagenic model of childhood sexual abuse, Coffey, Leitenberg, Henning, Turner, and Bennett (1996) had 192 community-dwelling women $(M$ age $=40$ years $)$ who had been sexually abused during childhood complete measures of the extent to which they currently experienced feelings of stigma, betrayal, powerlessness and self-blame in their lives, as well as the Brief Symptom Inventory (BSI). Regression analyses revealed that these women's current feelings of stigma and self-blame predicted their BSI scores. Similar findings were observed in Hazzard's (1993) study of 56 female survivors of childhood sexual abuse ( $M$ age $=39$ years), where women's current feelings of self-blame/stigmatization, betrayal, powerlessness, and traumatic sexualization were associated with interpersonal problems, depression, psychological distress, anxiety and low self-esteem. Further, Leskela, Dierperink, and Thuras (2002) reported that, in a sample of 107 now-senior communityresiding POWs, those with higher shame-proneness scores had moderately higher PTSD scores. Moreover, this relation between shame-proneness and PTSD remained significant even after controlling for the extent of POWs' combat exposure and percent weight loss during captivity. 
That current experiences of the dynamics associated with trauma affect senior trauma survivors' well-being is also indicated by the findings of Baider, Peretz, and Kaplan De-Nour (1992, 1993). In one study (Baider, Peretz, \& Kaplan-Denour, 1992), 53 senior cancer patients who had survived the Holocaust were matched with 53 cancer patients who had not experienced any severe life threat for age, gender, medical treatment, education, marital status, stage of cancer, and time since cancer diagnosis. Relative to the control group, the Holocaust survivors scored higher on measures of both their avoidance of their cancer (e.g., efforts to avoid thinking or talking about their cancer) and the intrusiveness of their cancer (i.e., intrusiveness of the cancer into their lives), and all of the subscales of the BSI.

In a subsequent study, Baider, Peretz, and Kaplan De-Nour (1993) compared the BSI scores of these Holocaust survivors with cancer with those of a matched group of 50 healthy Holocaust survivors. Analyses of these data indicated that the Holocaust survivors with cancer had higher scores on all of the BSI scales, with the exception of depression. Taken together, these findings suggest that Holocaust survivors over-react to current stressors, such as cancer, with the pattern of increased intrusiveness and avoidance associated with PTSD. Because both cancer and the Holocaust "are associated with fears of pain, disfigurement and disability .... uncertainty, loss of personal control .... social rejection [and] a sense of total helplessness," (Baider et al., 1992, p. 12), the authors concluded that, "people who have undergone varying but severe traumas in the past may recover but remain at constant risk and are likely to develop extreme psychological distress when faced with a new threat that has similar components or associative elements to the past traumas" (Baider et al., 1993, p. 354). 
The feelings seniors experienced during their earlier trauma may also be rekindled by experiences of additional trauma, such as elder abuse. In a Canadian survey of 2008 randomly selected community dwelling seniors ( $M$ age $=73$ years) by Podnieks and her colleagues (1990), 4\% reported experiencing at least one type of elder abuse and $0.8 \%$ reported experiencing more than one type. Material abuse (e.g., someone trying to persuade the respondent to give money) was experienced most frequently (2.5\%), followed by verbal abuse (1.4\%), physical abuse $(0.5 \%)$ and neglect $(0.4 \%)$. Taken together, Podnieks and colleagues (1990) reported that these rates suggest that an estimated 98,000 seniors across Canada have been victims of at least one form of elder abuse (Podnieks et al., 1990). Similar rates of elder abuse have been reported in other studies (e.g., Comijs et al., 1998; Pillemer \& Finkelhor, 1988).

Seniors are also at risk for abuse by nursing home staff. In a telephone survey, Pillemer and Moore (1989) asked nurses and nurses aids working in long-term care facilities to report on the number of times they had committed and had witnessed other staff perpetrating physical and verbal abuse toward nursing home residents. A third (36\%) reported observing another staff member engage in at least one act of physical aggression toward a resident and $81 \%$ reported having witnessed a staff member engage in verbal abuse toward a resident. In addition, $10 \%$ reported having committed at least one act of physical aggression toward a resident and $40 \%$ admitted to perpetrating at least one incident of verbal abuse. Moreover, seniors in residential care may also be abused by other residents (Shinoda-Tagawa, et al., 2004).

Taken together, then, it is conceivable that senior trauma survivors are vulnerable to the stressors associated with aging because these stressors are frequently associated with the 
dynamics underlying their original traumatic experience, dynamics that include the experience of powerlessness, stigmatization and betrayal. It is also conceivable that some stressors of aging are reminiscent of particular traumas. Danieli (1981), for example, noted how relocation and confinement to a nursing home and the death of spouses and friends are reminiscent of the experiences, losses and loneliness endured by Holocaust survivors. Similarly, the PTSD of the 29 WWII veterans in Kaiman's (2003) weekly psychotherapy group were exacerbated by the attacks of September 11, which caused them to experience hypervigilance, anxiety, nightmares, intrusive combat memories, feelings of isolation and outbursts of aggression. It took over a year for these veterans' symptoms to return to what they had been before the attack.

A normal psychological process associated with aging, namely reminiscence, may also contribute to the exacerbated, re-emergent and delayed PTSD noted among some senior trauma survivors. Reminiscence may occur when trauma survivors lose the social roles or the loved ones and friends that kept their minds occupied and away from their traumatic memories (Danieli, 1997). This possibility is suggested by studies documenting the negative effect of retirement on both Holocaust survivors and war veterans (Snell \& PadinRivera, 1997). In this regard Safford (1995) argued that employment provided Holocaust survivors with an escape from painful memories. Deprived of this escape, Holocaust survivors have been observed to experience nightmares and other PTSD symptoms (Danieli, 1981). Similarly, in his therapy work with 29 senior war veterans with PTSD, Kaiman (2003) found that most of the men's symptoms became worse when they retired.

Reminiscence may also occur as a natural response to the development tasks associated with aging. In Erickson's (1968) model of psychosocial development, successful 
aging requires finding meaning and significance in one's life as it has been lived, a task that involves reminiscence. For some, however, reminiscence may be problematic in that it may "lead to depression, guilt, obsessive rumination, and in extreme cases, suicide" (Parker, 1995, p. 520). Wong and Watt's (1991) study of 171 seniors between the ages of 65 and 95 yielded findings consistent with this possibility. Wong and Watt (1991) assessed the extent to which seniors engaged in various types of reminiscence, including 'obsessive reminiscence,' which is exemplified by an inability to integrate problematic past events and is associated with guilt and despair, 'integrative reminiscence,' which is characterized by resolving conflicts, accepting negative life events and seeing the past as worthwhile, and 'instrumental reminiscence,' which involves recalling past achievements to gain insight into ways of dealing with current challenges. Seniors who displayed integrative or instrumental reminiscence had better physical and mental well-being than those who displayed obsessive reminiscence.

Finding meaning during reminiscence may be difficult for many trauma survivors. Not surprisingly, many Holocaust survivors cannot accept the horrors and find meaning in the atrocities perpetrated against them (Krystal, 1995). Aging war veterans have also been noted to experience resentment and guilt (Kaiman, 2003). That it may be difficult for trauma survivors to find meaning in their traumatic experiences is also suggested by Coleman's (1986) case study of a senior WW I veteran whom he described as "a compulsive reminiscer of what he observed in those few years, and he struggles to make sense of the war and see it in proper focus" (Coleman, 1986, pp. 50-51). Fifty years later, memories of the war popped into his mind. "He remembered how awful the living conditions were ... he remembered hearing a wounded soldier out in no-man's-land 
shouting for his mother ... he had so many vivid memories of the dead"' (Coleman, pp. 5051). Thus, as Aarts and Op den Velde (1996, p.370) stated with respect to Holocaust survivors and POWs, it is "hard to give meaning to and accept former torments and the murders of loved ones. To find reason or congruity in such horrors seems an impossible task." Likewise, in their study of 77 female incest survivors aged 18 to 72 , Silver, Boon, and Stone (1983) found that $50 \%$ were unable to make sense of their victimization, victimization that, on average, occurred 20 years earlier. Moreover, those who were unable to find some meaning in their abuse had more frequent intrusive ruminations, were more distressed and had poorer social functioning. In fact, even those who were able to find some meaning in their abuse continued to experience vivid memories and feelings associated with their abuse.

In sum, it is possible that the exacerbated, re-emergent and delayed PTSD experienced by senior trauma survivors stems, at least in part, from the retraumatizing rather than healing consequences of reminiscence. Aging may also contribute to PTSD because the processes associated with aging, including the stressors associated with aging, involve the psychosocial dynamics underlying trauma. As a result, aging may present trauma survivors with a double burden: the burden of aging and the burden of trauma

\section{The Present Study}

To date, the literature indicates that a sizeable number of seniors have experienced some form of trauma and that some continue to suffer long-term psychological and physical consequences. As yet, however, little research has examined the effects of different types of trauma on seniors. In particular, do survivors of interpersonal and noninterpersonal trauma suffer the same fate? Does gender make a difference? While men are more likely to have 
experienced a traumatic event, women experience traumatic events as more threatening (Norris, Foster, \& Weisshaar, 2002) and are two times more likely to have a lifetime experience of PTSD than men (Norris et al, 2002; Seedat \& Stein, 2000). In addition, PTSD tends to take a more chronic course in women compared to men. The sole exception to this pattern is for rape, where the risk of PTSD is the same for both men and women (Norris et al., 2002). In Norris's (1992) study, for example, men were more likely to have experienced a traumatic event compared to women $(73.6 \%$ vs. $64.8 \%)$. In particular, men were more likely than women to have experienced physical assault (18.7\% vs. $11.7 \%)$, a motor vehicle accident $(27.9 \%$ vs. $20.1 \%)$ and combat $(19.3 \%$ vs. $0 \%)$. Women, on the other hand, were more likely than men to have experienced sexual assault (7.3\% vs. $1.3 \%)$. In addition, across traumas the rates of PTSD were $40 \%$ higher among women than men. The most dramatic gender differences in response to trauma were observed for crimerelated traumas (robbery, sexual assault, physical abuse), where women showed a rate of PTSD twice that of men (12\% vs. $6 \%)$. Given these findings, the present study will examine the impact of gender on senior trauma survivors' well-being. ${ }^{2}$

The proposed research is also designed to extend previous research on the aftereffects of trauma, which has been limited to analyses of psychological and physical health, by examining social well-being. In Joffe et al's (2003) study, described earlier,

\footnotetext{
${ }^{2}$ Women's greater vulnerability to PTSD in response to trauma cannot be fully explained by gender differences in the type of trauma or perceptions of threat and fear (Norris et al., 2002). Rather, women's increased physiological reaction to stress, their greater disposition to major depressive disorder, their more frequent exposure to the stressors of poverty, discrimination and oppression, the social acceptability of women but not men expressing the emotions associated with trauma such as fear, helplessness and horror (Norris et al., 2002) and women's social predisposition to more deleterious events (Gavranidou \& Rosner, 2003) have all been linked to women's heightened risk for developing PTSD in response to trauma.
} 
Holocaust survivors were more likely to report having no hobbies, as compared to the refugee and Australian groups ( $23 \%$ vs. $12 \%$ and $8 \%$, respectively). In addition, $60 \%$ of the Holocaust survivors rated their social lives as 'poor' or 'fair,' compared to $44 \%$ of the refugees and $32 \%$ of the Australians, respectively. Surprisingly, however, the groups did not differ in the extent to which they were involved in social activities (i.e., the amount of formal contact with friends, community centers and clubs). Thus, while the Holocaust survivors were socially active, they were not socially satisfied. Shmotkin and colleagues (2003) also found that Holocaust survivors $(n=126)$ were less likely to have a hobby compared to Europeans who had immigrated before WW II $(n=206)$ or after WW II $(n=$ 145). However, contrary to Joffe et al's (2003) findings, the now-senior Holocaust survivors engaged in fewer social activities (e.g., volunteer work, socializing with friends, reading, watching television and listening to the radio) than the pre-war immigrants. Given these mixed findings, the present study will examine the impact of interpersonal trauma on seniors' social well-being.

Finally, this research will examine some of the factors that may mediate or moderate the impact of earlier trauma on seniors' well-being. For example, do the current stressors of aging moderate the impact of earlier trauma on well-being and, if so, how? Is it because senior trauma survivors are more likely to use maladaptive avoidance coping strategies in response to these stressors, because these stressors replicate the psychosocial dynamics of trauma, and/or because senior trauma survivors are more likely to engage in detrimental obsessive reminiscence?

This study is also designed to test the model illustrated in Figure 1. In this model earlier trauma is depicted as increasing the use of avoidance coping, obsessive 
reminiscence, the current stressors of aging, and revictimization. Avoidance coping and obsessive reminiscence are seen as having a detrimental effect on physical and social wellbeing via their effects on PTSD. In addition, earlier trauma is thought to increase the number of current stressors in seniors' lives, as observed by Yehuda, et al. (1995). Further, earlier trauma is depicted as increasing the risk for elder abuse. Relevant here is Pittaway, Westhues, and Peressini's (1995) study of 385 adults aged 55 to 100 ( $M$ age $=73.8$ years) where participants who had been assaulted as a child were more than twice as likely to report having been physically abused since the age of 55 compared to those who had not been assaulted as a child (i.e., 27 vs. $12 \%$, respectively). Even more striking, those who had been assaulted as a younger adult were almost five times more likely to have experienced physical abuse since the age of 55 (i.e., 49 vs. $10 \%$, respectively). These relations with earlier abuse were also true for the other types of abuse examined in this study, namely chronic verbal abuse, material or financial abuse, and neglect. In the model, then, both the stressors of aging and experiences of revictimization are depicted as contributing to feelings associated with the psychosocial dynamics of trauma, feelings that may contribute to PTSD and thereby to physical and social well-being. 


\section{Method}

\section{Procedure}

Participants were men and women 60 years of age and older who responded to a request to participate in a study of "Seniors' Life experiences Coping and Well-Being." Requests were distributed through local newspapers in the Ottawa Carleton region and posters placed in Ottawa locations frequented by seniors, including seniors' centres, grocery stores, bingo halls, and Ottawa Legion branches. These requests read: "Are you 60 or older? If so we would like you to participate in a 1.5 hour survey of Senior's Life Experiences, Coping and Well-Being: Do at home and mail in. $\$ 30$ for your participation. Confidentiality assured. Help others by sharing your experiences."

Seniors who called regarding the study were informed that the purpose of the research was to learn about the stressful experiences seniors have had throughout their lives, how they cope with these experiences, and how these experiences might affect their physical, psychological and social well-being. Participants were also told that, because some of the questions ask about potentially upsetting events such as their exposure to child abuse, war, the Holocaust and the death of a spouse, they might find completing the survey distressing. Prospective participants who continued to express an interest in the study were then informed that their participation would take about an hour and a half, that they would receive $\$ 30$ for their time and labour, and that they could complete the survey at home and return it by mail, at the University, or have a researcher come to their residence or other mutually convenient location.

Every participant chose to complete the survey at home. As shown in Appendix A, which contains all of the materials used in this study, each package that was mailed out 
contained an instruction sheet, the survey, a request for payment form, and two prepaid selfaddressed envelopes, one to return the survey and one to return the request for payment form. The request for payment form also had a place where participants indicated whether they would like a copy of the results and if they would be willing to participate in an interview about their stressful life experiences for a subsequent project.

The instruction sheet restated the contents of the survey and told participants to complete the survey at their own pace, stopping or taking breaks whenever they wished. The researchers' phone numbers were provided if participants had any questions or comments about the survey, as was a list of community resources that participants could call if they found the survey upsetting. Participants were also informed that, if they were distressed as a result of completing the survey, arrangements could be made for them to meet with a clinical psychologist at no cost. The completion and return of the survey was taken as participants' informed consent.

\section{Participants}

The participants consisted of 310 seniors ( $62.6 \%$ women) 60 years of age and older $(M$ age $=69.2, S D=7.3$, range $=60$ to 100 years $)$. Approximately one third $(32.4 \%)$ of these respondents were between the ages of 60 and $64,26.2 \%$ were between the ages of 65 and $69,18.1 \%$ were between the ages of 70 and $74,12.6 \%$ were between the ages of 75 and $79,7.1 \%$ were between the ages of 80 and $84,2.3 \%$ were between the ages of 85 and 89 , and $1.2 \%$ were at least 90 years old. A comparison with Statistics Canada data on gender for the senior Canadian population (Statistics Canada, 2004c) indicates that $55.2 \%$ of the Canadian population aged 60 and over are female. Thus, women were overrepresented in the present sample. This sample is, however, representative of the Canadian senior 
population by age group, with one exception: this sample had twice as many seniors between the ages of 85 and 89 (i.e., 12.3\% vs. 5.4\%) (Statistics Canada, 2004c).

Just under half (45.7\%) of the participants were of British descent, approximately a third were Canadian (31.5\%), and 6.5\% were French. Other ethnic backgrounds reported by fewer than $5 \%$ of the respondents were German, Ukrainian, Italian, Polish, Romanian, Dutch and Russian. Statistics Canada's 2001 Census data for ethnic origin are not specific to the senior population in Canada. However, comparisons with data for the population living in Ottawa-Hull (Statistics Canada, 2001d) suggest that this sample overrepresents people of British descent (45.7\% vs. $14.5 \%$ ), although some of this apparent overrepresentation may stem from the fact that Statistics Canada's data includes Francophones living in Hull.

In regard to religion, approximately half $(51.3 \%)$ of the participants identified themselves as Protestant and almost a third described themselves as Roman Catholic (29.5\%). An additional $8.6 \%$ indicated having no religion and $7.1 \%$ indicated being Christian. Statistics Canada's (2002e) 2001 Census data indicate that Catholicism $(54.0 \%)$ is more common than being Protestant (33.3\%) among seniors aged 65 and older living in Ottawa-Hull whereas for both respondents aged 60 and over $(29.5 \%$ and $51.3 \%$, respectively) and those aged 65 and over (28.8\% and 53.7\%) being Protestant was more common than Catholicism. Again, however, this difference may stem from the predominance of Catholicism in Hull relative to Ottawa. This sample is also slightly over representative of seniors aged 60 and over (7.1\%) and those aged 65 and over who are Christian (5.4\%) compared to seniors aged 65 and over living in Ottawa-Hull (1.9\%). This sample is, however, representative of seniors who have no religion. In particular, the $6.6 \%$ 
of seniors aged 65 and over living in Canada who indicate they have no religion is comparable to the $8.6 \%$ of respondents aged 60 and over and $8.3 \%$ of those aged 65 and over who did so.

Over half of the participants were married (57.8\%). Others reported being widowed (19.7\%), divorced (15.8\%), single (never married) (4.8\%) and separated (2.9\%). Over half of the participants reported living with their spouse or partner (56.8\%) and just over a third reported living alone (33.9\%). Fewer respondents reported living with other relatives, inlaws or friends $(5.8 \%)$, in senior residential facilities $(2.6 \%)$, and living with people they are not related to (e.g., paid help) (1.0\%). Overall, the marital status of this sample appears to be representative of seniors aged 60 and over living in Canada (Statistics Canada, 2002f), with one exception: This sample had twice as many seniors aged 60 and over who were divorced ( $15.5 \%$ vs. $5.2 \%)$. This sample also appears to be representative of seniors aged 65 and over living in Canada with respect to living arrangement (Statistics Canada, 2002g), with one exception: Compared to Canadians aged 65 and over $(0.7 \%)$, more respondents aged 60 and over (5.8\%) and aged 65 and over (7.2\%) reported living with their relatives.

These respondents were generally well-educated, having completed an average of 14.4 years of school $(S D=3.0$ years), and most $(60.8 \%)$ reported having at least some type of postsecondary education (i.e., at least 14 years of education), including trade school, college, university and graduate school. Over a third of the participants (36.2\%) indicated having at least some or completed high school, while only $2.9 \%$ indicated having completed less than some highschool education. The seniors in this sample appear to be slightly more educated than the Canadian senior population. In particular, while $60.8 \%$ of those aged 60 and over and $55.0 \%$ of the respondents aged 65 and over had at least some post secondary 
education, only $28.4 \%$ of the senior population aged 65 and over living in Ottawa has at least some postsecondary education (Statistics Canada, 2002h). Consistent with this, only $2.9 \%$ of the participants aged 60 and over and $3.8 \%$ of those aged 65 and over reported less than some highschool education, while approximately a quarter $(24.9 \%)$ of the seniors aged 65 and older in Ottawa-Hull have less than some highschool education. However, the number of participants aged 60 and over (36.2\%) and 65 and over (41.2\%) with at least some high school education was comparable to the number of seniors aged 65 and over living in Ottawa-Hull (46.7\%).

Not surprisingly, most respondents were retired (82.9\%). Others reported being employed part-time $(7.4 \%)$ or full-time $(5.8 \%)$, not employed but seeking work $(1.9 \%)$, and not employed and not seeking work (1.9\%). When asked about the type of work they currently do or did most of their lives, being a housewife (15.0\%), secretarial work $(12.1 \%)$, teaching (9.5\%), working for the government (8.3\%), and working as a tradesman (e.g., electrician, plumber, wood worker) $(8.3 \%)$ were common, followed by education administrators $(5.1 \%)$, working in sales and marketing $(4.5 \%)$, working in private business (4.5\%), research scientists (3.2\%), and working in retail or as store clerks (2.2\%). Types of employment reported by fewer than $2 \%$ of the sample were being in the armed forces, working with computers, the food industry, real estate and accounting. Consistent with the well-educated nature of the sample, then, most participants were professionals or white collar workers.

Finally, participants' median annual family income was between $\$ 35,000$ and $\$ 44,999$. In particular, $11.9 \%$ had yearly incomes less than $\$ 15,000$, while roughly equal numbers of participants reported annual family incomes of $\$ 15,000$ to $\$ 24,999(13.1 \%)$, 
$\$ 25,000$ to $\$ 34,999(12.1 \%), \$ 35,000$ to $\$ 44,999(13.1 \%)$, and $\$ 45,000$ to $\$ 54,999(13.7 \%)$. In addition, $9.2 \%$ had annual family incomes between $\$ 55,000$ and $\$ 64,999,4.5 \%$ between $\$ 65,000$ and $\$ 74,999$, and $18 \%$ reported annual family incomes of $\$ 75,000$ or more. Thus, the majority of the sample was financially well-off and had higher annual family incomes than the average senior aged 65 years and older living in Canada (Statistics Canada, 2000i). Generally, the median annual family income of the respondents in this sample who were aged 60 and over and aged 65 and over $(\$ 35,000$ to $\$ 44,999)$ was two times larger than that of seniors living in Canada $(\$ 17,267)$. This disparity appears to stem from the large difference in the number of seniors in the lowest and highest income brackets. While $11.9 \%$ of the respondents aged 60 and over and $12.0 \%$ of respondents aged 65 and over reported annual family incomes less than $\$ 15,000,33.8 \%$ of the senior Canadian population aged 65 and over have family incomes under $\$ 15,000$. Conversely, while over one third of the Canadian senior population aged 65 and older (37.8\%) have annual family incomes between $\$ 15,000$ and $\$ 24,999$, this was true of only $13.1 \%$ of the respondents aged 60 and over and $14.8 \%$ of those aged 65 and over. In addition, while only $1.9 \%$ of Canadian seniors aged 65 and older have annual family incomes of $\$ 80,000$ or more, $18 \%$ of the participants aged 60 and over and $13.9 \%$ of those aged 65 and over reported annual family incomes of $\$ 75,000$ or more.

In sum, the typical participant in this study was a 69 year-old, retired, married, Canadian born, Protestant living with their spouse, with at least some postsecondary education and an annual family income between $\$ 35,000$ and $\$ 44,999$. Compared to the seniors living in Canada and/or Ottawa-Hull, the respondents in this study are slightly more likely to be women, Protestant, of British descent, are more educated and have higher 
annual family incomes. This sample is, however, fairly representative of seniors living in Canada with respect to age, marital status and living arrangements.

\section{Measures}

Participants completed measures of their demographic characteristics (i.e., age, gender, ethnicity, etc), experiences of trauma and well-being, as well as measures of potential mediators and moderators of the relations between trauma and well-being (i.e., coping strategies, reminiscence, current stressors, and exposure to the psychosocial dynamics of trauma). To reduce order effects, these measures appeared in randomized orders.

Traumatic experiences. Participants' exposure to 20 potentially traumatic events was assessed with items from Higgins and Follette's (2002) study of now-senior female trauma survivors, the Life Stressor Checklist Revised (LSCL-R; Wolfe \& Kimerling, 1997), Norris' (1992) Life Stressor Checklist and Kubany and colleagues (2000) Traumatic Life Events Questionnaire. Also included in the trauma measure were items developed specifically for this study assessing physical and sexual abuse (touching and intercourse) since the age of 60 , being detained in a concentration camp (e.g., during the Holocaust or in Bosnia), and being a POW. Four of the 20 items assessed experiences of noninterpersonal traumas, namely being in a serious disaster (e.g., earthquake or tornado), having a serious car accident, having a serious accident of a different nature (e.g. job related accident, plane crash), and witnessing a violent death. The remaining 16 events referred to experiences of interpersonal traumas, namely, being robbed, physically attacked by a stranger, witnessing or hearing family violence as a child, sexual abuse (sexual touching and intercourse) and physical abuse as a child, adult and senior, combat experiences, being in a concentration 
camp, and being a POW. Respondents were asked to indicate whether or not they experienced each of these events and to describe, "any stressful experience(s) that we did not include that you would like to mention."

The scales from which items were derived are reliable and valid. For example, 52 female war veterans' endorsements on the LSCL-R were moderately correlated with a diagnosis of PTSD, chronic health conditions, acute physical health symptoms and subjective perceptions of health (Kimerling, Clum, \& Wolfe, 2000). The construct validity of the LSCL-R was also demonstrated in a sample of $88 \mathrm{HIV}+$ women, where more frequent endorsement of the LSCL-R items predicted higher levels of psychological distress, depression and somatic symptoms (Kimerling, Armistead, \& Forehand, 1999).

Participants who indicated that they have had at least one stressful experience were asked to respond to additional questions regarding their "worst" stressful experience, that is, "the experience which caused you the most distress (i.e., anxiety, worry, saidness, grief, etc.)." These additional questions asked how often they experienced their "worst" stressful experience, their age when they first had this experience and their age when they last had this experience. Using 5-point scales ranging from No distress (0) to Extreme distress (4), respondents were also asked to rate how much distress the event caused them at the time it occurred and now. In addition, to assess the extent seniors continue to be troubled by memories of their "worst stressful experience" participants were asked to use a scale ranging from No, never (0) to Yes, very often (4) to rate how often they 'think about this experience now,' a scale ranging from Much less often (0) to Much more often (4) to rate 'how often they think about this stressful experience now compared to when you were younger, say in your 30 s or 40 s' and a scale ranging from No, never (0) to Yes, very often 
(4) to rate how often things 'seem to trigger your thoughts, memories or mental images of this experience.' Participants who responded affirmatively to the last question were also asked to describe these triggers. Finally, respondents were asked to use scales ranging from No, never $(0)$ to Yes, very often (4) to rate how often they feel 'a need to talk to someone about this experience,' how often they 'talk to anyone about this experience,' and how often they spoke 'to a professional (e.g., a psychiatrist, psychologist, doctor or pastor) because of difficulties you were having as a result of this experience.' Respondents were also asked whether they wanted to tell us anything else about this "worst" stressful experience.

Measures of well-being. Participants' psychological, physical and social well-being were assessed. There are a number of measures that might be used to assess the psychological consequences of trauma. Foa, Cashman, Jaycox, and Perry (1997), for example, developed and validated a short self-report measure of PTSD based on DSM-IV criteria. Most measures, however, do not provide a comprehensive assessment of the variety of symptoms following trauma, such as depression, anxiety and those associated with Complex PTSD. Moreover, most measures do not have published scale norms for seniors. Because the Trauma Symptom Inventory-Alternate (TSI-A; Briere, 1995) assesses the diverse aftereffects of trauma and provides published norms for men and women over the age of 55, it was chosen for the present study. ${ }^{3}$

In the TSI-A, respondents were asked to use ranging from Never (0) to Often (3) to rate how often they had each of 84 experiences in the past six months. The 84 items

\footnotetext{
${ }^{3}$ Although the TSI-A does not provide a direct measure of PTSD, it is possible to assess PTSD indirectly by examining respondents' scores on the three TSI-A scales that assess the three defining symptom clusters of PTSD (i.e., the Anxious Arousal, Intrusive Experiences and Defensive Avoidance scales).
} 
represent eight clinical subscales: Anxious Arousal (e.g., trembling or shaking), Intrusive Experiences (e.g., becoming angry for little or no reason), Depression (e.g., feeling like life wasn't worth living), Defensive Avoidance (e.g., stopping yourself from thinking about the past), Dissociation (e.g., feeling like you are outside of your body), Intrusive Experiences (e.g., sudden disturbing memories when you were not expecting them), Impaired Self-Reference (e.g., not understanding why you did something), and Tension Reduction Behaviour (e.g., intentionally hurting yourself even though you weren't trying to commit suicide). The TSI-A also provides scores for three validity scales, namely Atypical Response (ATR), Response Level (RL) and Inconsistent Response (INC). ATR items assess the tendency to over-endorse items and the possibility of a psychotic or disorganized state, RL scores reflect the possibility of responses distorted by defensiveness or avoidance, and the INC scale measures response inconsistency due to random responding, reading difficulties, poor concentration or dissociation.

The TSI-A has demonstrated acceptable psychometric properties in both clinical and nonclinical samples. A study of convergent validity with 449 trauma survivors (Briere, 1995) revealed that TSI-A scores were correlated with two measures of posttraumatic stress, namely the Impact of Events Scale (IES; Horowitz, Wilner, \& Alvarez, 1979) and the Symptom Checklist (SCL; Foy, Sipprelle, Rueger, \& Carroll, 1984). As expected, TSI-A Anxious Arousal scores were highly correlated with SCL arousal scores, TSI-A Defensive Avoidance scores were highly correlated with SCL and IES avoidance scores, and TSI-A Intrusive Experiences scores were highly correlated with SCL and IES intrusion scores. Moreover, the TSI-A predicted a significant amount of the variance in women's 
victimization over and above that explained by the IES and SCL. Although not statistically significant, the same pattern was evident among men.

The TSI-A validity scales also have good convergent validity. In a study of 100 university students (Briere, 1995), ATR and RL scale scores were moderately correlated with scores on scales measuring similar constructs from the Personality Assessment Inventory (PAI; Morey, 1991) and the Minnesota Multiphasic Personality Inventory (MMPI-2; Keane, Malloy, \& Fairbanks, 1984). In particular, ATR scores were moderately correlated with scores on the Negative Impression Management Scale of the PAI and the Infrequency scale of the MMPI-2. Further, RL scores were moderately correlated with scores on the Positive Impression Management Scale of the PAI and the Defensiveness scale of the MMPI-2. Although INC scores were not correlated with scores on the PAI Inconsistency scale, this was probably due to the low internal reliabilities of both measures in this sample (.43 and .23 , respectively).

The construct validity of the TSI-A has been demonstrated in studies with various samples. In a community sample of 836 participants, childhood and adult experiences of interpersonal violence were significantly associated with higher TSI-A scores. TSI-A scores also correctly predicted PTSD status in $91 \%$ of the cases. In a sample of 279 university students, experiences of childhood sexual abuse were associated with higher scores on the Anxious Arousal, Anger/Irritability, and Intrusive Experiences scales, indicating PTSD. In addition, females scored higher on the Anxious Arousal, Depression, Anger/Irritability, Dissociation, Intrusive Experiences, Defensive Avoidance and the Impaired Self-Reference scales (Briere \& Smiljanich, 1994a). In a clinical sample of 233 psychotherapy outpatients and 137 psychiatric inpatients, those with experiences of 
childhood or adult physical and/or sexual victimization scored higher on all eight TSI-A scales compared to those without such victimization experiences (Briere, Elliott, Harris, \& Cotman, 1995).

The TSI-A also demonstrates good internal reliability. The mean alpha reliability rating of the TSI-A scales was .86 in a community sample of 828 people, .84 in a sample of 3,659 Navy recruits (Briere, 1995), .84 in a sample of 279 university students (Briere \& Smiljanich, 1994a), and .87 in a clinical sample of 370 psychiatric inpatients and psychotherapy outpatients (Briere et al., 1995). In the community sample, the alpha coefficients for the RL, ATR and INC validity scales were $.80, .75$ and .51 , respectively.

After completing the TSI-A, participants were asked to use scales ranging from Much less often (0) to Much more often (4) to rate the extent to which they experienced the TSI-A symptoms less or more frequently when they were a child (under age 13), a teenager (between 13 and 19), a young adult (aged 20 to 35) and during middle-age (between 36 and 50 years). These items were included to gain insight into the pattern of respondents' psychological responses to trauma over the lifespan. That is, whether their symptoms were continuous, recurrent, exacerbated with aging or had a delayed onset coinciding with aging.

Participants' physical well-being was assessed primarily with items derived from the physical health component of the Older Americans Resources and Services instrument (OARS; Duke University, 1978; Fillenbaum, 1988), an instrument originally developed as a structured interview and one with published norms. As measures of their use of health services, participants were asked to indicate how many times they saw a doctor, how many days they were in the hospital and how many days they were in a nursing home or rehabilitation center because of a physical health problem in the past six months. To assess 
their physical health, respondents were asked to indicate the number of sick days in the past six months, whether or not they had each of 26 physical health problems and chronic conditions (e.g., diabetes, asthma, high blood pressure) and, using a scale ranging from Not at all (0) to A great deal (4), the extent to which these problems/illnesses interfere with their daily activities. Participants were also asked to report the number of prescribed medications they were taking and to rate their physical health relative to that of their same-sexed peers using a scale ranging from Very poor (0) to Excellent (4).

When used as a structured interview, the OARS has good psychometric properties. For example, 11 raters with diverse professional backgrounds were in complete agreement for $74 \%$ of the ratings of 30 interviews (Fillenbaum, 1988). In addition, in a 5-week testretest trial of the instrument with 30 community residents representative of those aged 65 , $91 \%$ of the questions were rated identically (Fillenbaum, 1988). The OARS appears to have criterion validity in that a Spearman rank correlation of .82 was attained between interviewers' and physicians' assessments of the physical health of 33 seniors from a family medical clinic (Fillenbaum, 1988). The OARS also appears to have adequate sensitivity as it revealed predictable differences between independent community dwelling seniors $(N=$ $2,146)$, patients in a geriatric health clinic $(N=199)$, clients of adult day care centers for people aged 60 and older $(N=119)$ and institutional residents $(N=100)$ (Fillenbaum, 1988). The sensitivity of the OARS has also been demonstrated in longitudinal studies where the OARS detected changes over time as a result of life events and the receipt of health and social services (George \& Fillenbaum, 1985). Evidence for the sensitivity and validity of the OARS when used as a self-report instrument comes from Higgins and Follette (2002) and Gentlewarrior (1997), where senior women who had experienced 
interpersonal trauma reported more physical health problems and using more medications in the last six months compared to those without a history of interpersonal trauma.

Participants' social well-being was measured using Morgan, Dallosso, and Ebrahim's (1985) Social Engagement scale and three items from Shmotkin and colleagues (2003). The Social Engagement scale is a dichotomously scored (Yes/No) 10-item measure of seniors' personal engagement in their social milieu (e.g., 'Have you been away on a holiday in the last year?' 'Do you use the public library?'). In a sample of 111 seniors of varying functional ability (Morgan et al., 1985) the split-half reliability of the scale was .61 and the alpha coefficient was .67. Further, the scale was able to differentiate between seniors with high and low functional ability and higher social engagement scores were associated with greater life satisfaction. Derived from Shmotkin et al. (2003), participants were asked, 'Do you take part in volunteer activities?' and, using scales ranging from No, never (0) to Yes, everyday (3), to rate how often they go out to the movies, concerts or restaurants and how often they play cards or other games with people.

Potential moderators/mediators. Participants' coping strategies, reminiscence, current stress, and exposure to the psychosocial dynamics underlying trauma were considered as potential moderators and/or mediators of the relations between trauma and well-being. Participants' coping styles were assessed using the Brief Coping Orientation to Problems Experienced Scale (Brief COPE; Carver, 1997), a 28-item measure of adaptive and problematic coping responses to stressful life events derived from its longer parent, the full COPE (Carver, Scheier, \& Weintraub, 1989). The Brief COPE is comprised of 12 twoitem subscales: Active Coping (e.g., taking action to make the situation better), planning (e.g., thinking hard about what steps to take), Positive Reframing (e.g., looking for 
something good in what is happening), Acceptance (e.g., learning to live with it), humor (e.g., making jokes about it), Religion (e.g., praying or meditating), Emotional Support (e.g., getting emotional support from others), Instrumental Support (e.g., getting help and advice from other people), Self-Distraction (e.g., turning to work or other activities to take my mind off things), Denial (e.g., saying to myself "this isn't real"), Venting (e.g., expressing my negative feelings), Substance Use (e.g., using alcohol or other drugs to help me get through it), Behavioural Disengagement (e.g., giving up trying to deal with it), and Self-Blame (e.g., criticizing myself). Participants indicated how often they usually use each strategy along scales ranging from I don't do this at all (0) to I do this a lot (3).

Using data from 168 community residents who participated in a study of recovery from Hurricane Andrew, the internal consistency of the 14 Brief Cope scales was acceptable, with alpha values ranging from .50 (Venting) to .90 (Substance Use). In addition, an exploratory factor analysis yielded a complex factor structure consistent with that reported for the full COPE (Carver, Scheier \& Weintraub, 1989) and nine of the 14 factors from the Brief COPE accounted for $72.4 \%$ of the variance in psychological wellbeing. The predictive validity of the Brief COPE was also demonstrated in a study of the coping strategies of 141 people with HIV/AIDS (Vosvick et al, 2002), where the use of Behavioural and Mental Disengagement coping strategies predicted poorer psychological health. Although the test-retest reliability and convergent validity of the Brief COPE have not been documented, because the factor structure underlying the Brief COPE is similar to that underlying the full COPE, information on the psychometric properties of the full COPE are relevant (Meyer, as cited in Vosvick et al., 2002). The COPE appears to have adequate test-retest reliability as indicated by 5-week test-retest correlations ranging from .48 to .86 
in a sample of 89 college students and 6-week test-retest correlations ranging from .42 to .89 in a sample of 116 college students (Carver et al, 1989).

The COPE also displays convergent validity. For example, the COPE scores of 306 undergraduate students were correlated with two other measures of coping, namely The Coping Strategy Indicator (CSI; Amirkham, 1990) and The Ways of Coping Revised (WOC-R; Folkman \& Lazarus, 1985). In this study, Seeking Social Support scores from the CSI and WOC-R were significantly associated with Seeking Instrumental and Social Support scores from the COPE. Similarly, Avoidance scores on the CSI and WOC-R were significantly associated with Mental Disengagement scores on the COPE. Convergent validity was also found between the Problem Solving scores on the SCI and WOC-R and the Active Coping, Planning and Suppression of Competing Activities scores on the COPE. In addition, the COPE predicted physical health symptoms, life satisfaction, and positive and negative affect (Clark, Borman, Cropanzano, \& James, 1995).

The predictive validity of the full COPE was also demonstrated in a study examining the relations between the coping strategies of 71 people with spinal cord injuries and psychological well-being. In this study, Behavioural Disengagement scores were associated with higher depression scores, while both Behavioural Disengagement and Venting scores predicted dysphoric thoughts and feelings associated with the participant's injury, including anxiety, depression, hostility, reduced self-esteem, body image problems and inappropriate guilt. Acceptance, an adaptive method of coping, predicted lower levels of the above symptoms as well as lower levels hopelessness, intrusive memories, anger, depression and anxiety (Kennedy, Lowe, Grey, \& Short, 1995). 
The nature of respondents' reminiscence was measured with 15 items developed on the basis of Wong and Watt's (1991) discussion of reminiscence. Five of these questions were designed to assess integrative reminiscence (e.g., "when you think about this experience, do you ever have trouble accepting that it actually happened,' reverse coded), five items measured instrumental reminiscence (e.g., 'think about this stressful experience as a way of getting ideas about how to cope with a problem you are having now'), and five questions assessed obsessive reminiscence (e.g., 'do you ever find that you can't get thoughts, memories or mental images of this experience out of your mind even though you want to,' 'when you think about this experience, do you ever feel angry or resentful that it happened to you'). Respondents were asked to rate how often they engaged in each behaviour using scales ranging from $N o$, never (0) to Yes, all the time (4).

The Elders Life Stress Inventory (ELSI; Aldwin, 1990) was used to assess seniors' current exposure to stressors. Using the ELSI, respondents were asked to indicate whether or not they had experienced each of 31 stressful events in the past year (e.g., major deterioration of health, death of spouse, institutionalization of spouse). The ELSI can be scored by calculating the sum of respondents' stressfulness ratings or simply by counting the number of stressors. Aldwin (1990) reported that the two approaches were equally correlated with the number of physical health symptoms.

Concurrent validity of the ELSI has been demonstrated in three different surveys of seniors. The number of items endorsed was similar in all three surveys ( 1.83 vs. 2.38 vs. 2.64) and item endorsement was constant across a wide range of age (Aldwin, 1990). Further, the number of items checked on the ELSI is similar to the number of items checked on much longer scales designed for older adults, such as the 54-item Louisville Older 
Persons Events Scale (Murrell, Norris \& Hutchins, 1984) and Krauses' (1986) 77-item scale. The ELSI is also moderately correlated with both psychological and physical symptoms (Derogatis, 1983).

The extent to which respondents are currently exposed to the psychosocial dynamics associated with trauma was measured using 27 items developed on the basis of Finkelhor and Browne's (1985) and Heney and Kristiansen's (1998) theoretical discussions of the nature of these dynamics, Liem, O'Toole, and James' (1996) analyses of the themes of power and betrayal in sexual abuse survivors' stories of interpersonal relationships, and Palmore's (2001) Ageism Survey. Nine items assessed seniors' exposure to situations associated with powerlessness (e.g., 'needing someone's help to do what you used to do on your own,' 'someone assuming you could not understand things because of your age'), nine items assessed exposure to experiences associated with shame and stigma (e.g., 'being called an insulting name related to your age,' 'being seen as unattractive because of your age'), and nine items evaluated exposure to experiences that could instill feelings of betrayal (e.g., 'someone you care about leaving or abandoning you,' 'someone breaking a promise they made to you'). Participants were asked to rate how often they had each experience in the last six months using scales ranging from Never (0) to Many times (3).

Additional measures. The Posttraumatic Growth Inventory (Tedeschi \& Clahoun, 1996) was included as the last measure in the questionnaire in an attempt to reduce any feelings of distress that participants experienced as a result of answering earlier questions about traumatic and stressful life events. This 21 -item measure assesses the degree to which people experience positive outcomes following traumatic experiences, specifically New 
Possibilities $(\alpha=.84)$, Relating to Others $(\alpha=.85)$, Personal Strength $(\alpha=.72)$, Spiritual Change $(\alpha=.85)$ and Appreciation for Life $(\alpha=.67)$. 


\section{Results}

\section{Preliminary Analyses}

Preliminary analyses examined the validity and reliability of the predictor, potential mediating/moderating and criterion variables, as well as their descriptive statistics and intercorrelations. In addition, assumptions of normality, linearity and homoscedascity were evaluated and, for some of the variables, outliers with scores more than three standard deviations about the mean were removed and/or log transformations were conducted to reduce skew ${ }^{4}$.

Validity analyses. Participants' scores on the three TSI-A validity scales were examined to facilitate the validity of the data. The data of one participant with a T-score of 100 on the Atypical Response scale was excluded from further analysis because T-scores greater than or equal to 90 on this scale reflect a generalized tendency to over-endorse items of a psychotic state. The data of a second participant with a T-score of 73 on the Response Level scale was eliminated because $\mathrm{T}$-scores of at least 73 suggest responses distorted by defensiveness or avoidance. Finally, the data provided by a third participant was not considered because this person had a T-score of 81 on the Inconsistent Response scale where scores greater than or equal to 75 suggest responses affected by poor attention or concentration, dissociative experiences, or reading difficulties (Briere, 1995).

Scale homogeneity. Item and factor analyses were conducted to explore the possibility of reducing the data and developing internally consistent measures of the mediating and criterion variables. Principal component analyses with varimax rotations were performed on the measures of coping, reminiscence, and exposure to the psychosocial

\footnotetext{
${ }^{4}$ Results and discussion of the measures of trauma, well-being, negative reminiscence, avoidance coping, and traumagenic dynamics refer to the log transformations of these variables.
} 
dynamics underlying trauma. The number of factors extracted were guided by scree tests and the interpretability of the factor structures (Gorsvch, 2003). Items with complex loadings and those loading less than .4 on any factor were discarded.

Although the scree plot suggested that two factors underlay the 28-item Brief COPE, a three-factor solution was chosen because it had fewer items with complex or low factor loadings (i.e., 4 vs. 9 items). Nevertheless, one item regarding substance use was deleted because of its low factor loading and four items involving the use of self-distraction and humour were deleted because of their complex factor loadings. As shown in Table 1, which presents the loadings of each item on each factor, the eight items loading on the first factor were from the Active Coping, Planning, Positive Reframing and Acceptance scales. Because these items involve taking action to make the situation better, this factor was labelled Taking Action. Factor 2 was defined by eight items from the Emotional, Instrumental, Religion and Venting scales that involve seeking support and comfort from other sources, and was therefore called Seeking Support. Finally, the seven items loading on the third factor included items from the Behavioural Disengagement, Denial and SelfBlame scales, as well as one item from the Substance Use scale, and was therefore labelled Avoidance Coping. These factors accounted for $16.3 \%, 13.7 \%$ and $10.3 \%$ of the variance in the inter-item correlations, respectively. After deleting one item with a low item-total correlation, namely, "Do you use alcohol or other drugs to help you get through it," the remaining items comprising these measures were internally consistent, as displayed in Table 2. Given this, scores were derived from the mean of participants' responses to the relevant items, resulting in higher scores reflecting more frequent taking action, seeking support and avoidance coping. 
The factor analysis of the 13-item reminiscence measure yielded two independent factors. One item, "Do you ever think about past experiences in order to find a way to solve a problem you are having now?" was deleted because it loaded moderately on both factors. As shown in Table 3, which presents the loadings of each item on each factor, the first factor was labeled Negative Reminiscence because the seven items loading on this factor pertained to dwelling on past experiences, being unable to integrate problematic past events and experiencing guilt and shame when thinking about the past. This factor accounted for $32.2 \%$ of the variance in the inter-item correlations. Factor 2 was called Positive Reminiscence because it was defined by five items referring to acceptance, drawing on past events to help others, and viewing one's life as meaningful. This factor accounted for $18.2 \%$ of the variance in the inter-item correlations. As displayed in Table 2 , item analyses revealed that the items comprising these measures were internally consistent. Given this, scale scores were derived by calculating the mean of participants' responses to the relevant items, resulting in higher scores reflecting more frequent negative and positive reminiscence.

As shown in Table 2, the item analysis of the Elders' Life Stress Inventory revealed a modest alpha and low mean inter-item correlation. This is not surprising given the dichotomous nature of the items comprising the scale (Pedhazer \& Schmelkin-Pedhazer, 1999). Thus, current stress scores were calculated by counting the number of current stressors participants endorsed.

The factor analysis of the items assessing the frequency of seniors' exposure to the traumagenic dynamics (i.e., the items measuring stigma, betrayal and powerlessness) resulted in a one-factor solution. Although this is inconsistent with Finkelhor and Browne's 
(1985) theoretical distinction between the dynamics of stigma, betrayal and powerlessness, it is congruent with their description of how these dynamics can contribute to the same negative aftereffects. For example, Finkelhor and Browne (1985) suggest, "depression can be seen as growing out of stigmatization, betrayal or powerlessness" (p. 536). This one factor solution is also consistent with theoretical discussions of shame, where it is described as involving feelings of both worthlessness and powerlessness (Leskela, et al., 2002). Given this, and the correlations $(.52, .55$ and $.61, p \mathrm{~s}<.01)$ between the distinct measures of stigma $(\alpha=.79)$, betrayal $(\alpha=86)$ and powerlessness $(\alpha=.75)$, the one-factor solution shown in Table 4 was retained. After deleting five items with factor loadings less than .40 ("Being told a joke that makes fun of older people," "Needing someone's help to do something that you used to do on your own," "Being denied a position of responsibility because of your age," "Being seen as unattractive because of your age" and "Someone invading your privacy"), the remaining 22 items were internally consistent (see Table 2). Respondents' traumagenic dynamics scores were calculated by taking the mean of their responses to these 22 items, resulting in higher scores reflecting more frequent exposure to the dynamics associated with trauma.

Item analyses of the TSI-A total and 8 clinical scale scores indicated that these measures of psychological well-being were internally consistent (see Table 5). However, the item in the Tension Reduction Behaviour scale referring to "Intentionally hurting yourself" was removed because it had a low item-total correlation. Scale scores for TSI-A total and the eight clinical scales were computed by calculating the mean of participants' responses to the relevant items, resulting in higher scores reflecting less psychological wellbeing. As shown in Table 6, seniors' TSI-A scale scores were at least moderately 
interrelated, with correlations ranging from .37 to $.86(M r=.54)$. Given this, only total TSI-A scores were considered in the subsequent analyses.

Before conducting the factor and item analyses of the physical health items (i.e., number of doctor visits, sick days, hospital visits, nursing home or rehabilitation centre visits, physical symptoms, prescribed medications and subjective health rating), these items were transformed into Z-scores. In addition, the item asking, "During the past 6 months, how many days did you spend in a nursing home or rehabilitation centre because of a physical health problem?" was deleted due to a lack of variability (i.e., only one participant had spent any days in a nursing home or rehabilitation centre) and participants' responses to the item asking them to rate their overall physical health relative to their peers was multiplied by -1 to make its direction consistent with that of the other items. As shown in Table 7, a principal component analysis revealed a one-factor solution underlying the physical health items. This one factor accounted for $42.9 \%$ of the variance in the inter-item correlations. After removing one item with a low total-item correlation ("During the past six months, how many days were you in the hospital because of a physical health problem), an item analysis indicated that these items formed an internally consistent measure of physical health (see Table 8). The mean of seniors' responses to the remaining five items was therefore calculated, with higher scores reflecting poorer physical health.

After transforming the social well-being items into Z-scores and deleting the item assessing participants' accessibility to a telephone because of a lack of variability, a principal components analysis indicated a one-factor solution (see Table 9). Nevertheless, an item analyses revealed a low mean inter-item correlation among these items, even when three items with low factor loadings ("Have you made a personal phone call in the last 
week," "Do you use the public library" and "Do you play cards or other games with other people") were removed (see Table 8). As was true of the measure of current stress, however, this was not surprising given the dichotomous nature of most of the items. Social well-being scores were therefore computed by calculating the mean of participants' responses to these items, resulting in higher scores reflecting greater social well-being.

Descriptive statistics and correlations among the predictor variables. Overall, $83.9 \%$ of the sample reported that they had experienced at least one of the 20 types of traumas they were asked about. ${ }^{5}$ As shown in Table 10, which presents the frequency of each type of trauma, approximately $30 \%$ of the participants had experienced a natural disaster, child physical abuse and a bad car accident, and about a quarter had experienced child sexual touching, witnessing family violence and adult physical abuse. Between 10 and $17 \%$ reported experiences of an accident such as a plane crash or fire, being robbed or present during a robbery where the robber had a knife, witnessing a violent death, adult sexual touching, witnessing war or combat, and physical assault. The least frequently experienced traumas, reported by $0.9 \%$ to $8.7 \%$ of the participants, were adult rape, child sexual abuse, war or combat, elder physical and sexual abuse, being a POW, and being a concentration camp survivor. Based on the total number of traumas endorsed, these seniors experienced an average of $2.73(S D=2.42)$ traumas during their lives.

${ }^{5}$ Participants listed a number of events when asked, "Have you had any stressful experience(s) that we did not include that you would like to mention?" These events included divorce, personal illness, and the death or illness of a loved one. For the purposes of this research, none of these events was considered traumatic because these traumas did not meet the first DSM-IV criterion for PTSD, namely that "the person has experienced, witnessed or been confronted with an event that involved actual or threatened death or serious injury or a threat to the physical integrity of oneself or others" (APA, 1994, p. 467467). 
Two trauma scores were calculated, one based on the number of interpersonal traumas experienced (i.e., robbery, witnessing family violence as a child, child sexual abuse [touching and intercourse], child physical abuse, physical assault by a stranger and by someone known, adult sexual abuse [touching and intercourse], elder sexual abuse [touching and intercourse], elder physical abuse, witnessing warfare, combat experiences, being held in a concentration camp and being a prisoner of war) and the other based on the number of noninterpersonal traumas experienced (i.e., natural disaster, a bad car accident, some other bad accident, and witnessing a violent death). On average, these participants had experienced one or two interpersonal traumas $(M=1.69, S D=1.77)$ and only one noninterpersonal trauma $(M=0.94, S D=1.04), t(309)=7.48, p<.001, \eta^{2}=.425$. The two trauma measures were moderately correlated, $r=.30, p<.01$, suggesting that seniors who experienced more interpersonal traumas were moderately likely to have experienced more noninterpersonal traumas.

Descriptive statistics and correlations among the criterion variables. The descriptive statistics for participants' total TSI-A scores, presented in Table 8, indicated that this sample of seniors enjoyed relatively good psychological health. Specifically, in the past 6 months, on average, they rarely experienced the psychological difficulties assessed by the TSI-A. Consistent with this, only four participants (1.3\%), two women and two men, met the clinical cutoffs for the three TSI-A scales that reflect PTSD, namely Anxious Arousal, Defensive Avoidance and Intrusive Experiences, and were thus classified as having PTSD. These four participants had experienced both noninterpersonal and interpersonal traumas. In regard to interpersonal trauma, all four had experienced at least one type of abuse. In particular, three had experienced child physical abuse, child sexual abuse or both and three 
had experienced physical assault, rape and/or partner abuse. An additional 12 participants (3.9\%), six women and six men, met the clinical cutoff for two of the three PTSD scales and were thus classified as having partial PTSD. ${ }^{6}$ Specifically, four respondents met the clinical cutoff for the Anxious Arousal and Defensive Avoidance scales, six met the clinical cutoff for the Defensive Avoidance and Intrusive Experiences scales, and two met the clinical cutoff for the Anxious Arousal and Intrusive Experiences scales. Like the four participants classified as having PTSD, these 12 participants had experienced both noninterpersonal and interpersonal traumas, including at least one type of abuse. No participant classified as having PTSD or partial PTSD had experienced any type of war-related trauma.

These respondents also enjoyed good physical health. As shown in Table 8, in the past six months they visited a doctor two or three times, had four or five sick days, and spent less than one day in hospital, a nursing home or a rehabilitation centre for health symptoms. On average, these seniors had two or three physical health problems or illnesses, were taking three prescribed medications (typically beta blockers and medication for high cholesterol, high blood pressure and osteoporosis), and believed their health was as good as that of their same-sexed peers. This sample of seniors was also very involved in their social milieu. In particular, on average these participants engaged in four or five of the eight listed social activities, although they only rarely played cards and other games but occasionally went out to the movies, the theatre, concerts or restaurants.

\footnotetext{
${ }^{6}$ Studies suggest that the diagnostic criteria for PTSD may be too restrictive because they often exclude people suffering from clinically significant symptoms of PTSD. As a result, researchers often consider partial PTSD, which is sometimes defined as meeting the criteria for two of the three symptom clusters associated with PTSD (Schutzwohl \& Maercker, 1999).
} 
Correlational analyses revealed that participants with poorer physical health had slightly poorer psychological, $r=.26, p<.001$, and social well-being, $r=-.20, p<.001$. Total TSI-A scores, however, were independent of social well-being scores, $r=-.10, n s$.

Other analyses indicated that, relative to now, seniors who had experienced at least one trauma experienced the psychological symptoms assessed by the TSI-A somewhat less often as a child $(M=1.25, S D=1.29)$, a teenager $(M=1.43, S D=1.24)$, and a young adult $(M=1.49, S D=1.11)$, and 'about the same' $(M=1.77, S D=1.06)$ as they did during middle age. A one-way repeated measures analysis of variance (ANOVA) indicated a significant time effect, Wilks' $\lambda=.898, F(3,125)=4.71, p<.01, \eta^{2}=.10$, and follow-up polynomial contrasts indicated a significant linear increase in the severity of TSI-A symptoms over time, $F(1,127)=6.05, p<.05$. Participants' age at the time of the offset of their 'worst' trauma was examined to see if participants' described their psychological symptoms as 'about the same' as their symptoms during middle age, but worse than their symptoms as a child, teenager or young adult simply because their trauma occurred when they were middle aged or older (i.e., at least 36 years old). To the contrary, however, participants were on average 28.0 years old $(S D=18.6$ years $)$ when they experienced their worst trauma and $74.0 \%$ experienced their worst trauma before they were 36 years old. Given this, the steady increase in the frequency of senior trauma survivors' psychological symptoms across the lifespan suggests that some of these trauma survivors may be experiencing exacerbated, re-emergent or delayed PTSD symptoms as they age.

Additional analyses examined the descriptive statistics for seniors' responses to the questions asking them about their 'worst' trauma (See Table 11). Of the 130 participants who answered the questions regarding their worst trauma, the majority $(70.8 \%)$ responded 
in regard to an interpersonal rather than noninterpersonal trauma. A 2-way mixed factor ANOVA, with type of trauma (noninterpersonal vs. interpersonal) as the between participants factor and time (distress now vs. then) as the within participants factor yielded a significant effect due to time, $F(1,127)=250.66, p<.001, \eta^{2}=.66$, in that seniors' worst trauma caused them considerable distress at the time it occurred $(M=2.91, S D=0.98)$ but only slight distress now $(M=0.89, S D=1.08)$. The main effect of type of trauma, $F(1$, $127)=0.65, n s$, and the interaction of time and type of trauma, $F(1,127)=0.31, n s$, were nonsignificant. In addition, these seniors reported that they only occasionally think about this experience now, although they think about it now slightly more than they thought about when they were younger. Type of trauma did not affect how often these respondents think about this event now, $t(127)=.23, n s$, or how often they think about this event now compared to when they were younger, $t(116)=.22, n s$. Participants also indicated that certain things, namely television programs, news stories, and seeing or talking to particular friends and family, 'rarely' to 'sometimes' triggered their thoughts, memories, or mental images of their worst trauma. Again, type of trauma did not affect how often participants' memories of their worst trauma were triggered, $t(128)=.60, n s$. In addition, a 2-way mixed factor ANOVA, with type of trauma (noninterpersonal vs. interpersonal) as the between participants factor and feel the need versus actually talk about their trauma as the within participants factor yielded a significant effect due to feel the need versus actually talk about their worst trauma, $F(1,128)=8.10, p<.01$, in that seniors felt the need to talk to someone about this experience more than they actually talked about it. The main effect of type of trauma, $F(1,128)=0.09$, ns, and the interaction of type of trauma and felt the need to talk versus actually talked about it, $F(1,128)=3.09, n s$, were nonsignificant. Finally, on 
average these seniors reported talking to a professional because of difficulties associated with their 'worst' trauma between 'never' and 'once' $(M=0.53, S D=1.01)$, a rate that did not differ as a function of type of trauma, $t(127)=0.13, n s$.

\section{Descriptive statistics and correlations among the mediating/moderating variables.}

The descriptive statistics for the mediating/moderating variables (i.e., measures of coping, reminiscence, current stress, and the traumagenic dynamics) are presented in Table 2. On average, these seniors used taking action coping "a medium amount," seeking support coping "a little bit," and avoidance coping between "not at all" and "a little bit." A one-way repeated measures ANOVA revealed a sizeable difference in respondents' use of these three types of coping, Wilks' $\lambda=.243, F(2,306)=478.74, p<.001, \eta^{2}=.764$. Pairwise comparisons showed that participants more frequently engaged in taking action than seeking support coping, $t(308)=16.14, p<.001, \eta^{2}=.463$, which, in turn, they engaged in more frequently than avoidance coping, $t(308)=17.92, p<.001, \eta^{2}=.514$. Consistent with these differences in the use of coping strategies, these seniors more frequently engaged in positive reminiscence, which on average they did "sometimes," than negative reminiscence, which they did "rarely," $t(305)=13.15, p<.001, \eta^{2}=.364$.

On average, in the past year these respondents experienced three or four of the 31 stressful life events they were presented with, with most experiencing between one and six current stressors. As displayed in Table 12, which lists the frequency of each stressor, in the past 6 months at least a third had experienced the death of a friend, deterioration in the health of a family member, a deterioration in their memory, and a major decrease in pleasurable activities. About a quarter of the participants had experienced the death of a family member or the deterioration of their health. The least common stressors, 
experienced by fewer than $10(3.2 \%)$ people, were the death of a child or grandchild, marital separation, divorce or marriage, being burglarized or robbed, the loss of prized possessions, the institutionalization of a spouse, and a change to a less desirable line of work. Finally, in the last 6 months these seniors were, on average, only rarely exposed to the psychosocial dynamics associated with trauma.

As shown in Table 13, which displays the correlations among the mediating/moderating variables, the three types of coping were interrelated. Seniors who engaged in taking action coping were moderately more likely to engage in seeking support coping and those who engaged in more avoidance coping were slightly more likely to engage in both taking action and seeking support coping. In contrast, the near zero correlation between the two reminiscence measures indicates that seniors' use of each type of reminiscence was independent. Consistent with this, respondents who more frequently engaged in negative reminiscence were slightly more likely to use seeking support coping and moderately more likely to use avoidance coping, while those who engaged more frequently in positive reminiscence were slightly more likely to use taking action and seeking support coping. In addition, respondents who reported more current stressors engaged in slightly more seeking support and avoidance coping, slightly more negative reminiscence, and were moderately more exposed to traumagenic dynamics. Finally, respondents who more frequently encountered traumagenic dynamics reported slightly more seeking support and avoidance coping, moderately more negative reminiscence, and moderately more current stressors. 


\section{Main Analyses}

The main analyses examined the correlations between the predictor, mediating/moderating and criterion variables. Path analyses (Baron \& Kenny, 1986) were then conducted to assess the viability of the hypothesized model of the variables mediating the relation between earlier trauma and current well-being, and hierarchical regression analyses tested the effects of variables hypothesized to moderate the trauma-well-being relation.

Correlations between the predictor and criterion variables. The correlations between the predictor and criterion variables are presented in Table 14. As shown there, seniors who experienced more interpersonal traumas had moderately poorer psychological well-being and slightly poorer physical health. Similarly, seniors who more frequently experienced noninterpersonal traumas had slightly poorer psychological and physical health.

Partial correlations between the measures of trauma and well-being, controlling for the other type of trauma, were calculated to assess the independent effects of each type of trauma. As shown in Table 14, when noninterpersonal trauma was controlled, participants who experienced more interpersonal traumas continued to have moderately poorer psychological well-being and slightly poorer physical health. In contrast, when interpersonal trauma was controlled the correlation between noninterpersonal trauma and TSI-A scores became nonsignificant, while the correlation between noninterpersonal trauma and physical health remained significant. Thus, while seniors with more experiences of interpersonal trauma have moderately more psychological symptoms and slightly poorer 
physical health, seniors with more experiences of noninterpersonal trauma have only slightly poorer physical health.

Analyses examining the correlations of seniors' responses to the questions regarding their 'worst' trauma with the measures of well-being revealed moderately poorer psychological well-being on the part of seniors who currently experienced greater distress as a result of their worst trauma, $r=.40, p<.001$, seniors who more frequently think about their worst trauma, $r=.34, p<.001$, seniors whose thoughts, memories and mental images of their worst trauma are more frequently triggered, $r=.35, p<.001$, seniors with a greater need to talk to someone about this experience, $r=.44, p<.001$, those who more frequently talk to others about this experience, $r=.29, p<.001$, and those who more frequently talked to a professional about difficulties they were having as a result of their worst trauma, $r=$ $.35, p<.001$. In addition, slightly poorer physical health was reported by seniors who thought more frequently about their worst traumatic experience, $r=.20, p<.05$, those who felt a greater need to talk to someone about this experience, $r=.17, p=.05$, and those who more frequently talked to others about their experience, $r=.18, p<.05$. Participants' social well-being was independent of particiapants'responses to these questions about their worst traumatic experience.

Correlations between the predictor and mediating/moderating variables. The simple and partial correlations between the predictor and potential mediating/moderating variables are also presented in Table 14. As shown there, seniors who experienced more interpersonal traumas engaged in slightly more taking action and seeking support coping, as well as moderately more negative reminiscence and slightly more positive reminiscence. They also experienced moderately more current stress and encountered traumagenic 
dynamics moderately more often. Although respondents' experiences of noninterpersonal trauma were independent of all of the coping measures, seniors who experienced more noninterpersonal traumas engaged in slightly more positive reminiscence, experienced slightly more current stress and encountered traumagenic dynamics slightly more often.

Partial correlations were calculated to assess the independent relations between the measures of trauma and potential mediating/moderating variables. As shown in Table 14, when experiences of noninterpersonal traumas were controlled, respondents who experienced more interpersonal traumas continued to engage in slightly more negative reminiscence, experienced slightly more current stress, and encountered traumagenic dynamics slightly more frequently. Respondents' experiences of interpersonal traumas, however, became independent of all of the coping measures. When experiences of interpersonal traumas were controlled, experiences of noninterpersonal traumas remained slightly correlated with positive reminiscence, but not current stress or the traumagenic dynamics. In sum, while seniors' experiences of either type of trauma were independent of their coping strategies, seniors who experienced more interpersonal traumas engaged in slightly more negative reminiscence, encountered moderately more current stress, and were somewhat more exposed to psychosocial dynamics similar to those underlying trauma. Interestingly, seniors who experienced more noninterpersonal traumas reported more frequent positive reminiscence.

Correlations between the potential mediating/moderating and criterion variables. The correlations between the potential mediating/moderating and criterion variables are presented in Table 15. As shown there, seniors who engaged in more seeking support and avoidance coping, negative reminiscence, experienced more current stress and who were 
exposed more frequently to the traumagenic dynamics had at least moderately poorer psychological well-being. While no measure of coping was significantly correlated with physical health, seniors who engaged in more negative reminiscence had slightly poorer physical health, and those who experienced more current stress or more frequently encountered traumagenic dynamics had moderately poorer physical health. Finally, seniors who engaged in more taking action and seeking support coping, those who engaged in more positive reminiscence and those who less frequently encountered traumagenic dynamics were somewhat more involved in their social milieu.

Path analyses. Two path analyses were conducted to assess the extent to which the measures of coping, reminiscence, current stress and exposure to the dynamics underlying trauma mediated the observed relations between trauma (i.e., interpersonal and noninterpersonal trauma) and well-being (i.e., psychological and physical). ${ }^{7}$ Each path analysis involved a series of simultaneous regression analyses. In the first regression analysis, physical health was regressed onto total TSI-A scores and trauma. Total TSI-A scores were then regressed simultaneously onto the measures of coping, reminiscence, current stress, the traumagenic dynamics, and trauma. The measure of seniors' exposure to traumagenic dynamics was next regressed simultaneously onto their current stress and trauma scores to test whether traumagenic dynamics mediated the relation between current stress and well-being. Finally, the measures of coping, reminiscence, and current stress were each regressed individually onto trauma. Note that potential mediating variables that were not correlated significantly with both a predictor and a criterion variable were not considered in these analyses.

${ }^{7}$ Path analyses were not conducted for the measure of social well-being because it was not significantly correlated with either type of trauma. 
The first path analysis examined the variables mediating the observed relations between interpersonal trauma and psychological and physical well-being scores. When physical health scores were regressed simultaneously onto total TSI-A and interpersonal trauma, both TSI-A, $\beta=.201, t(307)=3.58, p<.001$, and interpersonal trauma were significant, $\beta=.143, t(307)=2.44, p<.05$, explaining $8.5 \%$ of the variance, $F(2,307)=$ $14.42, p<.001$. Thus seniors who experienced more interpersonal trauma and more psychological symptoms had poorer physical health.

Next, TSI-A scores were regressed simultaneously onto the measures of seeking support coping, negative reminiscence, current stress, traumagenic dynamics and interpersonal trauma. Together the five predictors accounted for $63.7 \%$ of the variance, $F(5,302)=101.55, p<.001$, but as shown by the tests of the individual beta weights displayed in Table 16, only negative reminiscence, traumagenic dynamics and interpersonal trauma made significant contributions to the equation. Thus, seniors who experienced more interpersonal trauma, who engaged more frequently in negative reminiscence, and had more frequent exposure to traumagenic dynamics were in poorer psychological health.

When the measure of senior's exposure to traumagenic dynamics was regressed simultaneously onto their current stress and interpersonal trauma scores, both current stress, $\beta=.391, t(307)=7.72, p<.001$, and interpersonal trauma, $\beta=.248, t(307)=.248, p<$ .001 , were significant, explaining $26.5 \%$ of the variance, $F(2,307)=55.39, p<.001$. Thus, seniors who experienced more interpersonal trauma and those with greater current stress in their lives were more frequently exposed to the dynamics associated with trauma.

In the last set of regression analyses, negative reminiscence and current stress were each regressed individually onto interpersonal trauma. In these analyses, negative 
reminiscence, $R^{2}=.071, \beta=.267, t(306)=4.84, p<.001$, and current stress, $R^{2}=.068, \beta=$ $.260, t(308)=4.72, p<.001$, were each associated with more interpersonal trauma. Thus, seniors who experienced more interpersonal trauma were more likely to engage in negative reminiscence and experienced more current stress.

Taken together, and as illustrated in Figure 2, these analyses indicate that interpersonal trauma had a direct effect on physical well-being, as well as four indirect effects; one mediated by its effect on psychological well-being, one mediated by its effect on negative reminiscence and, in turn, its impact on psychological well-being, one mediated by exposure to traumagenic dynamics and their impact on psychological well-being, and another mediated by current stress and its impact on traumagenic dynamics. In addition, interpersonal trauma had a direct effect and three indirect effects on psychological wellbeing; one mediated by negative reminiscence, one mediated by the traumagenic dynamics, and another mediated by current stress and its impact on traumagenic dynamics.

The next path analysis examined the variables mediating the relations of noninterpersonal trauma with psychological and physical well-being. When physical health scores were regressed simultaneously onto TSI-A and noninterpersonal trauma scores, both TSI-A, $\beta=.232, t(307)=4.09, p<.001$, and noninterpersonal trauma, $\beta=.222, t(307)=$ $4.28, p<.001$, were significant, explaining $11.6 \%$ of the variance, $F(2,307)=20.23, p<$ .001 . Thus, seniors who experienced more noninterpersonal trauma and more psychological symptoms had poorer physical health.

When total TSI-A scores were regressed simultaneously onto the measures of current stress, traumagenic dynamics, and noninterpersonal trauma, the three predictors collectively accounted for $41.2 \%$ of the variance, $F(3,306)=71.33, p<.001$. As shown by 
the tests of the individual beta weights displayed in Table 17, only traumagenic dynamics scores were significant. Thus, seniors who were more frequently exposed to traumagenic dynamics were in poorer psychological health.

When the measure of seniors' exposure to the traumagenic dynamics was regressed simultaneously onto their current stress and noninterpersonal trauma scores, current stress, $\beta$ $=.444, t(307)=8.67, p<.001$, but not noninterpersonal trauma, $\beta=.075, t(307)=1.46, n s$, was significant, explaining $21.1 \%$ of the variance, $F(2,307)=40.98, p<.001$. Thus, seniors with greater current stress were more frequently exposed to the dynamics associated with trauma.

Finally, current stress was significant when it was regressed onto noninterpersonal trauma scores, $R^{2}=.024, \beta=.155, t(308)=2.76, p<.01$. Thus, seniors who experienced more noninterpersonal trauma experienced more current stress.

Taken together, and as illustrated in Figure 3, these analyses indicate that noninterpersonal trauma had a direct effect on physical well-being, as well as an indirect effect mediated by current stress, the frequency of exposure to traumagenic dynamics, and psychological well-being. Noninterpersonal trauma did not, however, have a direct effect on psychological well-being. Rather, the impact of noninterpersonal trauma on psychological well-being was entirely mediated by current stress and the frequency of exposure to traumagenic dynamics.

In sum, the results of these path analyses suggest that seniors more frequently exposed to interpersonal trauma have poorer psychological and physical well-being, in part because of the effects of interpersonal trauma on negative reminiscence, current stress and exposure to psychosocial dynamics similar to those underlying trauma. In contrast, seniors 
more frequently exposed to noninterpersonal trauma have poorer physical health, in part because of the effect of noninterpersonal trauma on levels of current stress, exposure to traumagenic dynamics and psychological well-being. Thus, both interpersonal and noninterpersonal trauma affected physical well-being via their effects on current stress, traumagenic dynamics and psychological well-being. Only interpersonal trauma, however, had an effect on physical well-being that was mediated by negative reminiscence and psychological well-being.

Given the correlation between the frequency of seniors' exposure to interpersonal and noninterpersonal trauma, these path analyses were conducted after controlling for the effect of the other type of trauma by entering it into the equation on the first step.

In regard to the path analysis examining interpersonal trauma and psychological and physical well-being, when TSI-A and interpersonal trauma scores were regressed simultaneously in the second step, after noninterpersonal trauma scores were entered in the first step, TSI-A was significant, $\beta=.204, t(306)=3.55, p<.001$, but interpersonal trauma was not, $\beta=.085, t(306)=1.42, n s, R^{2}=.122, F(2,306)=10.21, p<.001$. Contrary to the result obtained when noninterpersonal trauma was not controlled, then, seniors with more experiences of interpersonal trauma did not have poorer physical health. There were no other differences in the results when noninterpersonal trauma was controlled. Thus, the three indirect effects of interpersonal trauma on psychological well-being and four indirect effects on physical well-being remained significant when noninterpersonal trauma was controlled.

When interpersonal trauma was controlled statistically by entering it into the equation on the first step, the results for of the regression analyses assessing the impact of 
noninterpersonal trauma remained the same, with one exception: Noninterpersonal trauma no longer predicted current stress scores when it was entered on the second step, $\beta=.083$, $t(307)=1.44, n s, R^{2}=.068$, after interpersonal trauma was entered on the first step. Thus, contrary to the findings observed when interpersonal trauma was not controlled statistically, seniors with more experiences of noninterpersonal trauma did not experience more current stress. However, noninterpersonal trauma continued to have a direct effect on physical well-being.

Moderator analyses. Hierarchical regression analyses were performed to assess the extent to which current stress moderated the relations between trauma (i.e., interpersonal and noninterpersonal trauma) and well-being (i.e., total TSI-A, physical health and social well-being scores). Each analysis involved regressing the well-being measure in question onto current stress and trauma simultaneously in the first block and the Trauma X Current stress interaction term in the second block. Before doing these analyses, the main effect and interaction terms were mean centered. Where the interactions were significant, regression equations were derived for different levels of current stress for participants with low versus high levels of trauma to understand the nature of the interaction. Specifically, predicted well-being scores were estimated for seniors with scores one standard deviation above and below the mean of current stress for participants with low and high levels of trauma.

The first set of analyses examined whether current stress moderated the relations between trauma (i.e., interpersonal and noninterpersonal) and psychological well-being. When total TSI-A total scores were regressed onto interpersonal trauma and current stress in the first step and the Interpersonal trauma X Current stress interaction in the second step, the main effects of interpersonal trauma, $\beta=.342, t(306)=2.61, p=.01$, and current stress, 
$\beta=.277, t(306)=5.20, p<.001$, were significant, $R^{2}=.200, F(3,306)=25.58, p<.001$, but the Interpersonal trauma X Current stress interaction was not, $R^{2}$ change $=.001, \beta=$ $.059, t(306)=0.44, n s$. Similarly when, total TSI-A scores were regressed onto current stress and noninterpersonal trauma in the first step and the Noninterpersonal trauma $\mathrm{X}$ Current stress interaction in the second step, the main effects of noninterpersonal trauma, $\beta$ $=.208, t(306)=3.79, p<.001$, and current stress, $\beta=.306, t(306)=5.56, p<.001$, were significant, $R^{2}=.162, F(3,306)=19.77, p<.001$, but the interaction was not, $R^{2}$ change $=$ $.000, \beta=.011, t(306)=0.20, n s$. In sum, then, current stress did not moderate the relation between either type of trauma and psychological well-being.

The next analyses examined whether current stress moderated the relation between trauma and physical well-being. When the measure of physical health was regressed onto interpersonal trauma and current stress in the first step and the Interpersonal trauma $\mathrm{X}$ Current stress interaction in the second step, the main effect of interpersonal trauma, $\beta=$ $.235, t(306)=1.70, n s$, was not significant but the main effect of current stress, $\beta=.273$, $t(306)=4.86, p<.001$, was significant, $R^{2}=.115, F(3,306)=13.39, p<.001$. The Interpersonal trauma X Current stress interaction was also nonsignificant, $R^{2}$ change $=.001$, $\beta=.095, t(306)=0.68, n s$. When the measure of physical health was regressed onto noninterpersonal trauma and current stress in the first step and the interaction term in the second step, the main effects of noninterpersonal trauma, $\beta=.563, t(306)=4.11, p<.001$, and current stress, $\beta=.274, t(306)=5.17, p<.001$, were significant, $R^{2}=.137, F(3,306)=$ $19.11, p<.001$, as was their interaction, $R^{2}$ change $=.021, \beta=.356, t(306)=2.74, p<.01$. The predicted physical health scores illustrated in Figure 4 indicated that seniors more frequently exposed to noninterpersonal trauma reported poorer physical well-being than 
seniors less frequently exposed to noninterpersonal trauma under high, but not low, levels of current stress.

Hierarchical regression analyses were next conducted to assess whether current stress moderated the relation between trauma and social well-being. When social wellbeing was regressed onto current stress and interpersonal trauma simultaneously in the first step and the interaction term in the second step, neither the main effect of current stress, $\beta=$ $.006, t(298)=0.11, n s$, nor the main effect of interpersonal trauma was significant, $\beta=$ $-131, t(298)=-0.88, n s, R^{2}=.000, F(3,298)=0.36, n s$. The Interpersonal trauma $\mathrm{X}$ Current stress interaction was also nonsignificant, $R^{2}$ change $=.003, \beta=-.151, t(298)=-$ $1.01, n s$. When the measure of social well-being was regressed onto noninterpersonal trauma and current stress simultaneously in the first step and the interaction in the second step, the main effect of current stress, $\beta=.011, t(298)=0.20, n s$, and the main effect of noninterpersonal trauma were not significant, $\beta=-.088, t(298)=-.61, n s, R^{2}=.000, F(3$, $298)=0.20, n s$. The interaction term was also nonsignificant, $R^{2}$ change $=.002, \beta=-.105$, $t(298)=-0.73, n s$

In sum, while current stress did not moderate the relation between either type of trauma and psychological and social well-being, current stress did moderate the relation of noninterpersonal trauma with physical well-being.

Three processes that might underlie the observed interactive effect of noninterpersonal trauma and current stress on physical health were examined, namely avoidance coping, negative reminiscence, and exposure to traumagenic dynamics. If high, but not low, levels of current stress evoke senior trauma survivors' inclination to use avoidance coping and engage in negative reminiscence, and these stressors replicate the 
traumagenic dynamics they experienced earlier, then avoidance coping, negative reminiscence and traumagenic dynamic exposure should have the same effects on wellbeing as noninterpersonal trauma. That is, avoidance coping, negative reminiscence and traumagenic dynamics should interact with current stress to affect physical health. Hierarchical regression analyses were conducted to assess these possibilities. When the measure of physical health was regressed onto avoidance coping and current stress on the first step and their interaction in the second, the main effect of current stress was significant, $\beta=.300, t(306)=5.34, p<.001$, but not the main effect of avoidance coping, $\beta=.052$, $t(306)=0.39, n s, R^{2}=.096, F(3,306)=10.78, p<.001$, or the interaction, $R^{2}$ change $=$ $.000, \beta=.012, t(306)=0.09, n s$. In contrast, when the measure of physical health was regressed onto negative reminiscence and current stress on the first step and their interaction on the second step, the main effect of negative reminiscence was significant, $\beta=.346$, $t(304)=2.52, p<.05$, the main effect of current stress was nonsignificant, $\beta=.099, t(304)$ $=0.93, n s, R^{2}=.100, F(3,304)=12.68, p<.001$, and the interaction was significant, $R^{2}$ change $=.012, \beta=.296, t(304)=2.00, p=.05$. As indicated by the predicted physical health scores presented in Figure 5, more frequent negative reminiscence was associated with poorer physical well-being for seniors with high, but not low, levels of current stress.

Finally, when physical health scores were regressed onto the traumagenic dynamics and current stress in the first step and their interaction in the second step, the main effects of traumagenic dynamics, $\beta=.551, t(306)=4.57, p<.001$, and current stress, $\beta=.192, t(306)$ $=3.36, p<.01$, were significant, accounting for $18.7 \%$ of the variance, $F(3,306)=25.21, p$ $<.001$. The interaction was also significant, $R^{2}$ change $=.011, \beta=.249, t(306)=2.02, p<$ .05 . The predicted physical health scores illustrated in Figure 6 indicated that, among 
seniors with high levels of currents stress, those more frequently exposed to traumagenic dynamics had poorer physical health. In contrast, the physical health of seniors with low levels of current stress did not differ as a function of their low versus high exposure to traumagenic dynamics.

That current stress interacted with negative reminiscence and exposure to traumagenic dynamics to affect seniors' physical health in the same way that it interacted with noninterpersonal trauma suggests that negative reminiscence and exposure to traumagenic dynamics may mediate the effect of noninterpersonal trauma on the physical well-being of seniors with high, but not low, current stress. If so, controlling for negative reminiscence and exposure to traumagenic dynamics should reduce or eliminate the interactive effect of noninterpersonal trauma and current stress on seniors' physical wellbeing. However, because negative reminiscence and exposure to traumagenic dynamics interacted with current stress to affect physical health, it was not possible to simply examine the Noninterpersonal trauma X Current stress interaction after partialing out the effects of negative reminiscence and traumagenic dynamics. Instead, the effect of noninterpersonal trauma on physical well-being was examined separately for seniors with high $(n=140)$ versus low $(n=170)$ levels of current stress, as determined by a median split at 1.73 , when negative reminiscence and traumagenic dynamics were and were not controlled.

The simple correlation between the noninterpersonal trauma and physical health scores of seniors with low levels of current stress was $.17, p<.05$. After partialing out the effects of negative reminiscence, this correlation was $.16, p<.05$, and after partialing out the effects of exposure to traumagenic dynamics this correlation was .13, ns. Although controlling for traumagenic dynamics rendered the correlation between noninterpersonal 
trauma and physical well-being nonsignificant, the magnitude of the reduction of the size of the correlation is insufficient to conclude that exposure to the dynamics of trauma mediate the relation between noninterpersonal trauma and physical health among seniors with low levels of current stress. Among seniors with high levels of current stress, the correlation between noninterpersonal trauma and physical health scores was $.30, p<.001$. After partialing out the effects of negative reminiscence, this correlation was $.30, p<.001$, and after partialing out the effects of exposure to traumagenic dynamics this correlation was .28, $p<.001$. Thus, negative reminiscence and traumagenic dynamics do not appear to mediate the observed effects of trauma on seniors with high levels of current stress.

In sum, the findings of these analyses of variables hypothesized to moderate the relation between trauma and well-being suggest that current stress moderates the relation between noninterpersonal trauma and physical health, but not the relations between noninterpersonal trauma and psychological and social well-being or between interpersonal trauma and any measure of well-being. In addition, the moderating effect of current stress on the noninterpersonal trauma-physical well-being relation does not appear to be mediated by the extent to which seniors engage in negative reminiscence, their exposure to psychosocial dynamics similar to trauma, or their use of avoidance coping.

\section{Additional Analyses}

Additional analyses examined the moderating effects of participants' gender, age, education and income, as well as the extent to which participants' demographic characteristics provided alternative explanations for the observed relations.

Moderating effects of demographic variables. Hierarchical regression analyses were conducted to assess whether the effects of interpersonal and noninterpersonal trauma 
on well-being were moderated by participants' gender, age, education, and income. For each demographic variable, a measure of well-being (i.e., TSI-A, physical or social wellbeing scores) was regressed onto a trauma measure (i.e., interpersonal or noninterpersonal) and a demographic variable (i.e., gender, age, education or income) simultaneously on the first step and the Trauma X Demographic variable interaction term on the second step. None of the interaction terms were significant. Hierarchical regression analyses were also conducted to assess whether the effects of the hypothesized mediator/moderator variables on well-being were moderated by participants' gender, age, education, and income. Once again, none of the interaction terms in these analyses were significant. Taken together, then, these findings indicate that respondents' gender, age, income and education did not moderate the effects of trauma on well-being or the effects the hypothesized mediating/moderating variables on well-being.

Alternative explanations for the observed findings. The correlations of seniors' demographic characteristics with the predictor (i.e., interpersonal and noninterpersonal trauma), mediating/moderating (i.e., the three types of coping, positive and negative reminiscence, current stress and traumagenic dynamics), and well-being measures (i.e., psychological, physical, and social) were examined to identify any confounds that might provide alternative explanations for any of the observed significant results.

The correlations of participants' gender, age, education and income are presented in Table 18. As shown there, relative to women, men experienced slightly more noninterpersonal traumas and engaged in moderately less seeking support coping. However, because gender was not related to any of the moderating/mediating variables, criterion variables involved in a significant relationship, participants' gender cannot provide 
an alternative explanation for any of the observed relations. Examining the correlates of age revealed that older seniors experienced slightly fewer interpersonal traumas, engaged in slightly more taking action, seeking support and avoidance coping and slightly less negative reminiscence, and had slightly poorer psychological and physical health. When age was controlled, however, the relations between interpersonal trauma and taking action coping, $r$ $=.13, p<.05$, seeking support coping, $r=.11, p<.05$, negative reminiscence, $r=.27, p<$ .001 , psychological well-being, $r=.34, p<.001$, and physical health, $r=.25, p<.001$, remained significant, as did the relations between seeking support coping and psychological well-being, $r=.40, p<.001$, avoidance coping and psychological well-being, $r=.49, p<$ .001 , and negative reminiscence and psychological well-being, $r=.68, p<.001$. Participants' age, then, did not provide an alternative explanation for the observed relations between interpersonal trauma, coping, negative reminiscence and psychological or physical well-being.

As shown in Table 18, seniors with more education engaged in moderately more taking action coping and positive reminiscence, and had moderately better social wellbeing. However, because respondents' education was independent of their scores on the measures of the mediating/moderating variables and the criterion variables that were involved in significant relations, education cannot provide an alternative explanation for any of the observed relations. Participants' annual family income, however, was related to a number of variables. In particular, seniors with larger annual incomes engaged in slightly less avoidance coping and negative reminiscence, slightly more positive reminiscence, experienced slightly less current stress, encountered traumagenic dynamics moderately less often and had moderately better psychological, physical and social well-being. When 
annual income was controlled, however, participants' negative reminiscence, $r=.69, p<$ .001 , current stress, $r=.327, p<.001$, and exposure to traumagenic dynamics, $r=.62, p<$ .001 , continued to be related to their psychological well-being. Similarly, when annual income was controlled, participants' negative reminiscence, $r=.12, p<.05$, current stress, $\mathrm{r}$ $=.28, p<.001$, and exposure to traumagenic dynamics, $r=.39, p<.001$, continued to be related to their physical well-being. Participants' yearly income, then, did not provide an alternative explanation for the observed relations.

Other analyses revealed that participants' ethnicity, religious orientation, relational status, living arrangements and employment status were also unable to provide alternative explanations for any of the observed significant relations. Thus, although there were some associations between participants' demographic characteristics, and their scores on the measures of trauma, potential mediating/moderating variables and well-being, when these demographic variables were controlled all of the relations between the trauma, potential mediating/moderating and well-being measures in question remained significant, suggesting that participants' demographic characteristics do not provide alternative explanations for the results obtained in the correlational, path and moderator analyses. 


\section{Discussion}

To date the literature indicates that most seniors have experienced some form of trauma and that some continue to suffer psychological and physical consequences as a result of their earlier trauma (Gentlewarrior, 1997; Green, 1993; Higgins, 1999; Higgins \& Follette, 2002; Kraaij and DeWilde, 2001; Norris, 1992). As yet, little research has examined the effects of different types of trauma or the processes by which trauma affects seniors' well-being. Do senior survivors of interpersonal and noninterpersonal trauma suffer the same fate? Are the processes associated with aging, such as reminiscence, the stresses of aging and exposure to psychosocial dynamics similar to those underlying trauma, involved in the relation between seniors' experiences of trauma and their well-being? The present study was designed to answer these questions.

Approximately $84 \%$ of the seniors in the present study experienced at least one type of trauma in their lifetime, a rate that is higher than the $69 \%$ documented in Norris' (1992) interviews with a community-based sample of 321 senior men and women. However, the frequency these seniors experienced particular types of trauma, especially interpersonal traumas, was consistent with the findings of some studies, but higher or lower than the rates reported in other studies. For example, while the rate of contact sexual abuse experienced as a child (touching $26 \%$ and intercourse $8 \%$ ) is consistent with the $30 \%$ rate of contact child sexual abuse observed in both Higgins and Follette's (2002) study of senior women and Finkelhor et al.'s (1990) representative sample in the United States, it is higher than the $16 \%$ observed in Gentlewarrior's (1997) study of senior professional women and the $3 \%$ in Kraaij and DeWilde's (2001) study of 194 Dutch elders. Similarly, that $29 \%$ of the seniors in the present study reported experiencing a bad car accident is higher than the $19 \%$ in 
Norris' (1992) study, but lower than the $39 \%$ of the senior women in Higgins and Follette's (2002) study. The most discrepant findings concerned the rates of partner abuse, rape and combat experience. The $9 \%$ rate of adult sexual intercourse is much lower than the rates of $24 \%$ and $15 \%$ reported by Higgins and Follette (2002) and Kraaij and DeWilde (2001), respectively, but higher than the $2 \%$ reported by Norris (2002). Similarly, the rate of partner abuse (22\%) is half the $49 \%$ reported by Higgins and Follette (2002), and the percentage of seniors who experienced war or combat $(5 \%)$ was one quarter the $20 \%$ in Norris' (1992) study. The rates of other traumas, however, were consistent with the findings of other studies. For example, that $30 \%$ of these seniors reported experiencing childhood physical abuse (30\%) is comparable to the $28 \%$ reported by Higgins (1999; Higgins \& Follette, 2002). Similarly, the rate of physical assault by someone known (11\%) is comparable to the $9 \%$ reported by Norris (1992) and the 7\% in Higgins and Follette's (2002) sample of senior women. In addition, that very few of the participants experienced elder physical abuse $(0.6 \%)$ is consistent with the rate of elder physical abuse $(0.5 \%)$ observed in Podnieks et al.'s (1990) survey of a representative sample of elders in Canada. Why the rates for some, but not all, types of trauma were consistent with those observed in other studies, is an open question. Conceivably, differences in how the samples were obtained (e.g., via calls for older adults generally as opposed to older adults who had experienced trauma), the demographic characteristics of the samples (e.g., in gender and education) and/or differences in the methods used to measure trauma (e.g., via interviews vs. paper-and-pencil surveys) may be responsible.

As expected participants were more likely to cite an interpersonal rather than noninterpersonal trauma as their worst trauma. Relative to noninterpersonal traumas, 
interpersonal traumas were not rated as more distressing like they were by senior women trauma survivors in Higgins and Follette (2002) study. In particular, while women in Higgins and Follette's (2002) study found their experiences of noninterpersonal trauma to be slightly stressful, they found their experiences of interpersonal trauma to be very stressful. Seniors experiences of interpersonal and noninterpersonal trauma in this study were equally stressful (i.e., both caused them considerable distress). It was also expected that type of trauma would affect how often these respondents think about their worst trauma now compared to in the past, how often certain things trigger their memories of their worst trauma, and how often they feel the need to and actually talk about their worst trauma. Type of trauma however, did not make a difference. Generally, seniors sometimes thought about their worst trauma, which was more often than they thought about it at earlier times in their lives. Furthermore, although certain things triggered seniors' memories of their worst trauma, this happened rarely. In addition, seniors felt the need to talk about their worst trauma more than they actually did talk about it.

Other analyses revealed that, relative to now, seniors who had experienced at least one trauma experienced psychological symptoms somewhat less as a child, teenager, and young adult, and about the same as they did during middle age. Given that $74.0 \%$ of the sample experienced their worst trauma before the age of 36 , the steady increase in the frequency of senior trauma survivor's psychological symptoms across the lifespan suggests that some of these trauma survivors may be experiencing exacerbated, re-emergent or delayed PTSD symptoms. These findings are consistent with those of Zeiss et al (1995), and Port (1998), who found evidence of re-emergent and delayed onset PTSD in now senior POW's, with Op den Velde et al. (1993) who found that 35\% of now senior WWII Dutch 
resistance veterans did not develop symptoms of PTSD for 25 years or more, and with case studies reported by Gagnon and Hersen (2000) and Walter (1992) who describe the reemergent and delayed onset of PTSD symptoms in senior women who were abused as children and adults

The rates of PTSD (1.9\%) and partial PTSD (3.9\%) observed here are also lower than the rates reported in other studies of multiple traumas. For example, $4 \%$ of the senior trauma survivors in Norris' (1992) study were diagnosed with PTSD. Similarly, the seniors in the present study generally had good psychological health. In particular, their mean TSIA scores indicated that they experienced the psychological symptoms associated with trauma no more than a few times in the previous six months. Further, compared to the normative data of Briere's (1995) standardization sample of 120 women and 120 men aged 55 and over, the TSI scale scores of the women in the present study were slightly lower while the scores of the men in this study were slightly higher. For example, in Briere's (1995) study, senior women's mean raw scores for the anxious arousal, intrusive experiences and defensive avoidance scales were $6.10,4.50$ and 5.98 respectively, compared to senior women in the present study who's mean raw scores for the anxious arousal, intrusive experiences and defensive avoidance scales were 5.38, 4.17 and 5.21. Similarly, in Briere's (1995) study, men's mean raw scores for the anxious arousal, intrusive experiences and defensive avoidance scales were 4.32, 2.94 and 3.75 respectively, compared to senior men in the present study who's mean raw score for the anxious arousal scale was slightly lower $(M=4,19)$, but who's intrusive experiences and defensive avoidance scales were slightly higher $(M=3.50$ and $M=4.06$, respectively). One likely explanation for the lower rates of PTSD and trauma-related psychological symptoms in the 
present sample is the relative infrequency of some traumas, particularly interpersonal traumas such as adult sexual assault, partner abuse and combat.

Consistent with the relative infrequency of their experiences of traumas known to have serious consequences for people's well-being, the seniors in this study also enjoyed relatively good physical and social health. For example, these seniors took slightly fewer medications than the members of Joffe et al.'s (2003) control group (i.e., 2.9 vs. 4.7 medications, respectively) and had fewer health problems (2.43 vs. 4.12$)$ but more visits to the doctor (2.77 vs. 1.32) than Shmotkin et al's., (2003) Holocaust survivors and control group of postwar immigrants. They also had better subjective health than the normative OARS data for community residents' aged 60 and older (Fillenbaum, 1988) (i.e., on average describing their health as 'about the same' as their same-sexed peers vs. describing their health as 'poor' compared to their same-sex peers). However, relative to the OARS norms, these seniors experienced physical health problems with the same frequency (i.e., 53.5\% had arthritis vs. $51 \%$ of the OARS normative sample, $34.2 \%$ had high blood pressure vs. $34.0 \%$ of the normative sample and, $22.3 \%$ vs. $22.0 \%$ of the OARS normative sample had circulation problems) but had slightly more sick days in the last 6 months (i.e., $20.8 \%$. vs. $12 \%$ had seven sick days or less). In regard to their social well-being, on average these seniors engaged in more social activities than the Holocaust survivors, non Holocaust survivors and English born Australians in Joffe et al's., study (2003) (i.e., 4.76 vs. 1.1 activities). They also indicated going out and playing cards or other games with other people as often (i.e., between rarely and frequently) as the Holocaust survivors and control groups in Shmotkin and colleagues' (2003) study. 
Despite their relatively infrequent exposure to more severe forms of trauma and their good health, and hence the restricted variance in the measures of these constructs, the correlational analysis indicated that seniors who experienced more interpersonal and noninterpersonal traumas had poorer psychological and physical health. These findings are consistent with those of a number of earlier studies (e.g., Landau \& Litwin's [2000] study of Holocaust survivors; Gentlewarrior's [1997] and Higgins' [1999; Higgins \& Follette, 2002] studies of senior women], including Schnurr et al.'s (1998) finding that now-senior male combat veterans who had experienced other types of interpersonal and noninterpersonal traumas had more PTSD symptoms and poorer physical health.

However, in the present study seniors who experienced an interpersonal trauma were moderately more likely to have experienced a noninterpersonal trauma. This finding makes sense in view of a mortality follow-up of former prisoners of war that revealed increased mortality due to both trauma, primarily accidents, and cirrhosis of the liver (Keehn, 1980). Conceivably, these veterans were more likely to die from cirrhosis of the liver because they used alcohol to self-medicate their PTSD symptoms (e.g., hyperarousal, insomnia) and their use of alcohol, in turn, increased their likelihood of dying from an accident. In addition, however, Keehn (p. 209) suggested that, "Increased feelings of frustration, anger, and tension lead to impatience and impulsive actions which are likely to contribute to both the risk of and severity of accidental and self-inflicted injury. Although no studies have examined the extent to which noninterpersonal trauma is associated with subsequent interpersonal traumatization, this seems likely to the extent that noninterpersonal trauma results in the symptoms associated with PTSD. For example, the use of drugs and/or alcohol as ways of self-medicating symptoms of PTSD following noninterpersonal trauma 
may impair people's judgments regarding their safety or influence the types of people they affiliate. In any case, the observed correlation between the two types of trauma is important because it means that the failure to control for one type of trauma may inflate the apparent impact of the other type of trauma. Indeed, in the present study controlling for seniors' experiences of interpersonal trauma rendered the correlation between noninterpersonal trauma and psychological well-being nonsignificant. In contrast, when seniors' experiences of noninterpersonal trauma were controlled statistically, the correlations of interpersonal trauma with psychological and physical well-being remained significant.

While participants' experiences of trauma were related to their psychological and physical well-being, their experiences of both interpersonal and noninterpersonal trauma were independent of their social well-being. This finding is surprising given that seniors' with poorer physical health had slightly poorer social well-being and that those with better social well-being were slightly more likely to use taking action and seeking strength coping, engaged in slightly more positive reminiscence, and were exposed to slightly fewer traumagenic dynamics. It is, however, consistent with Joffe and colleagues' (2003) finding that senior Holocaust survivors were as socially active as the members of a nontraumatized comparison group. Thus, although Shmotkin at al. (2003) found that senior Holocaust survivors were less socially active than a nontraumatized comparison group, the balance of studies to date suggests that seniors' experiences of trauma are independent of their social well-being. Nevertheless, more research is needed before this conclusion can be drawn with any confidence.

The findings of the path analyses provide some insight into the processes by which these seniors' experiences of trauma affected their psychological and physical well-being. 
In particular, the frequency of seniors' negative reminiscence, the number of current stressors in their lives, their exposure to the psychosocial dynamics associated with trauma and their psychological well-being mediated the observed relations between interpersonal trauma and physical well-being. That seniors' psychological symptoms mediated the relation between their experiences of interpersonal trauma and their physical well-being is congruent with studies of younger populations, which suggest the impact of trauma on physical health is mediated by PTSD (for a review see Green \& Kimerling, 2004). It is also in line with Schnurr and colleagues' (2000) finding that, although senior war veterans' combat exposure predicted the onset of a number of physical disorders, including arterial, gastrointestinal, dermatological, and musculoskeletal disorders, only the relation between combat exposure and pulmonary disorder remained significant after PTSD was controlled.

That the frequency of seniors' negative reminiscence mediated the relation between interpersonal trauma and well-being is also as expected in view of the findings of two rather distinct literatures, one indicating that senior Holocaust survivors (Krystal, 1995; Aarts \& Op den Velde, 1996), war veterans (Coleman, 1986; Kaiman, 2003) and incest survivors (Silver et al., 1983) continue to struggle to make sense of their interpersonal traumas and another documenting the negative impact of obsessive reminiscence, and the positive effects of integrative and instrumental reminiscence, on seniors' mental and physical well-being (Wong \& Watt, 1991).

Another expectation borne out by these data concerns the mediating role of seniors' exposure to the psychosocial dynamics associated with trauma, namely powerlessness, stigmatization/shame and betrayal (Finkelhor \& Browne, 1985; Heney \& Kristiansen, 1998; Kristiansen, 2003; Kristiansen \& Hay, 2000), in the relation of interpersonal trauma and 
well-being. The aftereffects of trauma, such as low self-esteem, self-blame, interpersonal dependency, dysfunctional interpersonal schemas, impaired risk detection, problems perceiving threat and dissociation, aftereffects associated with revictimization (Gold, Sinclair, \& Balge, 1999), may explain why senior survivors of interpersonal trauma are more frequently exposed to psychosocial dynamics similar to those associated with trauma. It is also possible that the neurobiological changes associated with trauma, such as those responsible for hypervigilance (Brewin, 2003), make senior survivors of interpersonal trauma more sensitive to, and hence aware of, these dynamics. That seniors' exposure to these dynamics detracted from their well-being is consistent with the results of a number of studies, including studies indicating that feelings of powerlessness, stigma, and betrayal are negatively related to the psychological well-being of adult women who have been sexually abused during childhood (Coffey et al., 1996; Hazzard, 1993), Leskela et al.'s (2002) finding that now-senior POWs' who were more shame-prone had moderately higher PTSD scores, and Wong and Cook's (1992, as cited in Leskela et al.) finding that veterans with PTSD scored higher on measures of shame than veterans with substance abuse or depression.

Finally, the observation that seniors' exposed to more interpersonal traumas reported more current stressors in their lives, and that the number of current stressors affected seniors' well-being via their effects on seniors' exposure to traumagenic dynamics, is congruent with the suggestions of a number of researchers (e.g., Baider et al., 1992; Danieli, 1981; Kaimen, 2003). That seniors who experienced more interpersonal traumas reported more current stressors is consistent with Yehuda et al.'s (1995) finding that, relative to a nontraumatized comparison group, Holocaust survivors reported more exposure to the 
stressors of aging. Although the mechanisms underlying this relation are unclear, they may, at least in part, be similar to those underlying trauma survivors' tendency to be revictimized (Gold, Sinclair, \& Balge, 1999). For example, interpersonal dependency or dysfunctional interpersonal schemas may contribute to worsening relationships with a friend, child or spouse, and the use of drugs or alcohol to medicate the symptoms of trauma may contribute to deteriorations in finances and living conditions.

That seniors' with more current stressors were also exposed to more traumagenic dynamics is also as anticipated to the extent that the stressors of aging involve dynamics that render seniors less powerful, stigmatize them and/or leave them feeling betrayal (e.g., Baider, et al., 1993; Molinari \& Williams, 1999; Shmotkin et al., 2003). Reductions in the ability to do things, deteriorating finances and having to move to a less desirable residence, stressors assessed in this study, are disempowering experiences. Likewise, forced retirement or worsening relationships with a friend, child or spouse may contribute to feelings of shame and/or betrayal, and the deaths of friends and family may evoke feelings of abandonment and betrayal. Thus, senior trauma survivors' exposure to stress, and these stressors' ability to evoke emotions similar to those evoked by the psychosocial dynamics underlying trauma, may explain the findings of Yehuda et al. (1995; see also Kaup et al., 1994) and a number of case studies (Aarts \& Op den Velde, 1996; Hermann \& Eryavec, 1994; Kaimen, 2003) where changes in PTSD symptoms have been observed concurrent with the stressors of aging.

The results of the path analysis examining the impact of interpersonal trauma also suggest that, contrary to the suggestion that senior trauma survivors have poorer health because their earlier traumatization causes them to use more avoidance coping (e.g., 
Gagnon \& Hersen, 2000; Higgins, 1999), the extent to which these seniors engaged in avoidance coping did not mediate the impact of interpersonal trauma on well-being. In addition, these seniors' use of avoidance coping did not moderate the impact of current stress on seniors' well-being. Moreover, contrary to the suggestion that aging has robbed senior trauma survivors of their ability to cope (e.g., Buffum \& Wolfe, 1995; Sadavoy, 1996), but in line with seniors' ability to cope with natural disasters (Green et al., 1996), the seniors in the present study reported more frequently using positive forms of coping, such as action taking and seeking support, than avoidance coping.

In contrast to the complexity of the findings of the path analysis examining the impact of interpersonal trauma on seniors' well-being, the findings of the path analysis examining the impact of noninterpersonal trauma were straight forward. As was true of interpersonal trauma, the effect of these seniors' experiences of noninterpersonal trauma on their physical well-being was mediated by the number of stressors in their lives which, in turn, affected their exposure to traumagenic dynamics and, thereby, their psychological well-being. However, when seniors' experiences of interpersonal trauma were controlled, this indirect path between noninterpersonal trauma and physical health became nonsignificant. The only effect that remained, then, was the direct effect of seniors' experiences of noninterpersonal trauma on their physical health. This stands in contrast to the findings of the path analysis for interpersonal trauma when noninterpersonal trauma was controlled, where the only change involved the elimination of the direct path from interpersonal trauma to physical health. Conceivably, the direct effect of noninterpersonal trauma on physical health stems from physical injuries sustained at the time of the trauma. Alternatively, or in addition, processes other than those examined here may underlie the 
relation between noninterpersonal trauma and physical well-being. One likely candidate involves the neurobiological alterations following trauma, alterations that are associated with increased risk for heart disease, stroke, gastric ulcers, diabetes, asthma, and diseases stemming from impaired immune function (Bremner, 2002). Why these alterations would occur following noninterpersonal but not interpersonal trauma, however, challenges the feasibility of this account. Clearly, then, there is a need for research examining a comprehensive array of potential mediating variables.

Finally, the results of the analyses of potential moderating variables suggest that noninterpersonal trauma, negative reminiscence, and exposure to traumagenic dynamics are likely to detract from the physical well-being of seniors with many current stressors, but not those with few current stressors. However, the variance in physical well-being explained by these interactions was small (i.e., 1.1 to $2.1 \%$ ), especially compared to the variance explained by their constituent main effects (i.e., 10.0 to $11.5 \%$ ). In this sense, then, these findings are not notably different from the nonsignificant interactive effects of current stress and noninterpersonal trauma on psychological and social well-being, and the nonsignificant interactive effects of current stress and interpersonal trauma on all three measures of wellbeing. Moreover, and contrary to expectations, other analyses suggest that neither negative reminiscence, nor exposure to traumagenic dynamics or the use of avoidance coping, mediates the impact of noninterpersonal trauma on physical health.

Taken together, then, the present findings suggest that senior survivors of interpersonal trauma, but not senior survivors of noninterpersonal trauma, are vulnerable to poorer physical and psychological health and that such detrimental effects are a result of the impact of interpersonal trauma on seniors' tendency to engage in negative forms of 
reminiscence, the number of stressors in their lives, and their exposure to psychosocial dynamics similar to those they encountered at the time of their original trauma.

Like all research, the present study has a number of strengths and limitations that place upper and lower boundaries on the validity of the findings. The strengths of this study include the consideration of different types of trauma (i.e., interpersonal vs. noninterpersonal) and three types of well-being (i.e., psychological, physical and social), the consideration of variables that might mediate the effects of trauma on seniors' well-being, the use of measures normed for seniors (i.e., the TSI-A and some measures of physical health), and the use of inventories that also provide measures of the likelihood of response biases and inaccuracies. As discussed below, the limitations include issues relevant to the external and internal validity of the findings and, even more fundamentally, the reliability of the data.

At least two issues merit consideration in regard to the reliability of these data. One concern involves the reliability of the measures of trauma, well-being, coping, reminiscence, current stress, and exposure to traumagenic dynamics. However, a number of these constructs were measured using validated, reliable scales (i.e., Briere's [1995] TSI-A, Carver's [1997] Brief COPE, Aldwin's [1990] Elder Life Stress Inventory). Other constructs were measured using items derived from validated scales. The measure of trauma, for example, used items from Wolfe and Kimerling's (1997) Life Stressor Checklist Revised and Kubany et al.'s (2000) Traumatic Life Events Questionnaire, while the measures of physical and social well-being included items from the OARS (Duke University, 1978; Fillenbaum, 1988) and Morgan et al.'s (1985) Social Engagement Scale. In contrast, the measures of seniors' reminiscence and their exposure to the psychosocial 
dynamics associated with trauma were developed for the purpose of this research. Some confidence in the reliability of these measures comes from their internal consistency. That participants' responses to these measures were correlated, in predictable ways, with their scores on validated measures of other constructs (e.g., the TSI-A) suggests that they measured something consistently. Moreover, the fact that these measures' factor structures were consistent with theoretical discussions of the nature of reminiscence (i.e. Wong and Watt, 1991) and traumagenic dynamics (e.g., Finkelhor \& Browne, 1985; Leskela, et al. 2002), suggests that they have at least some construct validity.

Another, more specific concern involves the accuracy of participants' reports of traumatic experiences that may have occurred years ago. Indeed, the 'worst' traumas reported by these participants occurred, on average, when they were 28 years old. Two studies suggest that these seniors' reports of trauma are stable over time. In one study, Elder and Clipp (1989) compared the detailed descriptions of combat experiences provided by 107 WWII in 1946 with their descriptions 40 years later, in 1988, and found their accounts to be largely consistent. In another study, Krimsley, Gallangher, Weathers, Kutter, and Kaloupek (2003) found that 76 male military veterans' (aged 37 to 65 years) retrospective reports of sexual assault and abuse, accidents, disasters, and combat experiences were generally consistent over time. They did, however, recall somewhat more traumatic experiences during the second assessment.

More generally, other research indicates that remote memories hold up well with age, although there is some evidence for a "reminiscence bump" in that older adults are more likely to recall events that happened when they were between the ages of 10 and 30 (Erber, 2005). Further, research indicates that people's memories of the central rather than 
peripheral details of significant events are very accurate, with rates ranging from $82 \%$ to 96\% (Brown, Scheflin, \& Hammond, 1998). In view of these findings, and given that respondents were only asked to report whether they had a traumatic experience, as opposed to the details of this experience, it is likely that their retrospective reports are sufficiently. accurate. Moreover, because the data of three participants with high scores on the TSI-A validity scales were excluded, it is unlikely that participants' responses were distorted by a tendency to over-endorse items or a psychotic or disorganized state, defensiveness or avoidance, or random responding, reading difficulties, poor concentration or dissociation. Finally, it is important to note that any inaccuracies would probably detract from, rather than increase, the likelihood of observing significant relations between trauma and wellbeing.

At least two aspects of this study challenge the internal validity of the findings. The most basic challenge, of course, stems from the correlational nature of these data. As a result, there is no definitive way of establishing the validity of the direction of the effects assumed in this research. For example, rather than seniors' psychological well-being causing their physical well-being, perhaps their physical well-being affected their psychological well-being. Similarly, rather than negative reminiscence contributing to psychological well-being, perhaps seniors' psychological well-being affects the nature of their reminiscence. Of particular concern is the possibility that participants' reports of trauma, current stressors, etc., were subject to a mood congruency effect. Perhaps seniors who were psychologically distressed viewed their past and current circumstances more pessimistically, as more traumatic and more stressful. Relevant here is Brewin, Andrews, and Gotlib's (1993) review of research examining the impact of depression and anxiety on 
retrospective reports of traumatic experiences. Contrary to the mood congruency hypothesis, their review indicated that retrospective reports of trauma are both accurate and stable, even with changes in mood or clinical status. They conclude "...the evidence supports the view that adults asked to recall salient factual details of their own childhood are generally accurate, especially concerning experiences that fulfill criteria if having been unique, consequential, and unexpected. This does not mean that adults necessarily recall a wealth of peripheral details associated with these experiences, but rather that their recollections of the central features of the event are accurate and reasonably stable over time (p.87). To the extent that this is the case, the causal direction assumed in this research seems reasonable.

A second challenge to the internal validity of these findings comes from the possibility that the variance shared by the variables in this study is simply a result of the use of similar measurement methods. While some variables were measured using multiplepoint Likert-type scales (e.g., TSI-A, coping, reminiscence, traumagenic dynamics) and others were measured using dichotomous response scales (e.g., the measures of trauma, current stressors and most of the items measuring social well-being) or a mixture of response formats (i.e., the measure of physical well-being), all of the variables were measured using paper-and-pencil self-reports. Shared method variance, however, cannot explain the differences in the correlations associated with the measures of interpersonal and noninterpersonal trauma. Nor can it account for the relation of trauma with some (i.e., psychological and physical well-being), but not other (i.e., social well-being) measures of well-being. As a result, it seems unlikely that shared method variance, in itself, is responsible for the observed relations. 
Finally, to the extent that these data are used to make inferences about elders living in the Ottawa-Carleton region or Canada, the representativeness of the sample is a concern. Comparisons with census data suggest that this sample is representative of seniors living in Canada in regard to age, marital status and living arrangements. However, comparisons with census data for seniors living in Canada and Ottawa-Hull suggest a slight overrepresentation of women and a clear overrepresentation of seniors endorsing Protestant faiths, those of British descent, and those with more education and higher annual family incomes. To some extent the overrepresentation of Protestant faiths and seniors of British descent may stem from the fact that these comparisons were made with data regarding the characteristics of seniors living in Ottawa-Hull, as opposed to the Ottawa-Carleton region. If so, this sample is primarily biased by its overrepresentation of well-educated seniors with high annual incomes. That this occurred is, perhaps, not surprising given that seniors with more education, and hence greater incomes, are more likely to be interested in contributing to research. They may also find completing a survey easier and less time consuming than seniors with less education. In any case, to the extent that seniors with more education and higher incomes have greater or fewer experiences of trauma, these data should not be used to estimate the rates of trauma for seniors in Ottawa-Carleton or Canada. In the present study, however, participants' education and income were independent of their experiences of interpersonal and noninterpersonal trauma. In contrast, the observed correlations between respondents' education and social well-being, and those between their income and psychological, physical and social well-being, suggest that these data slightly overestimate the well-being of seniors living in Ottawa-Carleton and Canada. 
Other demographic analyses indicated that participants' gender, age, education and income did not moderate the relations observed in this study (e.g., between trauma and wellbeing). These relations, then, should apply to all seniors aged 60 and over. Indeed, because these respondents experienced fewer interpersonal traumas known to have severe consequences, namely partner abuse, rape and combat, and were in relatively good health, it is conceivable that the correlations observed here underestimate the actual impact of trauma on seniors' well-being. Within this context it is also worth noting that, consistent with previous findings indicating that men are more likely than women to have experienced a traumatic event (e.g., Norris et al., 2002), the men in this study reported more experiences of noninterpersonal trauma. In particular, men were twice as likely to have experienced child physical abuse and child sexual intercourse. They were less likely however, to have witnessed family violence. One explanation for the gender differences in the frequency of participants' experiences of particular types of trauma may be due to reporting biases or to their interpretation of the trauma question. In particular, the stigma surrounding abuse may have led to women underreporting their experiences of abuse. In addition, what a man qualifies as child physical may not be interpreted as child physical for a woman.

However, unlike previous research indicating that women experience traumatic events as more threatening (Norris et al., 2002) and are twice as likely to have a lifetime experience of PTSD (Norris et al., 2002; Seedat \& Stein, 2000), gender did not moderate the impact of trauma on these seniors' well-being. Although speculative, the underrepresentation of senior women reporting experiences of partner abuse and rape may account for this discrepancy. 
To the extent that these data are reliable and valid, the findings of this research have a number of implications for efforts to enhance the well-being of senior trauma survivors and research. That seniors' psychological well-being mediated the impact of interpersonal trauma on physical well-being suggests that efforts to improve senior trauma survivors' psychological health may generalize to improvements in their physical health. Further, that negative reminiscence, current stress and exposure to traumagenic dynamics mediated the relation between seniors' experiences of interpersonal trauma and their psychological wellbeing, suggests that interventions designed to improve the psychological and physical health of senior survivors of interpersonal trauma might usefully focus on their use of negative reminiscence and their exposure to the stresses of aging and the psychosocial dynamics associated with trauma.

That interventions targeting senior trauma survivors' reminiscence are likely to be effective is suggested by preliminary studies of the impact of Life Review Therapy (LRT). "LRT is a directed process of reminiscence in which a therapist helps the patient to organize and evaluate his or her memories of the consecutive stages of life. Life review can be described as a social-cognitive process by which biographical memories are selected, transformed, and reorganized as a function of the given context (e.g., the current emotional state, the precise instructions to reminisce, and the therapist-patient relationship)" (Maercker, 2002, p. 240). In a pilot study assessing the effects of a 10 to 13 session structured LRT designed to "help the patient engage in the healing activity or reminiscing on the "highs" ad "lows" of his or her life and to alleviate depression, persistent rumination, and distressing self-doubts" (Maercker, 2002, p.240), Maercker (2002) found that throughout treatment, immediately after treatment and three months posttreatment, LRT 
successfully reduced the PTSD symptoms of three senior survivors of the 1945 bombing of Dresden. Interestingly, the avoidance scores of two of these three trauma survivors were greater at the end of therapy, leading Maercker to suggest that cognitive avoidance strategies, such as distancing and minimizing negative aspects, may be effective for this age group. Case studies suggest that LRT may also be used successfully with senior survivors childhood sexual abuse (McInnis-Dittrich, 1996) and the Holocaust (Schindler, Spiegel, \& Malachi, 1992, cited in Maercker, 2002). In addition, the fact that the senior trauma survivors in this study reported more frequently feeling the need to talk about their 'worst' trauma than they actually did talk about this trauma, suggests that they may be receptive to this type of therapy.

Interventions designed to reduce senior trauma survivors' exposure to the psychosocial dynamics associated with trauma may also contribute to the well-being of senior trauma survivors. Relevant here is an intervention developed by Kristiansen (2005) that targets the behaviour of the people in senior trauma survivors' lives, including family members and caregivers (e.g., physicians, therapists, etc.). In this approach family members and caregivers are taught about the psychosocial dynamics associated with trauma (i.e., powerlessness, stigma/shame and betrayal), how these dynamics are replicated in the daily lives of senior trauma survivors, and the impact of the replication of these dynamics on senior trauma survivors. This education also provides family members and caregivers with strategies to minimize the extent they act in ways that replicate these dynamics. For example, offering seniors choices whenever possible, responding positively to seniors' efforts to control their lives, and believing what they say are likely to enhance their sense of control. Respecting senior trauma survivors' privacy and acknowledging their feelings in 
response to boundary violations (e.g., during medical procedures or personal care) and asking them what might make required violations easier may also increase their feelings of power. Likewise, explaining any limits to confidentiality would likely increase senior trauma survivors' sense of control because it would allow them to make informed choices about their disclosures. In this intervention family members and caregivers are also trained to recognize when a situation may have triggered senior trauma survivors' feelings from the past (i.e., through over-reactions), and provided with strategies to help senior trauma survivors cope with these aversive experiences. Although promising, the effectiveness of this type of intervention has yet to be established.

Finally, interventions that reduce senior trauma survivors' vulnerability to the stresses of aging may also reduce the impact of their prior traumatization on their wellbeing. Because a number of these stressors are inevitable (e.g., retirement and the death of friends and loved ones), interventions that target seniors' reactions to these stressors are more likely to be effective. Further, because these stressors appear to have adverse effects because they replicate the dynamics associated with trauma, senior trauma survivors might usefully be taught about the psychosocial dynamics associated with trauma, how these dynamics are replicated by the stressors of aging, and the impact of the replication of these dynamics on senior trauma survivors. Teaching senior trauma survivors relaxation techniques may also help them address any aversive hyperarousal triggered by these dynamics. Again, the effectiveness of this approach has yet to be determined. The use of experimental or quasi-experimental designs to test the impact of interventions designed to reduce senior trauma survivors' vulnerability to the stresses of aging and the psychosocial dynamics of trauma would have the additional benefit of providing evidence regarding the 
causal impact of current stress and traumagenic dynamics on senior trauma survivors' wellbeing.

In addition to assessing the impact of interventions designed to facilitate the wellbeing of senior trauma survivors, future research might endeavour to replicate these findings with a sample known to be representative of the population from which it is drawn. Although random digit dialing can be used to obtain a sample with a known probability of being representative, this is only feasible for very brief surveys. Structured interviews with seniors selected using probability sampling, then, may be the method of choice. So that the relation between trauma and well-being might be examined more closely, such research might include a more sophisticated measure of trauma that, for example, assesses the frequency and duration of different types of trauma, and a measure of social well-being that not only assesses the frequency of seniors' social activities, but also the quality of their social relationships (for a discussion see Dikel, Engdahl, \& Eberly, 2005). In view of the observed correlation between the frequency of seniors' experiences of interpersonal and noninterpersonal traumas, this research should examine the impact of one type of trauma while controlling for the impact of the other.

As suggested earlier, research examining a broader range of potential mediating variables, including neurobiological mediators, would be informative. So too would research examining the basis of the correlation between the frequency of seniors' experiences of interpersonal and noninterpersonal traumas. Such research might also assess the impact of earlier trauma on seniors' likelihood of experiencing elder abuse and the extent to which the feelings associated with the psychosocial dynamics of trauma mediate the relation between seniors' experiences of elder abuse and their well-being. It may also 
be informative to compare the coping strategies, reminiscence, current stress, and exposure to traumagenic dynamics of seniors classified as having continuous, reemergent, exacerbated or delayed PTSD.

Given the relative novelty of research examining the long-term impact of trauma on seniors' well-being, the number of areas worthy of research is virtually limitless. If nothing else, the fact that all of us will, hopefully, become members of the senior population and the probability that by that time most of us have endured some type of trauma, offers some hope to senior trauma survivors because this reality suggests that much of this research will be conducted. 


\section{References}

Aarts, P. G., \& Op den Velde, W. (1996). Prior traumatization and the process of aging: Theory and clinical implications. In B.A. van der Kolk, A.C. McFarlane, \& L. Weisaeth (Eds.), Traumatic stress: The overwhelming experience on mind, body, and society (pp. 359-377). New York: Guilford Press.

Aldwin (1990). The Elders Life Stress Inventory (ELSI). Egocentric and nonegocentric stress. In M. A. P. Stephens, S. E. Hobfoll, J. H. Crowther \& D. L. Tennenbaum (Eds.), Stress and Coping in Late Life Families (pp.49-59). New York: Hemisphere.

Allers, C., Benjack, K., \& Allers, N (1992). Unresolved childhood sexual abuse: Are older adults affected? Journal of Counseling and Development, 71, 14-17.

American Psychiatric Association. (1994). Diagnostic and statistical manual of mental disorders $\left(4^{\text {th }}\right.$ ed.). Washington, DC: Author.

American Psychological Association. (2000). Diagnostic and statistical manual of mental disorders ( $4^{\text {th }}$ ed., rev.). Washington, DC: Author.

Amirkhan, J.H. (1990). A factor analytically derived measure of coping: The coping strategy indicator. Journal of Personality and Social Psychology, 59, 1066-1075.

Baider, L., Peretz, T., \& Kaplan De-Nour, A. (1992). Effect of the Holocaust on coping with cancer. Social Science and Medicine, 34, 11-15.

Baider, L., Peretz, T., \& Kaplan De-Nour, A. (1993). Holocaust cancer patients: A comparative study. Psychiatry, 56, 349-355.

Baron, R.M., \& Kenny, D.A. (1986). The moderator-mediator variable distinction in social psychological research: Conceptual, strategic, and statistical considerations. Journal of Personality and Social Psychology, 51, 1173-1182. 
Beebe, G.W. (1975). Follow-up studies of World War II and Korean prisoners. American Journal of Epidemiology, 101, 400-422.

Bremner, J.D. (2002). Does stress damage the brain? Understanding trauma-related disorders from a mind-body perspective. New York: W.W. Norton \& Co.

Briere, J. (1995). Trauma Symptom Inventory professional manual. Odessa FL: Psychological Assessment Resources.

Briere, J., Elliott, D M., Harris, K., Cotman, A. (1995). Trauma Symptom Inventory. Psychometrics and association with childhood and adult victimization in clinical samples. Journal of Interpersonal Violence, 10, 387-401.

Briere, J., \& Smiljanich, K. (1994a). Child abuse history and Trauma Symptom Inventory scores in a University sample. Manuscript submitted for publication.

Brom, D., Durst, N., \& Aghassy, G. (2002). The phenomenology of posttraumatic distress in older adult Holocaust survivors. Journal of Clinical Geropsychology, 8, 189-201.

Brown, D., Scheflin, A.W.,\& Corydon Hammond, D. (1998). Memory, trauma treatment, and the law. New York: W.W. Norton \& Company.

Buffum, M., \& Wolfe, N. (1995). Posttraumatic stress disorder and the World War II Veteran. Geriatric Nursing, 16, 264-270.

Carver, C. S., (1997). You want to measure coping but your protocol's too long. Consider the Brief Cope. International Journal of Behavioural Medicine, 1997, 4, 92-100.

Carver, C. S., Scheier, M. F., \& Weintraub, J.K. (1989). Assessing coping strategies: A theoretically based approach. Journal of Personality and Social Psychology, 56, 267283. 
Clark, K. K., Borman, C. A., Cropanzano, R. S., \& James, K. (1995). Validation evidence for three coping measures. Journal of Personality Assessment, 65, 434-455.

Cloitre, M., Koenen, K., Gratz, K., Jakupcak, M. (2002). Differential diagnoses of PTSD in women. In R. Kimmerling, P. Ouimette \& J. Wolfe (Eds.), Gender and PTSD (117-149). The Guilford Press. New York.

Coffey, P., Leitenberg, H., Henning, K., Turner, T., \& Bennett, R. T. (1996). Mediators of the long-term impact of child sexual abuse: Perceived stigma, betrayal, powerlessness, and self-blame. Child Abuse and Neglect, 20, 447-455.

Coleman, P. G. (1986). Ageing and Reminiscence Processes. Social and Clinical Implications. John Wiley \& Sons Ltd.

Comjis, H.C., Pot, A.M., Smit, J.H., Bouter, L.M., \& Jonker, C. (1998). Elder abuse in the Community: Prevalence and Consequences. Journal of the American Geriatric society, 46, 885-888.

Creasy, H., Sulway, M. R., Dent, O., Broe, G. A., Jorm, A., \& Tennant, C. (1999). Is experience as a POW a risk factor for accelerated age related illness and disability? Journal of American Geriatric Society, 47, 60-64.

Danieli, Y. (1981). The aging survivor of the Holocaust. Journal of Geriatric Psychiatry, 14, 191-210.

Danieli, Y. (1997). As survivors age: An overview. Journal of Geriatric Psychiatry, 30, 9-26. Family Violence In Canada: A statistical profile 2003.

Delorey, C., \& Wolfe, K.A. (1993). Sexual violence and older women. Clinical Issues in Perinatal Womens Health Nursing, 4, 2, 173-179.

Derogatis, L.R. (1983). SCL-90-R: Administration, scoring, \& procedures manual for the 
revised version. Baltimore: Clinical Psychometric Research.

Dikel, T.N., Engdahl, B., \& Eberly, R. (2005). PTSD in former prisoners of war: Prewar, wartime and postwar factors. Journal of Traumatic Stress, 18, 69-77.

Duke University Center for the Study of Aging and Human Development: Multidimensional Functional Assessment: The OARS Methodology. Durham, NC, Duke University Center for the Study of Aging and Human Development, 1978.

Elder, G., \& Clipp, E. (1989). Combat experience and emotional health: Impairment and resilience in later life. Journal of Personality, 57, 311-341.

Erber, J.T. (2005). Aging \& older adulthood. Canada: Thomson Wadsworth.

Erikson, E. (1968). Identity, youth and crisis. New York: W.W. Norton \& Co.

Fields, R.B. (1996). Severe stress and the elderly: Are older adults at increased risk for posttraumatic stress disorder? In P.E. Ruskin \& J.A. Talbott (Eds.), Aging and posttraumatic stress disorder (pp. 79-100). Washington DC: American Psychiatric Press.

Fillenbaum, G. G. (1988). Multidimensional functional assessment of older adults: The Duke older Americans resources and services procedures. Hillsdale, NJ: Lawrence Erlbaum Associates.

Finkelhore, D., \& Brown, A. (1985). The traumatic impact of child sexual abuse: A conceptualization. American Journal of Orthopsychiatry, 55, 530-541.

Finkelhore, D., Hotaling, G., Lewis, I.A., \& Smith, C. (1990). Sexual abuse in a survey of adult men and women: Prevalence, characteristics and risk factors. Child Abuse and Neglect, 14, 19-28.

Foa, E.B., Cashman, L., Jaycox, L. H., \& Perry, K. (1997). The validation of a self-report 
measure of PTSD: The Post-Traumatic Diagnostic Scale (PTDS). Psychological Assessment, 9, 445-451.

Foy, D.W., Sipprelle, R.C., Rueger, D.B., \& Carroll, E.M. (1984). Etiology of posttraumatic stress syndrome in Vietnam veterans: Analysis of preliminary, military, and combat exposure influences. Journal of Consulting and Clinical Psychology, 52, 9-87.

Friedan, B. (1993). The fountain of age. New York: Simon \& Schuster.

Gagnon, M., \& Hersen, M. (2000). Unresolved childhood sexual abuse and older adults: Late-life vulnerabilities. Journal of Clinical Geropsychology, 6, 187-198.

Gavranidou, M., \& Rosner, R. (2003). The weaker sex? Gender and post-traumatic stress disorder. Depression and Anxiety, 17, 130-139.

Gentlewarrior, S. (1997). Symptoms of trauma in middle-aged and older female survivors of child sexual abuse: An ecological examination of risk and protective factors. Unpublished doctoral dissertation, School of Social Work, Simmons College, Newton Centre, Mass.

George, L. K. , \& Fillenbaum, G. G. (1985). OARS methodology. A decade of experience in geriatric assessment. Journal of the American Geriatric Society, 33, $607-615$.

Granatstein, J.L. (1969). Conscription in the Second World War 1939-1945. A study in political management. Toronto: Ryerson Press.

Green, A.H. (1993). Child sexual abuse: Long-term effects and intervention. Journal of American Academy of Child Adolescence Psychiatry, 32, 890-902.

Green, B.L., Gleser, G.C., Lindy, J.D., Grace, M.C., \& Leonard, A. (1996). Age-related 
reactions to the Buffalo Creek Dam collapse. In P.E. Ruskin \& J.A. Talbott (Eds.), Aging and posttraumatic stress disorder (pp. 101 - 125). Washington DC: American Psychiatric Press.

Green, B.L., \& Kimerling, R. (2004). Trauma, posttraumtic stress disorder, and health status. In P.P. Schnurr \& B.L. Green (Eds.), Trauma and health: Physical health consequences of exposure to extreme stress (pp. 13-42). Washington, DC: American.

Hausdorff, J.M., Levy, B.R., \& Wei, J.Y. (1999). The power of ageism on physical function of older persons: Reversibility of age-related gait changes. Journal of the American Geriatrics Society, 47, 1346-1349.

Hazzard, A. (1993). Trauma-related beliefs as mediators of sexual abuse impact in adult women survivors: A pilot study. Journal of Child Sexual Abuse, 2, 55-68.

Heney, J., \& Kristiansen, C.M. (1998). An analysis of the impact of prison on women survivors of childhood sexual abuse. In J. Harden \& M. Hill (Eds.), Breaking the Rules: Women in Prison and Feminist Therapy (pp. 29-44). Birmingham, NY: The Hawthorne Press.

Herman, J. (1992). Complex PTSD: A syndrome in survivors of prolonged and repeated trauma. Journal of Traumatic Stress, 5, 377-391.

Hermann, N., \& Eryavec, G. (1994). Delayed onset post-traumatic stress disorder in World War II veterans. Canadian Journal of Psychiatry, 39, 439-441.

Higgins, A.B (1999). The dialectic of trauma: Trauma symptoms and resiliency in older women. Unpublished doctoral dissertation, University of Nevada, Reno.

Higgins, A., \& Follette, V. (2002). Frequency and impact of interpersonal trauma in older women. Journal of Clinical Geropsychology, 8, 215-226. 
Horowitz, M.D., Wilner, N., \& Alvarez, W. (1979). Impact of Event Scale: A measure of subjective stress. Psychosomatic Medicine, 41, 209-218.

Joffe, C., Brodaty, H., Luscombe, G., \& Ehrlich, F. (2003). The Sydney holocaust study: Posttraumatic stress disorder and other psychosocial morbidity in an aged community sample. Journal of Traumatic Stress, 16, 39-47.

Jongedijk, R.A., Carlier, I.V., Schreuder, B.J., \& Gersons, B. (1996). Complex Posttraumatic Stress Disorder: An exploratory investigation of PTSD and DES NOS among Dutch war veterans. Journal of Traumatic Stress, 9, 577-586.

Kaiman, C. (2003). PTSD in the World War II combat veteran. American Journal of Nursing, 103, 32-42.

Kaup, B.A., Ruskin, P.E., \& Nyman, G. (1994). Significant life events and PTSD in elderly World War II veterans. The American Journal of Geriatric Psychiatry, 3, 239243.

Keane, T.M., Malloy, P.F., \& Fairbanks, J.A. (1984). Empirical development of an MMPI subscale for the assessment of combat-related posttraumatic stress disorder. Journal of Consulting and Clinical Psychology, 52, 888-891.

Keehn, R.J. (1980). Follow-up studies of World War II and Korean conflict prisoners III: Mortality to January 1, 1976. American Journal of Epidemiology, 111, 194-211.

Kennedy, P., Lowe, R., Grey, N., \& Short, E. (1995). Traumatic spinal cord injury and psychological impact: A cross-sectional analysis of coping strategies. British Journal of Clinical Psychology, 34, 627-639.

Kilpatrick, D.G., \& Resnick, H.S. (1993). Posttraumatic stress disorder associated with exposure to criminal victimization in clinical and community populations. In J.R.T. 
Davidson \& E.B. Foa (Eds.), Posttraumatic Stress Disorder: DSM-IV and beyond (pp.113-143). Washington, DC: American Psychiatric Press.

Kimerling, R., Armistead, L., \& Forehand, R. (1999). Women: Association with serostatus, psychological symptoms and health status. Journal of Traumatic Stress, 12, 41-58.

Kimerling, R., Clum, G., \& Wolfe, J. (2000). Relationship among trauma exposure, chronic PTSD and self-reported health in women: Replication and extension. Journal of Traumatic Stress, 13, 115-128.

Kraaij, V., \& De Wilde, E.J. (2001). Negative life events and depressive symptoms in the elderly: A life span perspective. Aging and Mental Health, 5, 84-91.

Kraus, N. (1986). Social support, stress, and well-being among older adults. Journal of Gerontology, 41, 512-519.

Krinsley, K.E., Gallaghaer, J.G., Weathers, F.W., Kutter, C.J., \& Kaloupek, D.G. (2003). Consistency of retrospective reporting about exposure to traumatic events. Journal of Traumatic Stress, 16, 299-409.

Kristiansen, C.M. (2003, October). The long-term effects of childhood and adult abuse on senior women. Keynote address presented to the annual convention of the Ontario Association of Social Workers, Eastern Branch, Ottawa, Ontario.

Kristiansen, C.M. (2005, February). The effects of childhood and adult abuse on senior women. Paper presented to the "Sharing expertise: Working together to address abuse of older women" training conference, Guelph, Ontario.

Kristiansen, C.M., \& Hay, E.L. (2000, July). The impact of aging on women survivors of childhood and adult assault. Paper presented to the Annual Convention of the Canadian Psychological Association, Ottawa, Ontario. 
Krystal, H. (1981). The aging survivor of the Holocaust: Integration and self-healing in posttraumatic states. The Journal of Geriatric Psychiatry, 14, 165-189.

Krystal, H. (1995). Trauma and aging: A 30-year follow-up. In C. Caruth (Ed.), Trauma: Explorations in memory (pp.76-99).

Kubany, E. S., Haynes, S. N., Leisen, M. B., Owens, J. A., Kaplan, A. S., Watson, S. B., \& Burns, K. (2000). Development and preliminary validation of a brief broadspectrum measure of trauma exposure: The Traumatic Life Events Questionnaire. Psychological Assessment, 12, 210-224.

Kuch, K., \& Cox, B. (1992). Symptoms of PTSD in 124 survivors of the Holocaust. American Journal of Psychiatry, 149, 337-340.

Landau, R., \& Litwin, H. (2000). The effects of extreme early stress in very old age. Journal of traumatic stress, $13,473-487$.

Langer, E.J. (1983). The psychology of control. Beverly Hills, CA: Sage.

Langer, E.J., \& Rodin, J. (1976). The effects of choice and enhanced personal responsibility for the aged. A field study in an institutional setting. Journal of Personality and Social Psychology, 34, 191-198.

Leskela, J., Dieperink, M., \& Thuras, P. (2002). Shame and Posttraumatic Stress Disorder. Journal of Traumatic Stress, 15, 223-226.

Liem, J,H., O’Toole, J.G., \& James, J.B. (1996). Themes of power and betrayal in sexual abuse survivors' characterizations of interpersonal relationships. Journal of Traumatic Stress, 9, 745-761.

Maercker, A. (2002). Life-review technique in the treatment of PTSD in elderly patients. Rationale and 3 single case studies. Journal of Clinical Geropsychology, 8, 239-249. 
Mazure, C.M., Keita, G.P., \& Biehar, M.C. (2002). Summit on women and depression: Proceedings and recommendations. Washington, DC: American Psychological Association. www.apa.org/pi/wpo/women\&depression.pdf.

McInnis-Dittrich, K. (1996). Adapting life review therapy for elderly female survivors of of childhood sexual abuse. Canadian Psychology, 36, 221-235.

Molinari, V., \& Williams, W. (1995). An analysis of aging World War II POWs with PTSD: Implications for practice and research. Journal of Geriatric Psychiatry, 28, 99-114.

Morey, L. C. (1991). Personality Assessment Inventory professional manual. Odessa, FL: Psychological Assessment Resources.

Morgan, K., Dallosso, H.M. \& Ebrahim, S.B.J. (1985). A brief self-report scale for assessing personal engagement in the elderly: Reliability and validity. In A. Butler (Eds.), Ageing: Recent Advances \& Creative Responses (298- 304). Croom Helm: New Hampshire.

Murrell, S., Norris, F. H., \& Hutchins, G.L. (1984). Distribution and desirability of life events in older adults: Population and policy implications. Journal of Community Psychology, 12, 310-311.

Norris, F. (1992). Epidemiology of trauma: Frequency and impact of different potentially traumatic events on different demographic groups. Journal of Consulting and Clinical Psychology, 60, 409-418.

Norris, F., Foster, J., \& Weisshaar, D. (2002). The epidemiology of sex differences in PTSD across developmental, societal, and research contexts. In R. Kimerling, P. Ouimette \& J. Wolfe (Eds.), Gender and PTSD (pp. 3-43). New York: The Guilford 
Press.

Op den Velde, W., Falger, P.R.J., Hovens, J.E., de Groen, J.H.M., Lasschuit, L.J., Van Duijn, H., \& Schouten, E.G.W. (1993). Posttraumatic stress disorder in Dutch resistance veterans from World War II. In J.P. Wilson \& B. Raphael (Eds.), International handbook of traumatic stress syndromes (pp. 219-230). New York: Plenum.

Osgood, N., \& Manetta, A. (2002). Physical and sexual abuse, battering, and substance abuse: Three clinical cases of older women. Journal of Gerontological Social work, $38,99-113$.

Palmore, E. (2001). The ageism survey: First findings. The Gerontologist, 41,572-575.

Parker, R.G. (1995). Reminiscence: A continuity theory framework. The Gerontologist, $35,515-525$.

Peters, J., \& Kaye, L. (2003). Childhood sexual abuse: A review of its impact on older women entering institutional settings. Clinical Gerontologist, 26, 29-53.

Pearlman, S. (1993). Late mid-life astonishment: Disruptions to identity and self-esteem. Women and Therapy, 14, 1-12.

Pillemer, K., \& Finkelhor, D. (1988). The prevalence of elder abuse: A random sample survey. The Gerontologist, 28, 51-57.

Pillemer, K., \& Moore, D.W. (1989). Abuse of patients in nursing homes: Findings from a survey of staff. The Gerontologist, 29, 314-320.

Pittaway, E.D., Westhues, A., \& Peressini, T. (1995). Risk factors for abuse and neglect among older adults. Canadian Journal on Aging, 14, 20-44.

Podnieks, E., Pillemer, K., Nicholson, P., Shillington, T. \& Frizzell, A (1990). National 
survey on abuse of the elderly in Canada. Toronto: Ryerson Polytechnical Institute.

Port, C.L. (1998). Posttraumatic stress and aging in older survivors of remote trauma. Unpublished doctoral dissertation, University of Minnesota, Minneapolis.

Reich, F. (1996). From fantasy to dementia: The misdiagnosis and mistreatment of older adult women living in nursing homes with a history of untreated or undisclosed childhood sexual abuse. Unpublished doctoral dissertation, Antioch University, Keene, New Hampshire.

Resnick, H., Kilpatrick, D., Dansky., Saunders, B., \& Best, C. (1993). Prevalence of civilian trauma and posttraumatic stress disorder in a representative national sample of women.

Robb, C., Chen, H., \& Haley, W.E. (2002). Ageism in mental health and health care: A critical review. Journal of Clinical Geropsychology, 8, 1-12.

Roth, S., Newman, E., Pelcovitz, D., van der Kolk., B., \& Mandel, F.S. (1997). Complex PTSD in victims exposed to sexual and physical abuse: Results from the DSM-IV field trial for Posttraumatic Stress Disorder. Journal of Traumatic Stress, 10 , $539-555$.

Sadavoy, J. (1996). Survivors: A review of the late-life effects of prior psychological trauma. The American Journal of Geriatric Psychiatry, 5, 287-301.

Schmid, A.H. (1991) The deficiency model: An exploration of current approaches to late life disorders. Psychiatry, 54, 358-367.

Safford, F. (1995). Aging stressors for Holocaust survivors and their families. Journal of Gerontological Social Work, 24, 131-153.

Schnurr, P.P., Spiro, A., Aldwin, C.M., \& and Stukel, T.A. (1998). Physical symptom 
trajectories following trauma exposure: Longitudinal findings from the Normative Aging Study. Journal of Nervous and Mental Disease, 186, 522-528.

Schnurr, P.P. Sprio, A., \& Paris, A.H. (2000). Physician-diagnosed medical disorders in relation to PTSD symptoms in older male military veterans. Health Psychology, 19, 91-97.

Seedat, S. \& Stein D. (2000). Trauma and post-traumatic stress in women: A review. International Clinical Psychopharmacology, 15, 25-33.

Shmotkin, D., Modan, B., \& Blumstein, T. (2003). Tracing long-term effects of early trauma: A broad scope view of Holocaust survivors in late life. Journal of Consulting and Clinical Psychology, 71, 223-234.

Silver, R.L., Boon, C., \& Stone, M.H. (1983). Searching for meaning in misfortune: Making sense of incest. Journal of Social Issues, 39, 81-102.

Snell, F.I., \& Padin-Rivera, E. (1997). Post-traumatic stress disorder and the elderly combat veteran. Journal of Gerontological Nursing, 34, 13-18.

Statistics Canada (2002a, July 16). Age and sex, percentage change (1996-2001) for both sexes, for Canada, provinces and territories - 100\% data. Retrieved October 27, 2003, from http://www12.statcan.ca/english/census01/products/highlight/AgeSex/Page.cfm

Statistics Canada (2002b, July 16). Age and sex. Retrieved October 27, 2003, from http://www12.statcan.ca/english/census01/release/age_sex.cfm.

Statistics Canada (2004c, July 1). Population by age and sex. Retrieved June 27, 2005, from http://www.40.statcan.ca/101/cst01/demo10a.htm.

Statistics Canada (2004d). Population by selected ethnic origins, by census metropolitan areas (2001 Census). Retrieved Jul 20, 2005, from 
http://www40.statcan.ca/101/cst/demo27i.htm.

Statistics Canada (2002e). Religion (13) and Age Groups (8) for Population, for Canada, Provinces, Territories, Census Metropolitan Areas and Census Agglomerations, 2001 Census - 20\% Sample Data. Retrieved July 20, 2005, from

http://www12.statcan.ca/english/census01/products/standard/themes/RetrieveProductTable. Shinoda-Tagawa, T., Leonard, R., Pontikas, J., McDonough, J.E., Allen, D., \& Dreyer, P. (2004). Resident-to resident violent incidents in nursing homes. Journal of the American Medical Association, 291, 591-597.

Somer, E. (2000). Effects of incest in aging survivors: Psychopathology and treatment issues. Journal of Clinical Geropsychology, 6, 53-61.

Summit, R.C. (1983). Child sexual abuse accommodation syndrome. Child Abuse and Neglect, 7, 177-193.

Sutker, P., \& Allain, A. (1996). Assessment of PTSD and other mental disorders in World War II and Korean conflict POW survivors and combat veterans. Psychological Assessment, 8, 18-25.

van der Kolk, B.A. (1996). The complexity of adaptation to trauma: Self-regulation, stimulus discrimination, and characterological development. In B.A. van der Kolk, A.C. McFarlane \& L. Weisaeth (Eds.), Traumatic stress: The effects of overwhelming experience on mind, body and society (pp.69-77). New York: Plenum Press.

van der Kolk, B.A., McFarlane, A.C., \& Weisaeth, L. (1996). Traumatic Stress: The effects of overwhelming trauma on mind, body and society. New York: Guilford Press.

Vosvick, M., Gore-Felton, C., Koopman, C., Thoresen, C., Krumboltz, J., \& Spiegel, D. 
(2002). Maladaptive coping strategies in relation to quality of life among HIV + adults. Aids and Behavior, 6, 97-106.

Walter, K. (1992). That was then: Elderly survivors of incest. Journal of Psychosocial nursing, 30, 14-16.

Weintraub D., \& Ruskin, P. (1999). Posttraumatic Stress Disorder in the elderly: A review. Harvard Review of Psychiatry, 7, 144-152.

Weisaeth, L., \& Eitinger, E. (1993). Posttraumatic stress phenomena: Common themes across wars, disasters and traumatic events. In J.P. Wilson \& B. Raphael (Eds.), International handbook of traumatic stress syndromes (pp.69-77). New York: Plenum Press.

Wolfe, J., \& Kimerling, R. (1997). Gender issues in the assessment of Posttraumatic Stress Disorder. In J. Wilson \& T.M. Keane (Eds.), Assessing psychological trauma and PTSD (pp. 192-238). New York: Guilford.

Wolkenstein, B.H., \& Sterman, L. (1998). Unmet needs of older women in a clinic population: The discovery of possible long-term sequelae of domestic violence. Professional Psychology: Research and Practice, 29, 341-348.

Wong, P.T.P., \& Watt, L.M. (1991). What types of reminiscence are associated with successful aging? Psychology and Aging, 6, 272-279.

Yehuda, R., Kahana, B., Schmeidler, J., Southwick, S.M., Wilson, S., \& Giller, E.L. (1995). Impact of cumulative lifetime trauma and recent stress on current posttraumatic stress disorder symptoms in Holocaust survivors. American Journal of Psychiatry, 152, 1815-1818. 
Appendix A

Research Materials 


\section{Senior's Life Experiences, Coping and Well-Being Survey}

Thank you for your interest in Senior's Life Experiences, Coping and Well-Being Survey. The study is being conducted by Connie M. Kristiansen, Ph.D. and Jacquie Wickett, MA Candidate, of the Department of Psychology at Carleton University in Ottawa and is being funded by the Social Sciences and Humanities Research Council of Canada. It is being done to help us learn about older adults' life experiences, how they cope with theses experiences, and how these experiences affect their physical, psychological and social well-being. This information will be used to gain insight into ways of promoting older adults' well-being and helping them cope with life's challenges.

In this study, you will be asked to complete a survey that asks about your background (e.g., your age, education, ethnicity), the stressful experiences in your life (both now and in the past), how you cope with these experiences, and your physical, psychological and social health. Some of these questions ask about experiences that may be upsetting for some people, such as your exposure to distressing events like child abuse, war, the Holocaust and the death of a loved one. It is therefore important that you understand that your participation is voluntary and that you can refuse to answer any question. You may also stop participating at any time, for any reason. In other words, whether or not you participate and which questions you answer are all up to you. We also want you to know that your answers will be entirely confidential. Your survey will be coded with a number, rather than your name, and your identity will not be revealed in any presentations of the findings of the study.

It will take about 1.5 to 2 hours to do the survey and, as a way of thanking you for your time and effort, we will send you a cheque for $\$ 40$. You can complete the survey at own pace, taking breaks or doing it in several sittings. If any questions come up as you do the survey, or you have any comments, please don't hesitate to call us at the phone numbers listed below under our names. We would be especially grateful if you would call us if you are in any way upset by participating in this study. You can talk to us about it and, if you wish, we can arrange a consultation with a counsellor at no cost to you. If you feel the need to 
talk to someone, you can also call the 24-hour Ottawa Region Distress Centre at (613) 2383311 .

If you have any concerns about any ethical aspects of this research, you are invited to contact Dr. Chris Davis, Chair of the Carleton University Research Ethics Committee for Psychological Research, at (613) 520-2600, ext. 2251. If you have any questions or concerns about other aspects of the study, please contact Dr. Mary Gick, Chair of the Department of Psychology, at (613) 520-2600, ext. 2690.

Finally, your completion and return of the survey will be taken as your consent to participate in the survey.

Thanking you in advance for your interest, time and effort,

Connie M. Kristiansen, Ph.D.

Associate Professor of Psychology

(613) $520-2600$ ext. 2674

ckristia@ccs.carleton.ca
Jacquie Wickett

M.A. candidate

(613) 520-2600 ext. 1813

P.S. Please keep this cover letter in case you need any information (e.g., the phone numbers) in the future. 


\section{Background Questions}

Your sex (circle one): Male / Female

When were you born?

Day Month Year

What is your marital status? Single (never married)

_ Married or common-law

_ Widowed

_ Divorced

__ Separated

What is the highest grade of school or year in college/university you completed? (please circle your answer)

$\begin{array}{llllllllllllll}\text { Grades of school: } & 1 & 2 & 3 & 4 & 5 & 6 & 7 & 8 & 9 & 10 & 11 & 12 & 13\end{array}$

College/University: $\quad \begin{array}{lllll}1 & 2 & 3 & 4 & 5+\end{array}$

What is your ethnic background?

What is your religion?

* Are you currently: Employed full-time?

Yes No

Employed part-time?

Yes No

Retired?

Yes No

Not employed but seeking work?

Yes No

Not employed and not seeking work? Yes No

Please turn over to back of page $\Rightarrow$ 
What kind of work do you do now or did you do most of your life?

_ I was never employed

_ I was a housewife

_ I usually worked as a (please describe your main job):

Does/did your husband or wife work?

- No

_ I was never married

Yes. What kind of work did, or does, he or she do?

What is your total yearly family income, before taxes, from all sources (e.g., work, rental income, interest, pensions, support payments, etc.)? Check one:

_ Under $\$ 15,000$

_ $\$ 15,000-\$ 24,999$

_ $\$ 25,000-\$ 34,999$

_ $\$ 35,000-\$ 44,999$

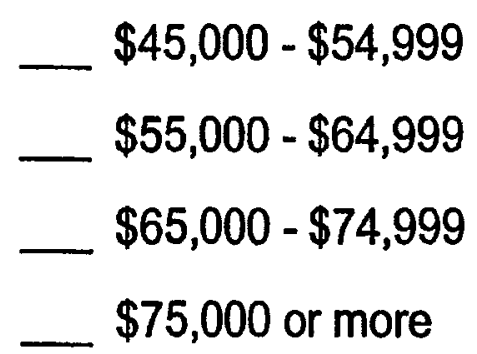

Who do you live with? (Tick the best answer)

_ I live alone

_ I live with my spouse/partner

_ I live with other relatives, in-laws or friends

_ I live with people I'm not related to (e.g., paid help)

_ I live in a seniors' residential facility 


\section{Stressful Life Experiences}

The following questions ask about 20 potentially stressful experiences that some people have had. Please circle 'Yes' or 'No' to indicate whether or not you have ever had each experience.

\section{Stressful Experience}

1. Have you ever experienced a natural disaster (e.g., an flood, earthquake, hurricane, etc.)?

2. Were you ever involved in a bad car accident?

3. Were you ever involved in any other kind of accident (e.g., a plane crash, a bad accident at work, or fire)?

4. Have you ever witnessed a violent death?

5. Have you ever been robbed or been present during a robbery where the robber(s) had a weapon?

6. Before the age of 16 , did you ever see or hear any physical violence between the members of your family (e.g., hitting, kicking, punching, choking, etc.)?

7. Were you ever hit or beaten up by a stranger or someone you didn't know very well?

8. Before the age of 16 , did anyone you know ever do anything like hit, kick, punch, choke, burn or beat you up?

9. As an adult (aged 16 to 59) did anyone you know ever do anything like hit, kick, punch, choke, burn or beat you up?

10. Since the age of 60 , did anyone you know ever do anything like hit, kick, punch, choke, burn or beat you up?

11. Before the age of 16 , were you ever sexually touched by, or made to sexually touch, someone 5 or more years older than you? Yes No

Answer (circle)

Yes No

Yes No

Yes No

Yes No

Yes No

Yes No

Yes No

Yes No
Yes No 


\section{Stressful Experience}

12. As an adult (aged 16 to 59) were you ever touched or made to touch someone in a sexual way against your will?

13. Since the age of 60 , were you ever touched or made to touch someone in a sexual way against your will?

14. Before the age of 16 , did you ever have sex (oral, anal or genital) with someone at least 5 years older than you?

15. As an adult (aged 16 to 59) did you ever have sex (oral, anal or genital) when you didn't want to because someone forced or threatened you?

16. Since the age of 60 , have you ever have sex (oral, anal or genital) when you didn't want to because someone forced or threatened you?

17. Have you ever witnessed any warfare or combat (e.g., seen a rocket attack, a bombing or people being shot at)?

18. Were you ever directly involved in any war or combat activities (e.g., as a soldier or marine)?

19. Were you ever held in an internment or concentration camp (e.g., during the Holocaust or in Bosnia)?

20. Were you ever held as a prisoner of war?

21. Have you had any stressful experience(s) that we did not include that you would like to mention? If yes, please describe the stressful experience(s):
Answer (circle)

Yes No

Yes No

Yes No

Yes No

Yes No

Yes No

Yes No

Yes No

Yes No

Yes No 


\section{Your "Worst" Stressful Experience}

If you never had any stressful experiences in your life, as indicated on the previous 2 pages, please move on to the next section of the survey, which is printed on white paper.

If you had only one stressful experience, as indicated on the previous 2 pages, please answer the next set of questions in regard to that experience.

If you had more than one of the stressful experiences on the previous 2 pages, which one was the "worst"? That is, which one caused you the most distress (e.g., anxiety, worry, sadness, grief, etc.)? Please write the name or number of that experience here: , and answer the next set of questions in regard to that 'worst' experience.

\section{Please answer the next set of questions in regard to this "worst" experience or your only stressful experience:}

- How much distress (anxiety, worry, sadness, grief, etc.) did this event cause you at the time it occurred? (Please circle one)

$\begin{array}{ccccc}\text { No } & \text { Slight } & \text { Moderate } & \text { Considerable } & \text { Extreme } \\ \text { distress } & \text { distress } & \text { distress } & \text { distress } & \text { distress }\end{array}$

- How much distress does it cause you now? (Please circle one)

$\begin{array}{ccccc}\text { No } & \text { Slight } & \text { Moderate } & \text { Considerable } & \text { Extreme } \\ \text { distress } & \text { distress } & \text { distress } & \text { distress } & \text { distress }\end{array}$

- How many times did you have this experience? times

- How old were the first time it happened? years old

- How old were you the last time it happened? years old

Please turn over to back of page $\Rightarrow$ 
- Do you ever think about this experience now?

$\begin{array}{ccccc}\text { No, } & \text { Yes, } & \text { Yes, } & \text { Yes, } & \begin{array}{c}\text { Yes, } \\ \text { never }\end{array} \text { but rarely } \\ \text { sometimes } & \text { often } & \text { very often }\end{array}$

- How often do you think about this experience now compared to when you were younger, say in your 30 s or 40 s?

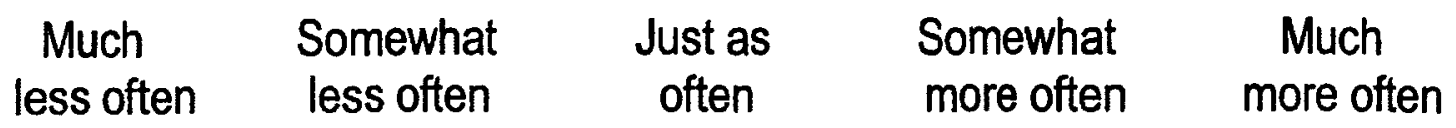

- Do any things ever seem to trigger your thoughts, memories or mental images of this experience (e.g., seeing something on TV or hearing a certain thing)? $\begin{array}{ccccc}\text { No, } & \text { Yes, } & \text { Yes, } & \text { Yes, } & \begin{array}{c}\text { Yes, } \\ \text { never }\end{array} \text { but rarely } \\ \text { sometimes } & \text { often } & \text { very often }\end{array}$ If "YES", please describe the things that trigger your thoughts, memories or mental images: 
- Do you ever feel a need to talk to someone about this experience or the thoughts, memories or mental images that you have about it?

$\begin{array}{ccccc}\text { No, } & \text { Yes, } & \text { Yes, } & \text { Yes, } & \begin{array}{c}\text { Yes, } \\ \text { never }\end{array} \text { but rarely } \\ \text { sometimes } & \text { often } & \text { very often }\end{array}$

- Do you ever talk to anyone about this experience or the thoughts, memories or mental images that you have about it?

No, never
Yes, but rarely

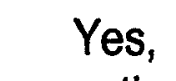
sometimes
Yes, often
Yes, very often

- Have you ever talked to a professional (e.g., a psychiatrist, psychologist, doctor or pastor) because of difficulties you were having as a result of this experience?

\begin{tabular}{|c|c|}
\hline $\begin{array}{l}\text { No, } \\
\text { never }\end{array}$ & $\begin{array}{l}\text { Yes, } \\
\text { once }\end{array}$ \\
\hline
\end{tabular}

- Is there anything else you would like to tell us about this "worst experience" or how it affects you? 


\section{Psychological Experiences in the Last 6 Months}

These questions ask about various psychological experiences that you may or may not have had. Please circle the one number that best describes how often you have had each experience in the last 6 months, using this scale:

$\begin{array}{cccc}0 & 1 & 2 & 3 \\ \text { Never } & \text { A few times } & \text { Fairly often } & \text { Many times }\end{array}$

\section{Experience in Last 6 Months?}

1. Nightmares or bad dreams

2. Trying to forget about a bad time in your life

3. Irritability or moodiness

4. Stopping yourself from thinking about the past

5. Getting angry about something that wasn't very important

6. Feeling empty inside

7. Sadness

8. Flashbacks (sudden memories of upsetting things)

9. Feeling like you were outside your body

10. Lower back pain

11. Sudden disturbing memories when you were not expecting them

12 , Wanting to cry

13. Not feeling happy

14. Becoming angry for little or no reason

15. Feeling like you don't know who you really are
Answer (circle)

$\begin{array}{llll}0 & 1 & 2 & 3\end{array}$

$\begin{array}{llll}0 & 1 & 2 & 3\end{array}$

$\begin{array}{llll}0 & 1 & 2 & 3\end{array}$

$\begin{array}{llll}0 & 1 & 2 & 3\end{array}$

$\begin{array}{llll}0 & 1 & 2 & 3\end{array}$

$\begin{array}{llll}0 & 1 & 2 & 3\end{array}$

$\begin{array}{llll}0 & 1 & 2 & 3\end{array}$

$\begin{array}{llll}0 & 1 & 2 & 3\end{array}$

$\begin{array}{llll}0 & 1 & 2 & 3\end{array}$

$\begin{array}{llll}0 & 1 & 2 & 3\end{array}$

$\begin{array}{llll}0 & 1 & 2 & 3\end{array}$

$\begin{array}{llll}0 & 1 & 2 & 3\end{array}$

$\begin{array}{llll}0 & 1 & 2 & 3\end{array}$

$\begin{array}{llll}0 & 1 & 2 & 3\end{array}$

$\begin{array}{llll}0 & 1 & 2 & 3\end{array}$

Please turn over to back of page $\Rightarrow$ 
How often you have had each experience in the last 6 months?
0
1
2
3
Never
A few times Fairly often
Many times

\section{Experience in Last 6 Months?}

16. Feeling depressed

17. Thoughts or fantasies about hurting someone

18. Your mind going blank

19. Fainting

20. Periods of trembling or shaking

21. Pushing painful memories out of your mind

22. Not understanding why you did something

23. Threatening or attempting suicide

24. Feeling like you were watching yourself from far away

25. Feeling tense or "on edge"

26. Not feeling like your real self

27. Wishing you were dead

28. Worrying about things

29. Not being sure of what you want in life

30. Being easily annoyed by other people

31. Starting arguments or picking fights to get your anger out

32. Having sex or being sexual to keep from feeling lonely or sad

\section{Answer (circle)}

$\begin{array}{llll}0 & 1 & 2 & 3\end{array}$

$\begin{array}{llll}0 & 1 & 2 & 3\end{array}$

$\begin{array}{llll}0 & 1 & 2 & 3\end{array}$

$\begin{array}{llll}0 & 1 & 2 & 3\end{array}$

$\begin{array}{llll}0 & 1 & 2 & 3\end{array}$

$\begin{array}{llll}0 & 1 & 2 & 3\end{array}$

$\begin{array}{llll}0 & 1 & 2 & 3\end{array}$

$\begin{array}{llll}0 & 1 & 2 & 3\end{array}$

$\begin{array}{llll}0 & 1 & 2 & 3\end{array}$

$\begin{array}{llll}0 & 1 & 2 & 3\end{array}$

$\begin{array}{llll}0 & 1 & 2 & 3\end{array}$

$\begin{array}{llll}0 & 1 & 2 & 3\end{array}$

$\begin{array}{llll}0 & 1 & 2 & 3\end{array}$

$\begin{array}{llll}0 & 1 & 2 & 3\end{array}$

$\begin{array}{llll}0 & 1 & 2 & 3\end{array}$

$\begin{array}{llll}0 & 1 & 2 & 3\end{array}$

$\begin{array}{llll}0 & 1 & 2 & 3\end{array}$ 
How often you have had each experience in the last 6 months?

$\begin{array}{cccc}0 & 1 & 2 & 3 \\ \text { Never } & \text { A few times } & \text { Fairly often } & \text { Many times }\end{array}$

\section{Experience in Last 6 Months?}

33. Getting angry when you didn't want to

34. Not being able to feel your emotions

35. Using nonprescribed drugs other than marijuana

36. Feeling jumpy

37. Absent-mindedness

38. Feeling paralyzed for minutes at a time

39. Needing other people to tell you what to do

40. Yelling or telling people off when you shouldn't have

41. Flirting or "coming on" to someone to get attention

42. Intentionally hurting yourself (e.g., scratching, cutting or burning) even though you weren't trying to commit suicide

43. Aches and pains

44. High anxiety

45. Wishing you had more money

46. Nervousness

47. Getting confused about what you thought or believed

48. Feeling tired

49. Feeling mad or angry inside

50. Getting into trouble because of your drinking
Answer (circle)

$\begin{array}{llll}0 & 1 & 2 & 3\end{array}$

$\begin{array}{llll}0 & 1 & 2 & 3\end{array}$

$\begin{array}{llll}0 & 1 & 2 & 3\end{array}$

$\begin{array}{llll}0 & 1 & 2 & 3\end{array}$

$\begin{array}{llll}0 & 1 & 2 & 3\end{array}$

$\begin{array}{llll}0 & 1 & 2 & 3\end{array}$

$\begin{array}{llll}0 & 1 & 2 & 3\end{array}$

$\begin{array}{llll}0 & 1 & 2 & 3\end{array}$

$\begin{array}{llll}0 & 1 & 2 & 3\end{array}$

$\begin{array}{llll}0 & 1 & 2 & 3\end{array}$

$\begin{array}{llll}0 & 1 & 2 & 3\end{array}$

$\begin{array}{llll}0 & 1 & 2 & 3\end{array}$

$\begin{array}{llll}0 & 1 & 2 & 3\end{array}$

$\begin{array}{llll}0 & 1 & 2 & 3\end{array}$

$\begin{array}{llll}0 & 1 & 2 & 3\end{array}$

$\begin{array}{llll}0 & 1 & 2 & 3\end{array}$

$\begin{array}{llll}0 & 1 & 2 & 3\end{array}$

$\begin{array}{llll}0 & 1 & 2 & 3\end{array}$

Please turn over to back of page $\Rightarrow$ 
How often you have had each experience in the last 6 months?

$\begin{array}{cccc}0 & 1 & 2 & 3 \\ \text { Never } & \text { A few times } & \text { Fairly often } & \text { Many times }\end{array}$

\section{Experience in Last 6 Months?}

51. Staying away from certain people or places because they reminded you of something

52. One side of your body going numb

53. Suddenly remembering something upsetting from the past

54. Wanting to hit someone or something

55. Feeling hopeless

56. Hearing someone talk to you who wasn't really there

57. Suddenly being reminded of something bad

58. Trying to block out certain memories

59. Using sex to feel powerful or important

60. Violent dreams

61. Just for a moment, hearing or seeing something upsetting that happened earlier in your life

62. Frightening or upsetting thoughts popping into your mind

63. Getting your own feelings mixed up with someone else's

64. Trying to keep from being alone

65. Losing your sense of taste

66. Feeling worthless

67. Your feelings or thoughts changing when you were with other people
Answer (circle)

$\begin{array}{llll}0 & 1 & 2 & 3\end{array}$

$\begin{array}{llll}0 & 1 & 2 & 3\end{array}$

$\begin{array}{llll}0 & 1 & 2 & 3\end{array}$

$\begin{array}{llll}0 & 1 & 2 & 3\end{array}$

$\begin{array}{llll}0 & 1 & 2 & 3\end{array}$

$\begin{array}{llll}0 & 1 & 2 & 3\end{array}$

$\begin{array}{llll}0 & 1 & 2 & 3\end{array}$

$\begin{array}{llll}0 & 1 & 2 & 3\end{array}$

$\begin{array}{llll}0 & 1 & 2 & 3\end{array}$

$\begin{array}{llll}0 & 1 & 2 & 3\end{array}$

$\begin{array}{llll}0 & 1 & 2 & 3\end{array}$

$\begin{array}{llll}0 & 1 & 2 & 3\end{array}$

$\begin{array}{llll}0 & 1 & 2 & 3\end{array}$

$\begin{array}{llll}0 & 1 & 2 & 3\end{array}$

$\begin{array}{llll}0 & 1 & 2 & 3\end{array}$

$\begin{array}{llll}0 & 1 & 2 & 3\end{array}$

$\begin{array}{llll}0 & 1 & 2 & 3\end{array}$ 
How often you have had each experience in the last 6 months?
0
1
2
3
Never
A few times Fairly often
Many times

\section{Experience in Last 6 Months?}

68. Worrying that someone is trying to steal your ideas

69. Not letting yourself feel bad about the past

70. Feeling like things weren't real

71. Feeling like you were in a dream

72. Not eating or sleeping for 2 or more days

73. Trying not to have any feelings about something that once hurt you

74. Daydreaming

75. Trying not to think or talk about things in your life that were painful

76. Feeling like life wasn't worth living

77. Being startled or frightened by sudden noises

78. Seeing people from the spirit world

79. Trouble controlling your temper

80. Being easily influenced by others

81. Wanting to set fire to a public building

82. Feeling afraid you might die or be injured

83. Feeling so depressed that you avoided people

84. Thinking that someone was reading your mind
Answer (circle)

$\begin{array}{llll}0 & 1 & 2 & 3\end{array}$

$\begin{array}{llll}0 & 1 & 2 & 3\end{array}$

$\begin{array}{llll}0 & 1 & 2 & 3\end{array}$

$\begin{array}{llll}0 & 1 & 2 & 3\end{array}$

$\begin{array}{llll}0 & 1 & 2 & 3\end{array}$

$\begin{array}{llll}0 & 1 & 2 & 3\end{array}$

$\begin{array}{llll}0 & 1 & 2 & 3\end{array}$

$\begin{array}{llll}0 & 1 & 2 & 3\end{array}$

$\begin{array}{llll}0 & 1 & 2 & 3\end{array}$

$\begin{array}{llll}0 & 1 & 2 & 3\end{array}$

$\begin{array}{llll}0 & 1 & 2 & 3\end{array}$

$\begin{array}{llll}0 & 1 & 2 & 3\end{array}$

$\begin{array}{llll}0 & 1 & 2 & 3\end{array}$

$\begin{array}{llll}0 & 1 & 2 & 3\end{array}$

$\begin{array}{llll}0 & 1 & 2 & 3\end{array}$

$\begin{array}{llll}0 & 1 & 2 & 3\end{array}$

$\begin{array}{llll}0 & 1 & 2 & 3\end{array}$

Please turn over to back of page $\Rightarrow$ 
- Overall, when you were a child (under the age of 13) did you have the 84 experiences listed on the previous pages more or less often than now?

$\begin{array}{clccc}\begin{array}{c}\text { Much } \\ \text { less often }\end{array} & \begin{array}{l}\text { Somewhat } \\ \text { less often }\end{array} & \begin{array}{c}\text { About the } \\ \text { same }\end{array} & \begin{array}{c}\text { Somewhat } \\ \text { more often }\end{array} & \begin{array}{c}\text { Much } \\ \text { more often }\end{array}\end{array}$

- Overall, when you were a teenager (between 13 and 19 years old), did you have the 84 experiences listed on the previous pages more or less often than now?

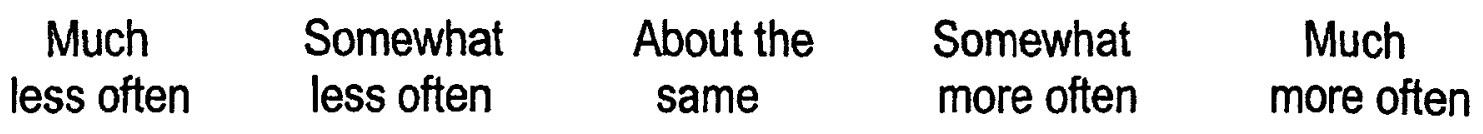

- Overall, when you were a young adult (aged 20 to 35), did you have the 84 experiences listed on the previous pages more or less often than now?

\begin{tabular}{|c|}
\hline less often \\
\hline
\end{tabular}

- Overall, when you were middle aged (between 36 and 50), did you have the 84 experiences listed on the previous pages more or less often than now?

\begin{tabular}{|c|}
\hline $\begin{array}{l}\text { Much } \\
\text { less often }\end{array}$ \\
\hline
\end{tabular}




\section{Physical Health}

The following questions ask about your health. If you are unsure about the exact answer, please give your best estimate.

1. During the past 6 months, how many times have you seen a doctor about your physical health (not counting any times you were a hospital inpatient)? times to the doctor

2. During the past 6 months, how many times were you so sick that you were unable to carry on with your usual activities? sick days

3. During the past 6 months, how many days were you in the hospital because of a physical health problem? days in hospital

4. During the past 6 months, how many days did you spend in a nursing home or rehabilitation centre because of a physical health problem? days in a nursing home/rehab centre

5. Compared to people your own age and sex, how would you rate your overall physical health? (Please circle one)
Very poor
Poor
Average
Good
Excellent

Please turn over to back of page $\Rightarrow$ 
6. Do you currently have any of the following health problems or illnesses?

\section{Problem or illness}

- Arthritis or rheumatism

- Glaucoma

- Asthma

- Emphysema or chronic bronchitis

- Tuberculosis

- High blood pressure

- Heart trouble

- Circulation troubles in arms or legs

- Diabetes

- Ulcers of the digestive system

- Other stomach, intestinal or gall bladder problems

- Liver disease

- Kidney disease

- Other urinary tract problems

- Cancer or leukemia

- Anemia or low iron in the blood

- Effects of stroke

- Parkinson's disease

- Epilepsy

- Cerebral Palsy
Have now?

Yes No

Yes No

Yes No

Yes No

Yes No

Yes No

Yes No

Yes No

Yes No

Yes No

Yes No

Yes No

Yes No

Yes No

Yes No

Yes No

Yes No

Yes No

Yes No

Yes No 
Problem or illness

- Multiple Sclerosis

- Muscular Dystrophy

- Effects of polio

- Thyroid or other gland problems

- Skin disorders (e.g., pressure sores or leg ulcers)

- Speech problems
Have now?

Yes No

Yes No

Yes No

Yes No

Yes No

Yes No

$>$ How much do any of the above problems interfere with your daily activities? (circle one answer)

Not at all A little Somewhat A good deal A great deal

7. Are you currently taking any medications prescribed by a medical doctor? No Yes - which ones? 


\section{Social Activities}

The following questions ask about your current social activities.

Social Activity

1. Do you have access to a telephone in your household?

2. Have you made a personal phone call in the last week?

3. Have you written a personal letter in the last week?

4. Do you attend religious services, gatherings or meetings?

5. Did you vote in the last federal or local elections?

6. Have you been away on a holiday in the last year?

7. Are you planning on going away on a holiday in the next year? Yes

8. Do you use the public library?

9. In the past month, have you attended a meeting or gathering of any club, organization, society, or group?

10. Do you take part in volunteer activities?
Answer (circle)

Yes No

Yes No

Yes No

Yes No

Yes No

Yes No

Yes No

Yes No

Yes No

11. Do you go out to the movies, the theatre, concerts or restaurants?
No, never
Yes, but rarely
Yes, often
Yes, every day

12. Do you play cards or other games with other people?
No, never
Yes, but rarely
Yes, often
Yes, every day 


\section{Current Stressful Experiences}

Listed below are various experiences that you may or may not have had in the past year. For each, please circle 'Yes' if you had the experience in the past year or 'No' if you did not have the experience in the past year.

\section{Experience in the last year?}

1. A deterioration in your memory

2. A major illness or deterioration in the health of a family member

3. A major decrease in doing the activities you really enjoy

4. A major deterioration in your health, a personal injury, or an illness

5. Death of a friend

6. Death of your spouse

7. Death of a son or daughter

8. Death of a grandchild

9. Death of some other close family member

10. Your child's divorce or marital separation

11. A decrease in responsibilities or hours where you work or volunteer

12. An increase in responsibilities or hours where you work or volunteer

13. The loss of a very close friend due to a move or break in the friendship

\section{Answer (circle)}

Yes No

Yes No

Yes No

Yes No

Yes No

Yes No

Yes No

Yes No

Yes No

Yes No

Yes No

Yes No

Yes No

Please turn over to back of page $\Rightarrow$ 
Experience in the last year?

Answer (circle)

14. Worsening relationship with a child

Yes No

15. Worsening relationship with your spouse

Yes No

16. Worsening relationship with someone other than your spouse or child

Yes No

17. Marital separation

Yes No

18. Divorce

Yes No

19. Marriage

Yes No

20. A major deterioration in your financial state

Yes No

21. Your retirement

Yes No

22. The retirement of your spouse

Yes No

23. Being burglarized or robbed

Yes No

24. The loss of prized possessions due to a move

Yes No

25. Assuming major responsibility for a parent

Yes No or spouse

26. A move to a less desirable residence

Yes No

27. The institutionalization of your spouse

Yes No

28. The institutionalization of a parent

Yes No

29. A deterioration in your living conditions

Yes No

30. A change to a less desirable line of work

Yes No

31. Troubles with your boss or co-workers

Yes No 


\section{Coping with Stress}

We are interested in how people respond to the difficult or stressful events they encounter in their lives. Please rate how much you usually use each of the following strategies in response to a stressful situation or event, using this scale:

I usually:

$\begin{array}{cccc}0 & 1 & 2 & 3 \\ \text { Don't } & \text { Do this } & \text { Do this a } & \text { Do this } \\ \text { do this at all } & \text { a little bit } & \text { medium amount } & \text { a lot }\end{array}$

\section{Response to Stress}

1. Turn to work or other activities to take your mind off things.

2. Concentrate your efforts on doing something about the situation you're in.

3. Say to yourself, "this isn't real."

4. Use alcohol or other drugs to make yourself feel better.

5. Get emotional support from others.

6. Give up trying to deal with it.

7. Take action to try to make the situation better.

8. Refuse to believe that it has happened.

9. Say things to let my unpleasant feelings escape.

10. Get help and advice from other people.

11. Use alcohol or other drugs to help you get through it.

12. Try to see it in a different light, to make it seem more positive.

\section{Answer (circle)}

$\begin{array}{llll}0 & 1 & 2 & 3\end{array}$

$\begin{array}{llll}0 & 1 & 2 & 3\end{array}$

$\begin{array}{llll}0 & 1 & 2 & 3\end{array}$

$\begin{array}{llll}0 & 12 & 2\end{array}$

$\begin{array}{llll}0 & 1 & 2 & 3\end{array}$

$\begin{array}{llll}0 & 1 & 2 & 3\end{array}$

$\begin{array}{llll}0 & 1 & 2 & 3\end{array}$

$\begin{array}{llll}0 & 1 & 2 & 3\end{array}$

$\begin{array}{llll}0 & 1 & 2 & 3\end{array}$

$\begin{array}{llll}0 & 1 & 2 & 3\end{array}$

$\begin{array}{llll}0 & 12 & 2\end{array}$

$\begin{array}{llll}0 & 1 & 2 & 3\end{array}$

Please turn over to back of page $\Rightarrow$ 
I usually:

$\begin{array}{cccc}0 & 1 & 2 & 3 \\ \text { Don't } & \text { Do this } & \text { Do this a } & \text { Do this } \\ \text { do this at all } & \text { a little bit } & \text { medium amount } & \underline{\text { a lot }}\end{array}$

\section{Response to Stress}

13. Criticize yourself.

14. Try to come up with a strategy about what to do.

15. Get comfort and understanding from someone.

16. Give up trying to cope.

17. Look for something good in what is happening.

18. Make jokes about it.

19. Do something to think about it less, such as go to the movies, watch TV, read, daydream, sleep, or shop.

20. Accept the reality of the fact that it has happened.

21. Express your negative feelings.

22. Try to find comfort in your religion or spiritual beliefs.

23. Try to get advice or help from other people about what to do.

24. Learn to live with it.

25. Think hard about what steps to take.

26. Blame yourself for things that happened.

27. Pray or meditate.

28. Make fun of the situation.
Answer (circle)

$\begin{array}{llll}0 & 1 & 2 & 3\end{array}$

$\begin{array}{llll}0 & 1 & 2 & 3\end{array}$

$\begin{array}{llll}0 & 1 & 2 & 3\end{array}$

$\begin{array}{llll}0 & 1 & 2 & 3\end{array}$

$\begin{array}{llll}0 & 1 & 2 & 3\end{array}$

$\begin{array}{llll}0 & 1 & 2 & 3\end{array}$

$\begin{array}{llll}0 & 1 & 2 & 3\end{array}$

$\begin{array}{llll}0 & 1 & 2 & 3\end{array}$

$\begin{array}{llll}0 & 1 & 2 & 3\end{array}$

$\begin{array}{llll}0 & 1 & 2 & 3\end{array}$

$\begin{array}{llll}0 & 1 & 2 & 3\end{array}$

$\begin{array}{llll}0 & 1 & 2 & 3\end{array}$

$\begin{array}{llll}0 & 1 & 2 & 3\end{array}$

$\begin{array}{llll}0 & 1 & 2 & 3\end{array}$

$\begin{array}{llll}0 & 1 & 2 & 3\end{array}$

$\begin{array}{llll}0 & 1 & 2 & 3\end{array}$ 


\section{Experiences with Other People}

The following questions ask about various experiences with other people that you may or may not have had. Please circle the one number that best describes how often you have had each experience in the last year, using this scale:

$\begin{array}{cccc}0 & 1 & 2 & 3 \\ \text { Never } & \text { A few times } & \text { Fairly often } & \text { Many times }\end{array}$

\section{Experience in the Last Year?}

1. Being told a joke that makes fun of older people.

2. Needing someone's help to do something that you used to do on your own.

3. Someone not giving you the care and attention you deserve. $0 \begin{array}{llll}0 & 1 & 2 & 3\end{array}$

4. Being called an insulting name related to your age.

5. Your concerns or complaints not being taken seriously because of your age.

6. Someone you care about leaving or abandoning you.

7. Being patronized or talked down to because of your age.

8. Having to rely on others (e.g., doctors) to keep up your health.

9. Someone not doing what they said they would do for you. $\quad \begin{array}{llll}0 & 1 & 2 & 3\end{array}$

10. Someone getting impatient with you when you were doing $\begin{array}{llll}0 & 1 & 2 & 3\end{array}$ something.

11. Someone assuming you could not understand things because of your age.

12. Friends or family not calling or visiting as often as they should. $\begin{array}{llll}0 & 1 & 2 & 3\end{array}$

$\begin{array}{llll}0 & 1 & 2 & 3\end{array}$

$\begin{array}{llll}0 & 1 & 2 & 3\end{array}$

Answer (circle)

$\begin{array}{llll}0 & 1 & 2 & 3\end{array}$

$\begin{array}{llll}0 & 1 & 2 & 3\end{array}$

$\begin{array}{llll}0 & 1 & 2 & 3\end{array}$

$\begin{array}{llll}0 & 1 & 2 & 3\end{array}$

$\begin{array}{llll}0 & 1 & 2 & 3\end{array}$

$\begin{array}{llll}0 & 1 & 2 & 3\end{array}$

Please turn over to back of page $\Rightarrow$ 
$\begin{array}{cccc}0 & 1 & 2 & 3 \\ \text { Never } & \text { A few times } & \text { Fairly often } & \text { Many times }\end{array}$

\section{Experience in the Last Year?}

13. Being denied a position of responsibility because of your age.

14. Someone making a decision that affected you without talking to you about it first.

15. Someone letting you down or disappointing you.

16. Being seen as unattractive because of your age.

17. Feeling unsafe when you were out in public.

18. Someone betraying your trust by telling a secret.

19. Being treated with less dignity and respect because of your age.

20. Someone invading your privacy (e.g., by going in your room or through your things without your permission).

21. Someone breaking a promise they made to you.

22. Being treated like a child because of your age.

23. Someone not taking your opinions or wishes seriously.

24. Someone taking advantage of your trust in them.

25. Someone telling you, "You're too old for that."

26. Someone (e.g., a waiter/waitress or store clerk) ignoring you because of your age.

27. Someone important to you acting as if they don't care about you.

\section{Answer (circle)}

$\begin{array}{llll}0 & 1 & 2 & 3\end{array}$

$\begin{array}{llll}0 & 1 & 2 & 3\end{array}$

$\begin{array}{llll}0 & 1 & 2 & 3\end{array}$

$\begin{array}{llll}0 & 1 & 2 & 3\end{array}$

$\begin{array}{llll}0 & 1 & 2 & 3\end{array}$

$\begin{array}{llll}0 & 1 & 2 & 3\end{array}$

$\begin{array}{llll}0 & 1 & 2 & 3\end{array}$

$\begin{array}{llll}0 & 1 & 2 & 3\end{array}$

$\begin{array}{llll}0 & 1 & 2 & 3\end{array}$

$\begin{array}{llll}0 & 1 & 2 & 3\end{array}$

$\begin{array}{llll}0 & 1 & 2 & 3\end{array}$

$\begin{array}{llll}0 & 1 & 2 & 3\end{array}$

$\begin{array}{llll}0 & 1 & 2 & 3\end{array}$

$\begin{array}{llll}0 & 1 & 2 & 3\end{array}$

$\begin{array}{llll}0 & 1 & 2 & 3\end{array}$ 


\section{Thinking About the Past}

Some people say that they think about the past as they get older. The following questions ask about your own experiences thinking about your past.

1. Do you ever think about your past experiences deliberately, that is, on purpose?

$\begin{array}{ccccc}\text { No, } & \text { Yes, } & \text { Yes, } & \text { Yes, } & \begin{array}{c}\text { Yes, } \\ \text { never }\end{array} \text { but rarely } \\ \text { sometimes } & \text { often } & \text { very often }\end{array}$

2. When you think about your past, do you ever feel angry or resentful about something that happened to you?

$\begin{array}{ccccc}\begin{array}{c}\text { No, } \\ \text { never }\end{array} & \begin{array}{c}\text { Yes, } \\ \text { but rarely }\end{array} & \begin{array}{c}\text { Yes, } \\ \text { sometimes }\end{array} & \begin{array}{c}\text { Yes, } \\ \text { often }\end{array} & \begin{array}{c}\text { Yes, } \\ \text { very often }\end{array} \\ & 2 & 2 & & \end{array}$

3. Do you ever think about your past experiences in order to find a way to solve a problem you are having now?

$\begin{array}{ccccc}\text { No, } & \text { Yes, } & \text { Yes, } & \text { Yes, } & \begin{array}{c}\text { Yes, } \\ \text { never }\end{array} \\ \text { but rarely } & \text { sometimes } & \text { often } & \text { very often }\end{array}$

4. When you think about your past, do you ever have trouble making sense of why some things happened to you?

$\begin{array}{ccccc}\text { No, } & \text { Yes, } & \text { Yes, } & \text { Yes, } & \begin{array}{c}\text { Yes, } \\ \text { never }\end{array} \text { but rarely } \\ \text { sometimes } & \text { often } & \text { very often }\end{array}$

Please turn over to back of page $\Rightarrow$ 
5. When you think about your past, do you ever think everything happened just the way it was supposed to happen?

$\begin{array}{ccccc}\begin{array}{c}\text { No, } \\ \text { never }\end{array} & \begin{array}{c}\text { Yes, } \\ \text { but rarely }\end{array} & \begin{array}{c}\text { Yes, } \\ \text { sometimes }\end{array} & \begin{array}{c}\text { Yes, } \\ \text { often }\end{array} & \begin{array}{c}\text { Yes, } \\ \text { very often }\end{array}\end{array}$

6. When you think about your past, do you ever wish things had happened differently?

$\begin{array}{lcccc}\begin{array}{l}\text { No, } \\ \text { never }\end{array} & \begin{array}{c}\text { Yes, } \\ \text { but rarely }\end{array} & \begin{array}{c}\text { Yes, } \\ \text { sometimes }\end{array} & \begin{array}{c}\text { Yes, } \\ \text { often }\end{array} & \begin{array}{c}\text { Yes, } \\ \text { very often }\end{array}\end{array}$

7. Do you ever find you can't get thoughts or memories about your past experiences out of your mind even though you want to?

$\begin{array}{ccccc}\begin{array}{c}\text { No, } \\ \text { never }\end{array} & \begin{array}{c}\text { Yes, } \\ \text { but rarely }\end{array} & \begin{array}{c}\text { Yes, } \\ \text { sometimes }\end{array} & \begin{array}{c}\text { Yes, } \\ \text { often }\end{array} & \begin{array}{c}\text { Yes, } \\ \text { very often }\end{array}\end{array}$

8. Do you ever think about your past life experiences because you want to tell someone about them so they can learn from your experience?
No,
Yes,
Yes,
Yes,
Yes, never but rarely sometimes
often very often

9. When you think about your past, do you ever feel guilty or ashamed about something that happened?

$\begin{array}{ccccc}\text { No, } & \text { Yes, } & \text { Yes, } & \text { Yes, } & \text { Yes, } \\ \text { never } & \text { but rarely } & \text { sometimes } & \text { often } & \text { very often }\end{array}$


10. When you think about your past, do you ever have trouble accepting that some of your experiences actually happened?

$\begin{array}{ccccc}\text { No, } & \text { Yes, } & \text { Yes, } & \text { Yes, } & \text { Yes, } \\ \text { never } & \text { but rarely } & \text { sometimes } & \text { many times } & \text { all the time }\end{array}$

11. When you think about your past, do you ever feel that your life has had a purpose and been meaningful?

$\begin{array}{ccccc}\text { No, } & \text { Yes, } & \text { Yes, } & \text { Yes, } & \begin{array}{c}\text { Yes, } \\ \text { never }\end{array} \text { but rarely } \\ \text { sometimes } & \text { often } & \text { very often }\end{array}$

12. Do you ever have trouble doing other things because memories or thoughts about your past experiences keep coming into your mind?

$\begin{array}{ccccc}\text { No, } & \text { Yes, } & \text { Yes, } & \text { Yes, } & \begin{array}{c}\text { Yes, } \\ \text { never }\end{array} \text { but rarely } \\ \text { sometimes } & \text { often } & \text { very often }\end{array}$

13. When you think about your past, do you ever think that you have lived the life you wanted to live?

$\begin{array}{ccccc}\text { No, } & \text { Yes, } & \text { Yes, } & \text { Yes, } & \text { Yes, } \\ \text { never } & \text { but rarely } & \text { sometimes } & \text { often } & \text { very often }\end{array}$




\section{Personal Growth}

Most people encounter hurdles, difficulties and down times at one or more times in their life. Although such negative life experiences may be difficult and unpleasant, some people say their negative life experiences had unexpected positive effects on them. Did you ever experience the following positive changes as a result of the negative experiences you encountered in your life?

Please circle the one number that best describes how much your negative life experiences caused each change, using this scale:

$\begin{array}{cccc}0 & 1 & 2 & 3 \\ \text { Not at all } & \text { A little } & \text { A fair bit } & \text { A good deal }\end{array}$

\section{Caused this Change for You?}

1. Made you change your priorities about what is important in life

2. Increased your appreciation of the value of your own life

3. Made you develop new interests

4. Made you feel more self-reliant

5. Increased your understanding of spiritual matters

6. Helped you see that you can count on people in times of trouble

7. Made you establish a new path for your life

8. Increased your sense of closeness with others
Answer (circle)

$\begin{array}{llll}0 & 1 & 2 & 3\end{array}$

$\begin{array}{llll}0 & 1 & 2 & 3\end{array}$

$\begin{array}{llll}0 & 1 & 2 & 3\end{array}$

$\begin{array}{llll}0 & 1 & 2 & 3\end{array}$

$\begin{array}{llll}0 & 1 & 2 & 3\end{array}$

$\begin{array}{llll}0 & 1 & 2 & 3\end{array}$

$\begin{array}{llll}0 & 1 & 2 & 3\end{array}$

$\begin{array}{llll}0 & 1 & 2 & 3\end{array}$

Please turn over to back of page $\Rightarrow$ 


$\begin{array}{cccc}0 & 1 & 2 & 3 \\ \text { Not at all } & \text { A little } & \text { A fair bit } & \text { A good deal }\end{array}$

\section{Caused this Change for You?}

9. Increased your willingness to express your emotions

10. Let you know that you can handle difficulties

11. Made you able to do better things with your life

12. Helped you accept that things will work out

13. Increased your appreciation of each day

14. Made new opportunities available that wouldn't have been there otherwise

15. Increased your compassion for others

16. Increased the effort you put into relationships

17. Made you more likely to try to change things that need changing

18. Increased the strength of your religious faith

19. Showed you that you were stronger than you thought

20. Taught you about how wonderful people are

21. Made you better able to accept your need for other people

\section{Answer (circle)}

$\begin{array}{llll}0 & 1 & 2 & 3\end{array}$

$\begin{array}{llll}0 & 1 & 2 & 3\end{array}$

$\begin{array}{llll}0 & 1 & 2 & 3\end{array}$

$\begin{array}{llll}0 & 1 & 2 & 3\end{array}$

$\begin{array}{llll}0 & 1 & 2 & 3\end{array}$

$\begin{array}{llll}0 & 1 & 2 & 3\end{array}$

$\begin{array}{llll}0 & 1 & 2 & 3\end{array}$

$\begin{array}{llll}0 & 1 & 2 & 3\end{array}$

$\begin{array}{llll}0 & 1 & 2 & 3\end{array}$

$\begin{array}{llll}0 & 1 & 2 & 3\end{array}$

$\begin{array}{llll}0 & 1 & 2 & 3\end{array}$

$\begin{array}{llll}0 & 1 & 2 & 3\end{array}$

$\begin{array}{llll}0 & 1 & 2 & 3\end{array}$ 


\section{Request for Participation Payment Form}

Thank you for completing our survey of Seniors' Life-Experiences, Coping and Well-Being. Your participation is greatly appreciated. The information you and other participants provide will be used to gain insight into ways of promoting older adults' well-being and helping them cope with the challenges some face.

- So we can mail you a cheque for $\$ 40$ for your time and effort, would you kindly provide the following information (please print):

Your name:

Full mailing address:

- Would you like us to mail you a summary of the results of this survey when they become available (in about 6 months)? Yes / No

- To learn more about older adults' life experiences and well-being, we would like to interview some of the people who took part in this study. Would you would be interested in participating in a confidential interview about your own life experiences and well-being? Yes / No

If you are interested in taking part in an interview, please provide the following information so we can contact you to tell you more about the interview: 
E-mail:

Phone:

Best time to call:

Then mail this form and your completed survey to us, together, in the large prepaid envelope. Note that, because you have submitted your name along with your survey, your survey answers will not be anonymous. However, we will use a code number, rather than your name, on your survey so that only we will know which survey goes with which person's name. As a result, your answers will be entirely confidential.

If you are NOT interested in taking part in an interview, please return this "Request for Participation Payment Form" to us in the small prepaid return envelope. Then return your completed survey to us, separately, using the large prepaid envelope. Returning this form and the survey in two separate envelopes will ensure that your answers are both confidential and anonymous.

Thanks again for helping us with this research. 
Appendix B

Tables and Figures 
Figure 1

\section{A Model of the Variables Mediating the Impact of Earlier Trauma on Seniors' Well-Being}

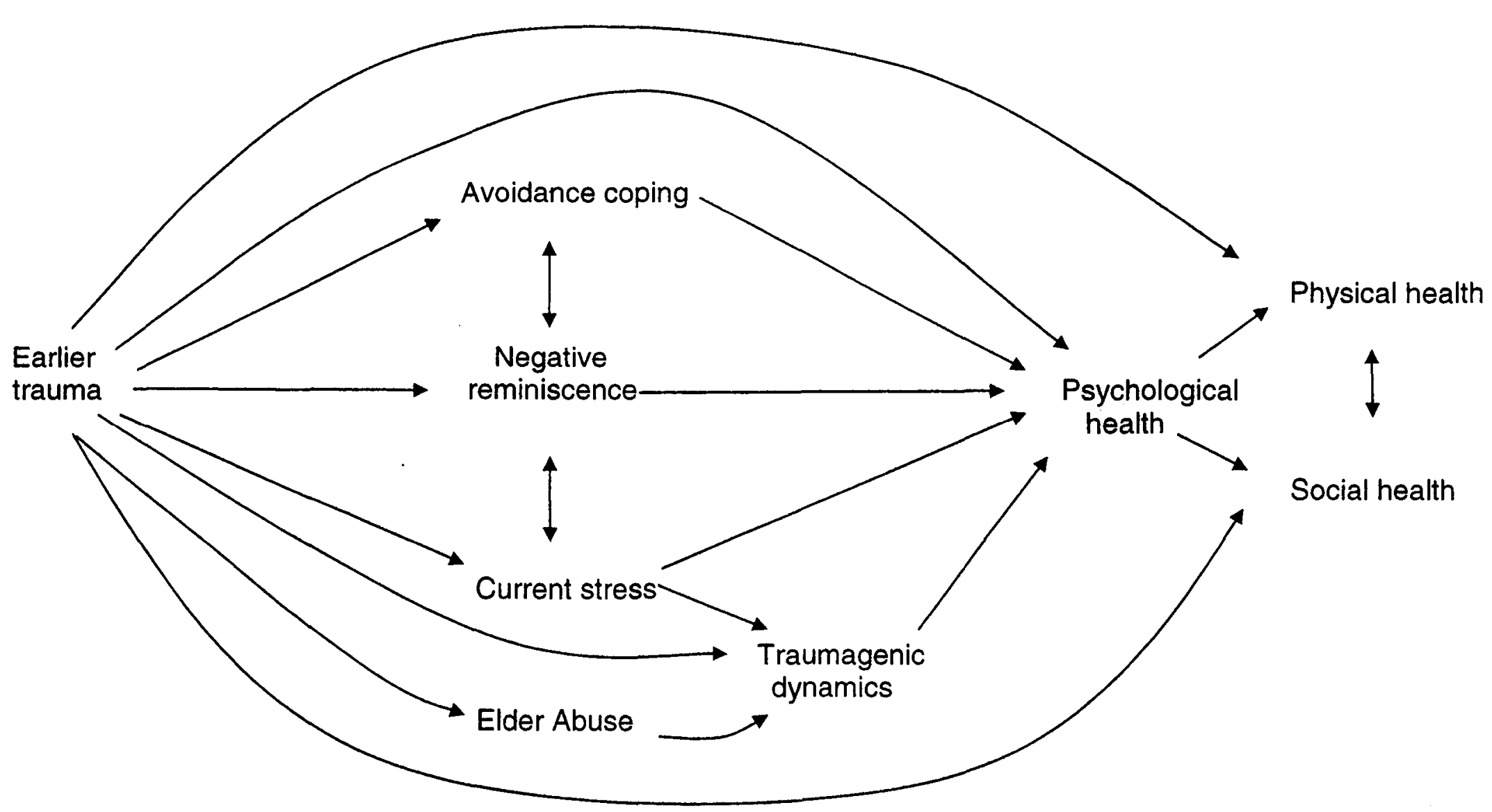


Table 1

Results of the Factor Analysis of the Brief COPE

Factor and item loadings

Factors and items

Taking action Seeking strength Negative coping

Taking Action:

Concentrate your efforts on doing something about the situation

.74

.23

.03

Take action to try to make the situation better

.73

.27

$-.12$

Try to see it in a different light, to make it seem more positive

.60

.21

.11

Try to come up with a strategy about what to do

.75

.22

$-.00$

Look for something good in what is happening

.61

.04

Accept the reality of the fact that it has happened

.68

.13

$-.01$

Learn to live with it

.17

.11

Think hard about what steps to take

Seeking strength:

Get emotional support from others

Say things to let my unpleasant feelings escape

Get help and advice from other people

Get comfort and understanding from someone

Express your negative feelings

Try to find comfort in your religion or spiritual beliefs 
Table 1 (cont'd)

Factor Structure for the Principal Components Analysis of the Brief COPE

\begin{tabular}{|c|c|c|c|}
\hline \multirow[b]{2}{*}{ Factors and items } & \multicolumn{3}{|c|}{ Factor and item loadings } \\
\hline & Taking action & Seeking strength & Negative coping \\
\hline Try to get advice or help from other people about what to do & .24 & .74 & -.03 \\
\hline Pray or meditate & .11 & .51 & -.03 \\
\hline \multicolumn{4}{|l|}{ Avoidance coping: } \\
\hline Say to yourself, "this isn't real." & .02 & .06 & .65 \\
\hline Give up trying to deal with it & .02 & .09 & .55 \\
\hline Refuse to believe that it has happened & .03 & .01 & .40 \\
\hline Use alcohol or other drugs to help you get through it & -.19 & .06 & .43 \\
\hline Criticize yourself & .34 & -.04 & .51 \\
\hline Give up trying to cope & .06 & -.05 & .59 \\
\hline Blame yourself for things that happened & .28 & -.09 & .40 \\
\hline \multicolumn{4}{|l|}{ Deleted items: } \\
\hline Use alcohol or drugs to make yourself feel better & .03 & .08 & .37 \\
\hline Make jokes about it & .37 & .14 & .39 \\
\hline Make fun of the situation & .37 & .09 & .38 \\
\hline $\begin{array}{l}\text { Do something to think about it less, such as go to the movies, } \\
\text { watch TV, read, daydream, sleep or shop }\end{array}$ & .28 & .31 & .46 \\
\hline Turn to work or other activities to take your mind off things & .32 & .23 & .41 \\
\hline
\end{tabular}


Table 2

Results of Item Analyses and Descriptive Statistics for the Potential

Mediating/Moderating Variables

\begin{tabular}{|c|c|c|c|c|c|c|}
\hline Variable & \# of items & $\alpha$ & $\begin{array}{l}M \text { inter- } \\
\text { item } r\end{array}$ & $\begin{array}{l}\text { Potential } \\
\text { range }\end{array}$ & $M$ & $S D$ \\
\hline \multicolumn{7}{|l|}{ Coping: } \\
\hline Taking action & 8 & .86 & .43 & $0-3$ & 1.81 & 0.68 \\
\hline Seeking support & 8 & .80 & .35 & $0-3$ & 1.21 & 0.62 \\
\hline Avoidance & 6 & .66 & .25 & $0-3$ & 0.62 & 0.39 \\
\hline \multicolumn{7}{|l|}{ Reminiscence: } \\
\hline Negative & 7 & .85 & .45 & $0-4$ & 1.01 & 0.70 \\
\hline Positive & 5 & .67 & .29 & $0-4$ & 1.76 & 0.72 \\
\hline Current stress & 31 & .64 & .04 & $0-31$ & 3.69 & 2.73 \\
\hline Traumagenic dynamics & 22 & .92 & .35 & $0-3$ & 0.37 & 0.34 \\
\hline
\end{tabular}


Table 3

Results of the Factor Analysis of the Measure of Reminiscence

$\underline{\text { Reminiscence factor }}$

Factor and item

Negative Positive

Negative reminiscence:

When you think about your past, do you ever feel angry

or resentful about something that happened to you?

When you think about your past, do you ever trouble making sense of why some things happened to you?

When you think about your past, do you ever wish things had happened differently?

Do you ever find you can't get thoughts or memories about your past experiences out of your mind even though you want to?

When you think about your past, do you ever feel guilty or ashamed about something that happened?

When you think about your past, do you ever have trouble accepting that some of your experiences actually happened?

Do you ever have trouble doing other things because memories or thoughts about your past experiences keep coming into your mind?

Positive reminiscence:

Do you ever think about your past experiences deliberately, that is, on purpose?

When you think about your past, do you ever think everything happened just the way it was supposed to happen?

Do you ever think about your past experiences because you want to tell someone about them so they can learn from your experiences?

When you think about your past, do you ever feel that your life has had purpose and been meaningful?

When you think about the past, do you ever think that you lived the life you wanted to live?

Deleted item:

Do you ever think about your past experiences in order to find a way to solve a problem you are having now? 
Table 4

Results of the Principal Components Analysis of the Measure of Exposure to the

Traumagenic Dynamics

Item

Loading

Being told a joke that makes fun of older people $\quad .26$

Needing someone's help to do something that you used to do on your own $\quad .38$

$\begin{array}{ll}\text { Someone not giving you the care and attention you deserve } & .72\end{array}$

Being called an insulting name related to your age $\quad .57$

Your concerns or complaints not being taken seriously because of your age $\quad .74$

Someone you care about leaving or abandoning you $\quad .57$

Being patronized or talked down to because of your age $\quad .71$

Having to rely on others (e.g., doctors) to keep up your health $\quad .50$

Someone not doing what they said they would do for you $\quad .64$

Someone getting inpatient with you when you were doing something $\quad .63$

Someone assuming you could not understand things because of your age $\quad .72$

Friends or family not calling or visiting as often as they should $\quad .52$

Being denied a position of responsibility because of your age $\quad .07$

Someone making a decision that affected you without talking to you about it first $\quad .56$

Someone letting you down or disappointing you $\quad .68$

Being seen as unattractive because of your age $\quad .37$

Feeling unsafe when you were out in public . $\quad .44$

Someone betraying your trust by telling a secret $\quad .43$

Being treated with less dignity and respect because of your age $\quad .71$

Someone invading your privacy (e.g., by going into your room or $\quad .36$ through your things without your permission)

Someone breaking a promise they made to you $\quad .61$

Being treated like a child because of your age $\quad .62$

Someone not taking your opinions or wishes seriously $\quad .63$

$\begin{array}{ll}\text { Someone taking advantage of your trust in them } & .74\end{array}$

Someone telling you, "You're too old for that." $\quad .50$

Someone (e.g., waiter/waitress or store clerk) ignoring you because of your age $\quad .47$

Someone important to you acting as if they don't care about you .65 
Table 5

Descriptive Statistics for the Measures of Psychological Well-Being

\begin{tabular}{lcccccc}
\hline & $\begin{array}{l}\text { \# of } \\
\text { Variable }\end{array}$ & \multicolumn{7}{c}{$\begin{array}{c}M \text { inter- } \\
\text { items } r\end{array}$} & $\begin{array}{c}\text { Potential } \\
\text { range }\end{array}$ & $M$ & $S D$ \\
\hline Total TSI-A: & 63 & .96 & .30 & $0-3$ & 0.46 & 0.37 \\
Anxious arousal & 8 & .85 & .40 & $0-3$ & 0.62 & 0.51 \\
Defensive avoidance & 8 & .87 & .45 & $0-3$ & 0.60 & 0.56 \\
Intrusive experiences & 8 & .86 & .44 & $0-3$ & 0.49 & 0.49 \\
Depression & 8 & .91 & .56 & $0-3$ & 0.48 & 0.50 \\
Anger/irritability & 9 & .90 & .52 & $0-3$ & 0.51 & 0.50 \\
Dissociation & 9 & .79 & .33 & $0-3$ & 0.41 & 0.38 \\
Impaired self $_{\text {Tension reduction }}{ }^{2}$ & 9 & .83 & .35 & $0-3$ & 0.36 & 0.41 \\
& 8 & .63 & .21 & $0-3$ & 0.16 & 0.24 \\
\hline
\end{tabular}

after deletion of item, "Intentionally hurting yourself." 
Table 6

Correlations Among TSI-A Scale Scores

$\begin{array}{llllllllll}\text { TSI-A scale } & 1 & 2 & 3 & 4 & 5 & 6 & 7 & 8\end{array}$

1. TSI-A total

2. Anxious arousal $.86^{* *}$

3. Defensive avoidance $.76^{* *} .58 * *$

4. Intrusive experiences $.78 * * \quad .58 * * \quad .74 * *$

5. Anger/irritability $\quad .69^{* *} .63 * * \quad .44 * * \quad .42 * *$

6. Depression $\quad .79^{* *} \quad .67^{* *} \quad .48^{* *} \quad .54^{* *} .48^{* *}$

7. Dissociation $\quad .73 * * \quad .63 * * \quad .42 * * \quad .47 * * \quad .49 * * \quad .59 * *$

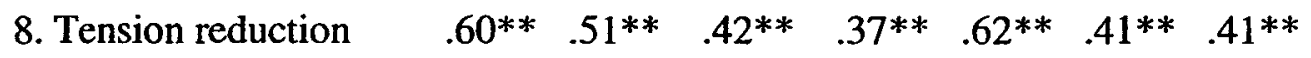

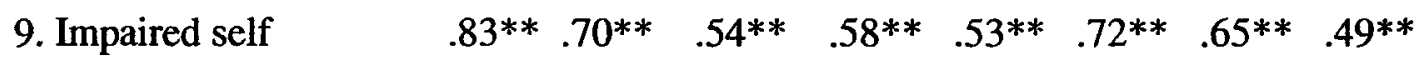

${ }^{* *} p<.001$. Two-tailed. 
Table 7

Item Loadings for the Principal Components Analysis of the Measure of Physical Health

Item

Loading

During the past 6 months, how many times have you seen a doctor about .59 your physical health (not including times you were a hospital inpatient)?

During the past 6 months, how many times were you so sick that you were unable to carry on with your usual activities?

During the past 6 months, how many days were you in hospital because of a physical health problem?

Compared to people you own age and sex, how would you rate your overall physical health?

Do you currently have any of the following health problems or illnesses?

Are you currently taking any medications prescribed by a medical doctor? 
Table 8

Descriptive Statistics for the Measures of Well-Being.

\begin{tabular}{|c|c|c|c|c|c|c|}
\hline Variable & $\begin{array}{l}\text { \# of } \\
\text { items }\end{array}$ & $\alpha$ & $\begin{array}{l}M \text { inter- } \\
\text { item } r\end{array}$ & $\begin{array}{l}\text { Potential } \\
\text { range }\end{array}$ & $M$ & $S D$ \\
\hline Total TSI-A & 63 & .96 & .30 & $0-3$ & 0.46 & 0.37 \\
\hline Physical health: & 5 & .74 & .35 & $-\quad-$ & - & - \\
\hline Doctor visits & 1 & - & - & $0-24$ & 2.77 & 2.81 \\
\hline Sick days & 1 & - & - & $0-180$ & 4.41 & 17.17 \\
\hline Hospital visits & 1 & - & - & $0-30$ & 0.46 & 2.39 \\
\hline $\begin{array}{l}\text { Nursing home/rehab } \\
\text { visits }\end{array}$ & 1 & - & - & $0-7$ & 0.02 & 0.40 \\
\hline Health symptoms & 24 & - & - & $0-24$ & 2.43 & 2.03 \\
\hline Medications & 1 & - & - & $0-15$ & 2.94 & 2.93 \\
\hline Subjective health & 1 & - & - & $0-4$ & 2.98 & 0.92 \\
\hline \multicolumn{7}{|l|}{ Social well-being: } \\
\hline Social activities & 8 & .57 & .12 & $0-8$ & 4.76 & 1.65 \\
\hline $\begin{array}{l}\text { Go to movies, theatre, } \\
\text { Concerts, restaurants }\end{array}$ & 1 & - & - & $0-3$ & 1.50 & 0.56 \\
\hline $\begin{array}{l}\text { Play cards and other } \\
\text { games }\end{array}$ & 1 & - & - & $0-3$ & 1.15 & 0.78 \\
\hline
\end{tabular}


Table 9

Results of the Principal Components Analysis of the Measure of Social Well-Being

Item

Loading

Have you made a personal phone call in the last week?

Have you written a personal letter in the last week?

Do you attend religious services, gatherings or meetings?

Did you vote in the last federal or local elections?

Have you been away on a holiday in the last year?

Are you planning on going away on a holiday in the next year?

Do you use the public library?

In the past month, have you attended a meeting or gathering of any club, organization, society, or group?

Do you take part in volunteer activities?

Do you go out to the movies, theatre, concerts or restaurants?

Do you play cards, or other games with other people? 
Table 10

Frequency of Participants' Experiences of Different Types of Trauma by Gender

\begin{tabular}{|c|c|c|c|c|c|c|}
\hline \multirow[b]{2}{*}{ Trauma } & \multicolumn{2}{|c|}{ Total } & \multicolumn{2}{|c|}{ Women } & \multicolumn{2}{|c|}{$\underline{\text { Men }}$} \\
\hline & $n$ & $\%$ & $n$ & $\%$ & $n$ & $\%$ \\
\hline \multicolumn{7}{|l|}{ Noninterpersonal } \\
\hline Natural disaster & 102 & 32.9 & 61 & 31.4 & 41 & 35.3 \\
\hline Bad car accident & 89 & 28.7 & 48 & 24.7 & 41 & 35.3 \\
\hline Other accident & 52 & 16.8 & 27 & 13.9 & 25 & 21.5 \\
\hline Witness violent death & 48 & 15.5 & 18 & 9.3 & 30 & 25.9 \\
\hline \multicolumn{7}{|l|}{ Interpersonal } \\
\hline Robbery & 51 & 16.4 & 31 & 16.0 & 20 & 17.2 \\
\hline Witness family violence & 73 & 23.5 & 52 & 26.8 & 21 & 18.1 \\
\hline Child sexual touching & 81 & 26.1 & 51 & 26.3 & 30 & 25.9 \\
\hline Child sexual intercourse & 24 & 7.7 & 11 & 5.7 & 13 & $11: 2$ \\
\hline Child physical abuse & 92 & 29.7 & 40 & 22.6 & 52 & 44.8 \\
\hline Adult physical assault (stranger) & 33 & 10.6 & 11 & 5.7 & 22 & 19.0 \\
\hline Partner abuse & 68 & 21.9 & 45 & 23.2 & 23 & 19.8 \\
\hline Adult sexual touching & 41 & 13.2 & 34 & 17.5 & 7 & 6.0 \\
\hline Adult sexual intercourse & 27 & 8.7 & 26 & 13.4 & 1 & 0.9 \\
\hline Elder sexual touching & 2 & 0.6 & 1 & 0.5 & 1 & 0.5 \\
\hline Elder sexual intercourse & 1 & 0.5 & 1 & 0.5 & 0 & 0.0 \\
\hline Elder physical abuse & 4 & 1.3 & 2 & 1.0 & 2 & 1.7 \\
\hline Witness warfare or combat & 40 & 12.9 & 16 & 8.2 & 24 & 20.7 \\
\hline War or combat experience & 16 & 5.2 & 4 & 2.1 & 12 & 10.3 \\
\hline Concentration camp & 1 & 0.9 & 0 & 0.0 & 1 & 0.9 \\
\hline Prisoner of war & 2 & 1.7 & 0 & 0.0 & 2 & 1.7 \\
\hline
\end{tabular}


Table 11

Descriptive Statistics for Participants' Responses to Questions regarding their 'Worst' Stressful Experience

\begin{tabular}{|c|c|c|c|c|c|c|c|c|}
\hline \multirow{3}{*}{\multicolumn{2}{|c|}{ 'Worst trauma' question }} & \multicolumn{7}{|c|}{ Type of 'worst trauma' } \\
\hline & & Potential range & \multicolumn{2}{|c|}{ Any trauma $(n=130)$} & \multicolumn{2}{|c|}{ Noninterpersonal $(n=92)$} & \multicolumn{2}{|c|}{ Interpersonal $(n=28)$} \\
\hline & & & $\underline{M}$ & $\underline{S D}$ & $\underline{M}$ & $\underline{S D}$ & $\underline{M}$ & $\underline{S D}$ \\
\hline \multirow[t]{2}{*}{ Distress: } & Then & $0-4$ & 2.91 & 0.98 & 3.05 & 0.98 & 2.85 & 1.13 \\
\hline & Now & $0-4$ & 0.89 & 1.08 & 0.89 & 1.16 & 0.85 & 1.06 \\
\hline \multicolumn{2}{|c|}{ Frequency think about it now } & $0-4$ & 1.34 & 0.88 & 1.37 & 0.88 & 1.33 & 0.88 \\
\hline \multicolumn{2}{|c|}{$\begin{array}{l}\text { Frequency think about now } \\
\text { compared to earlier }\end{array}$} & $0-4$ & 0.90 & 0.99 & 0.93 & 1.08 & 0.89 & 0.96 \\
\hline \multicolumn{2}{|c|}{ Frequency memories triggered } & $0-4$ & 1.27 & 1.03 & 1.17 & 0.93 & 1.31 & 1.08 \\
\hline \multirow{2}{*}{\multicolumn{2}{|c|}{$\begin{array}{l}\text { Frequency feel need to talk } \\
\text { about now } \\
\text { Frequency actually talk about } \\
\text { now }\end{array}$}} & $0-4$ & 0.91 & 0.88 & 0.61 & 0.79 & 0.79 & 0.99 \\
\hline & & $0-4$ & 0.74 & 0.94 & 0.97 & 0.68 & 0.88 & 0.85 \\
\hline \multicolumn{2}{|c|}{$\begin{array}{l}\text { Frequency talked to a } \\
\text { professional }\end{array}$} & $0-4$ & 0.53 & 1.01 & 0.55 & 1.06 & 0.52 & 0.99 \\
\hline
\end{tabular}


Table 12

Frequency of Participants' Experiences of Current Stressors

$\begin{array}{ll}\text { Current stressor } & N\end{array}$

Death of a friend

$128 \quad 41.3$

A major illness or deterioration in the health of a family member

$125 \quad 40.3$

A deterioration in your memory

$119 \quad 38.4$

$\begin{array}{lll}\text { A major decrease in doing the activities you really enjoy } & 101 & 32.6\end{array}$

$\begin{array}{lll}\text { Death of some other close family member } & 76 \quad 24.5\end{array}$

$\begin{array}{lll}\text { A major deterioration in your health, a personal injury or an illness } & 74 \quad 23.9\end{array}$

$\begin{array}{lll}\text { An increase in responsibilities or hours where you work or volunteer } & 54 & 17.4\end{array}$

$\begin{array}{llll}\text { A decrease in responsibilities or hours where you work or volunteer } & 48 & 15.5\end{array}$

$\begin{array}{llll}\text { Worsening relationship with a child } & 40 & 12.9\end{array}$

$\begin{array}{llll}\text { Worsening relationship with someone other than your spouse or child } & 39 & 12.6\end{array}$

$\begin{array}{llll}\text { The loss of a very close friend due to a move or break in the friendship } & 38 & 12.3\end{array}$

$\begin{array}{lll}\text { Your retirement } & 38 & 12.3\end{array}$

$\begin{array}{lll}\text { A major deterioration in your financial state } & 35 & 11.3\end{array}$

$\begin{array}{lll}\text { Your child's divorce or marital separation } & 29 & 9.3\end{array}$

$\begin{array}{lll}\text { Assuming major responsibility for a parent or spouse } & 28 & 9.0\end{array}$

$\begin{array}{lll}\text { A deterioration in your living conditions } & 22 & 7.1\end{array}$

$\begin{array}{lll}\text { The retirement of your spouse } & 19 & 6.1\end{array}$

$\begin{array}{lll}\text { Worsening relationship with your spouse } & 17 & 5.5\end{array}$

$\begin{array}{lll}\text { The institutionalization of a parent } & 16 & 5.2\end{array}$

$\begin{array}{llll}\text { Death of your spouse } & 15 & 4.8\end{array}$

$\begin{array}{lll}\text { A move to a less desirable residence } & 14 & 4.5\end{array}$

$\begin{array}{lll}\text { Troubles with your boss or co-workers } & 10 & 3.2\end{array}$

$\begin{array}{lll}\text { The loss of prized possessions due to a move } & 9 & 2.9\end{array}$

$\begin{array}{lll}\text { Marriage } & 7 & 2.3\end{array}$

$\begin{array}{lrr}\text { Being burglarized or robbed } & 5 & 1.6\end{array}$

$\begin{array}{lrr}\text { A change to a less desirable line of work } & 5 & 1.6\end{array}$

$\begin{array}{lll}\text { Marital separation } & 4 & 1.3\end{array}$

$\begin{array}{lll}\text { Death of a grandchild } & 4 & 1.3\end{array}$

$\begin{array}{lll}\text { Death of a son or daughter } & 3 & 1.0\end{array}$

$\begin{array}{lll}\text { The institutionalization of a spouse } & 3 & 1.0\end{array}$

$\begin{array}{lll}\text { Divorce } & 2 & 0.6\end{array}$ 
Table 13

Correlations Between the Potential Mediating/Moderating Variables

\begin{tabular}{llllllll}
\hline Variable & 1 & 2 & 3 & 4 & 5 & 6 \\
\hline
\end{tabular}

Coping:

1. Taking action $-$

2. Seeking strength $.50 * * *$

3. Avoidance $.18^{* *} .15^{* *}$

Reminiscence

4. Negative $.05 \quad .25 * * * \quad .49 * * *$

5. Positive $.27 * * * \quad .29 * * * \quad .03 \quad .03$

6. Current stress $\begin{array}{lllll}.11 & .21 * * * & .14^{*} & .22^{* * *} \quad .09\end{array}$

7. Traumagenics .07 $.21 * * *$ $.26^{* * *} \quad .45^{* * *} \quad .07$ $.46^{* *}$

Note. Ns range from 305 to 310 .

${ }^{*} p<.05 .{ }^{*} p<<.01 .{ }^{* * *} p<.001$. Two-tailed. 
Table 14

Simple and Partial Correlations of Measures of Trauma and Well-Being with Potential Mediating/Moderating Variables

Type of trauma

\begin{tabular}{llll} 
Measure & \multicolumn{2}{l}{ Interpersonal } & Noninterpersonal \\
& $r \quad$ Partial $r^{\mathrm{a}}$ & & Partial $r^{\mathrm{a}}$
\end{tabular}

Well-being:

TSI-A

Physical

Social

Coping:

Taking action

$.13^{*}$

.11

$.12^{*}$

.09

.11

.11

Avoidance

Reminiscence:
$.27 * * * \quad .24 * * *$

$.13^{*} \quad .05$

$.26 * * * \quad .24 * * *$

$.35 * * * \quad .22 * * *$
$.13^{*} \quad .03$

$.25 * * * \quad .19 * *$

$.01 \quad .01$

$\begin{array}{lllll}\text { Negative } & .27 * * * & .24 * * * & .09 & .03 \\ \text { Positive } & .13^{*} & .05 & .21 * * * & .19 * * \\ \text { Current stress } & .26 * * * & .24 * * * & .15^{* *} & .08 \\ \text { Traumagenics } & .35 * * * & .22 * * * & .15 * * & .06\end{array}$

Note. $\mathrm{Ns}=209$ and 182 for interpersonal and noninterpersonal trauma, respectively.

${ }^{a}$ Correlation after partialing out the effects of the other type of trauma.

${ }^{*} p<.05 .{ }^{* *} p<.01 .{ }^{* * *} p<.001$. Two-tailed. 
Table 15

Correlations of Well-Being with Potential Mediating/Moderating Variables

Variable TSI-A total Physical health Social well-being

Coping:

Taking action $\quad .08$

$.08 \quad .20 * *$

Seeking strength

$.27 * * *$

.04

$.22 * *$

Avoidance

$.49 * * *$

.08

.01

Reminiscence:

Negative

$.70^{* * *}$

$.16^{*}$

$-.01$

Positive

.02

$-.00$

$.15^{* *}$

Current stress

$.35 * * *$

$.31 * * *$

.01

Traumagenics

$.64 * * *$

$.43 * * *$

$.16^{* *}$

Note. Ns range from 306 to 310 .

${ }^{*} p<.05 .{ }^{* *} p<.01 . * * * p<.001$. Two-tailed 
Table 16

Results of Simultaneous Regression of the Measure of Psychological Well-Being onto the Potential Mediating Variables and Interpersonal Trauma

TSI-A

Variable

$\beta \quad t(302)$

\begin{tabular}{lcc} 
Seeking strength & .046 & 1.25 \\
Negative reminiscence & .491 & $12.19^{* *}$ \\
Current stress & .049 & 1.21 \\
Traumagenics & .350 & $7.93^{* *}$ \\
Interpersonal trauma & .091 & $2.39^{*}$ \\
\hline
\end{tabular}


Table 17

Results of Simultaneous Regression of the Measure of Psychological Well-Being onto the Potential Mediating Variables and Noninterpersonal Trauma

\section{TSI-A}

Variable

$\beta \quad t(306)$

Current stress

$.071 \quad 1.44$

Traumagenics

$.600 \quad 12.13^{* *}$

Noninterpersonal

.028

0.63

${ }^{*} p<.05 .{ }^{*} p<.001$. Two-tailed. 
Table 18

Correlations Between Participants Demographic Characteristics and the Trauma, Potential Mediating/Moderating and Well-Being Measures

Demographic characteristic

Study variable

Gender $^{\mathrm{a}}$

Age

Education

Income

Trauma:

Interpersonal

$-.05-.15 * *$

.07

$-.10$

Noninterpersonal

$-.18^{* *}$

$-.06$

.07

$-.01$

Coping:

Taking action

.07

$.18 * *$

$.24 * * *$

.07

Seeking strength

$.26 * * * \quad .19 * *$

.10

Avoidance

.07

$.12 *$

$-.01$

$-.12$

Reminiscence:

Negative

Positive

Current stress

Traumagenics

Well-being:

Psychological

Physical

Social

\section{.10}

$-.19 * *$

$-.02$

$.22 * *$

.01

$-.05$

.00

.10

.00

.03

$-.22 * * *$

.01
$-.07$

$-.14$

$.20 * * *$
$-.17 * *$

$.13 *$

$-.16 * *$

$-.23 * * *$

$-.22 * * *$

$-.25 * * *$

$.20 * * *$

Note. Ns range from 282 to 310 .

${ }^{\text {a }}$ Gender was dummy coded as 0 for males and 1 for females.

${ }^{*} \mathrm{p}<.05 .{ }^{* *} \mathrm{p}<.01 .{ }^{* * *} \mathrm{p}<.001$. Two-tailed. 
Figure 2

Results of the Path Analysis Examining Variables Mediating the Effects of Interpersonal Trauma on Well-Being

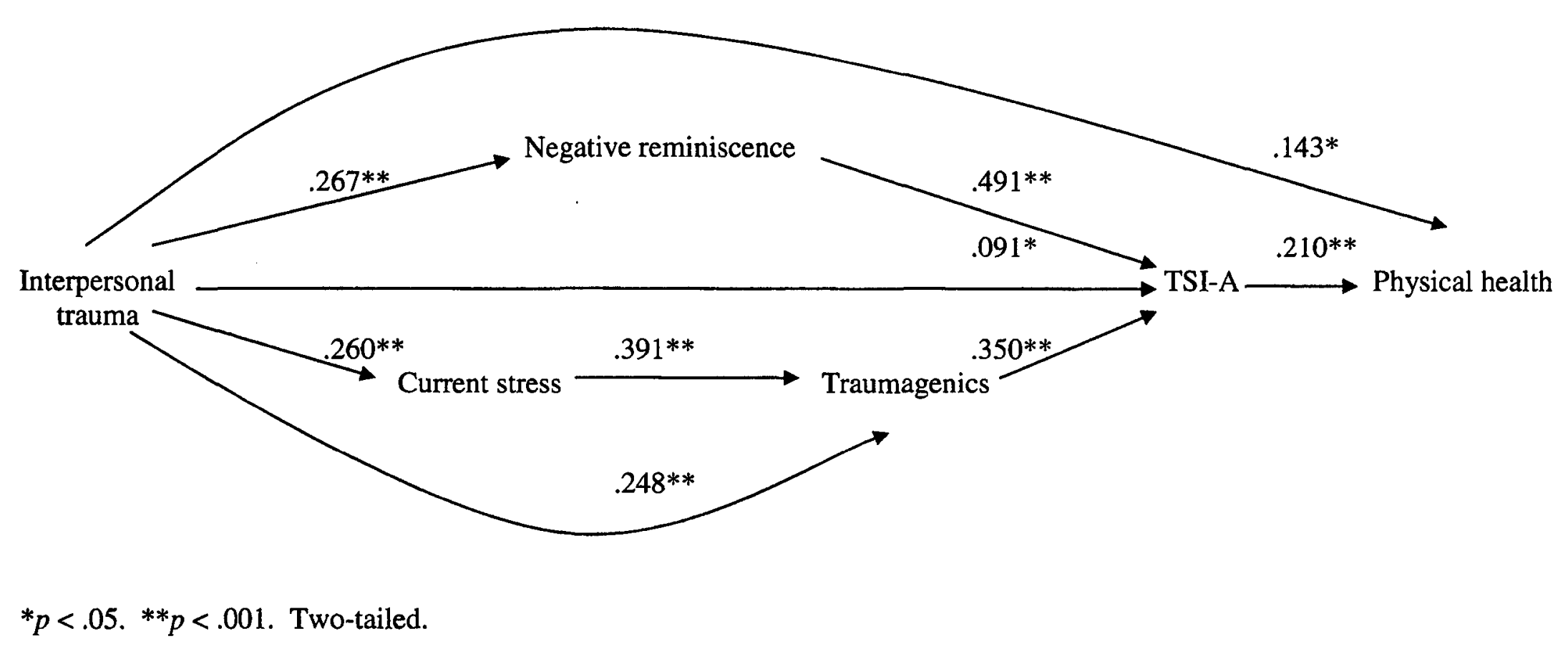


Figure 3

\section{Results of the Path Analysis Examining Variables Mediating the Effects of Noninterpersonal Trauma on Well-Being}

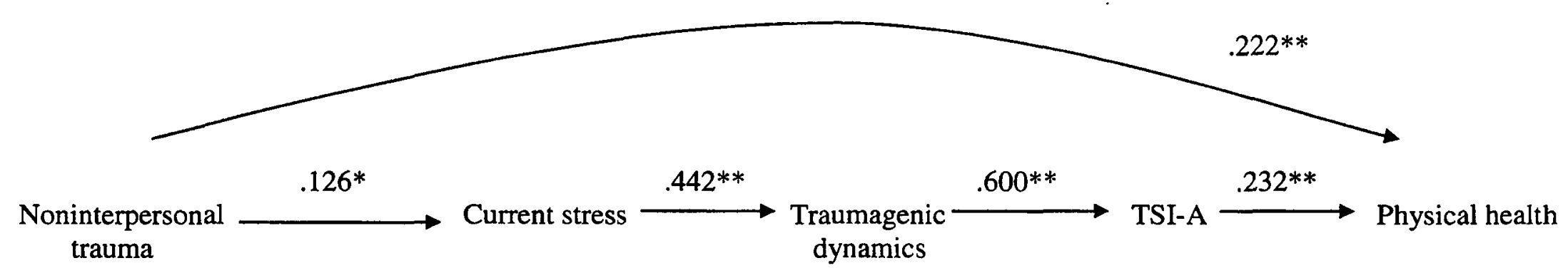

${ }^{*} p<.05 .{ }^{* *} p<.001$, Two-tailed. 
Figure 4

Predicted Scores Associated with the Interactive Effect of Noninterpersonal Trauma and Current Stress on Physical Health

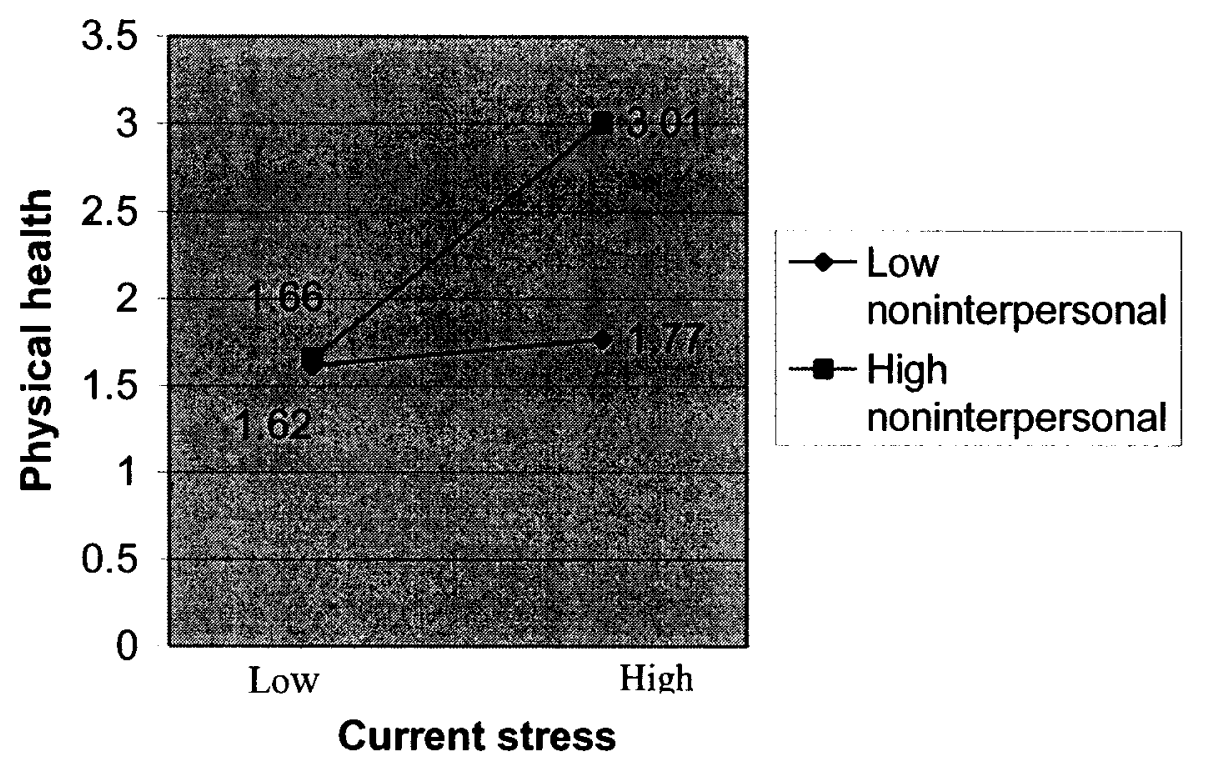


Figure 5

Predicted Scores Associated with the Interactive Effect of Negative Reminiscence and Current Stress on Physical Health

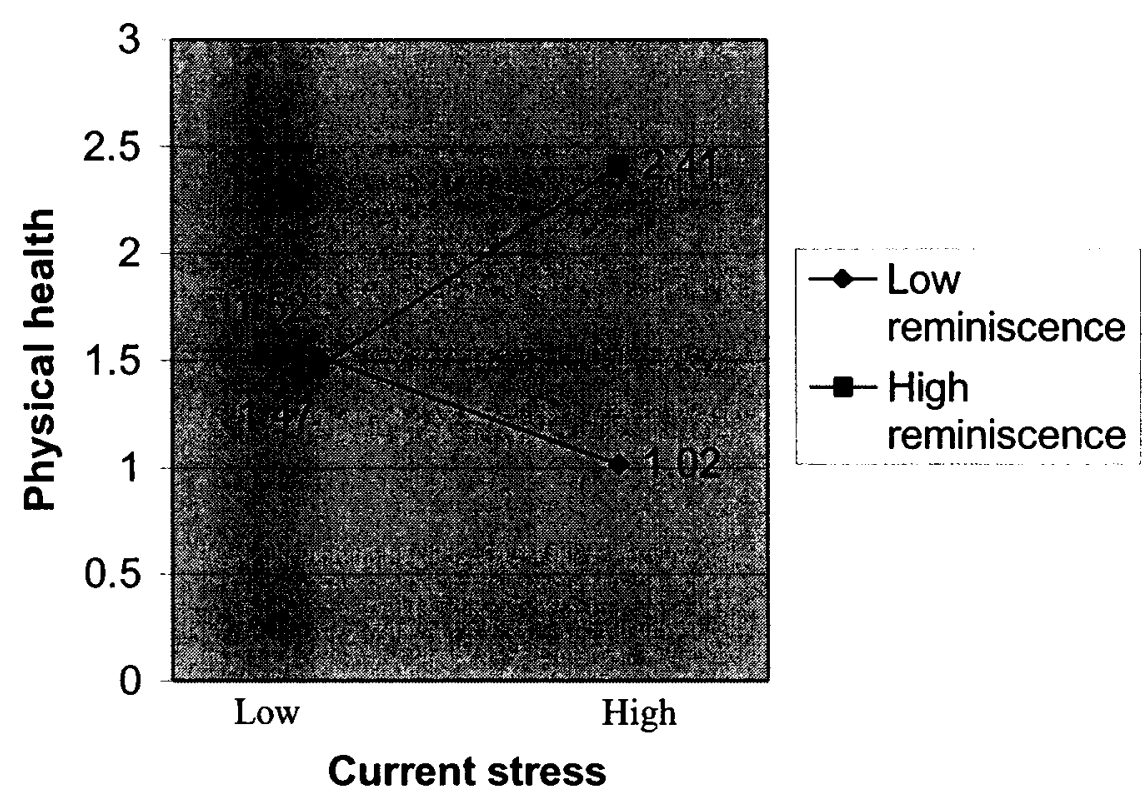


Figure 6

Predicted Scores Associated with the Interactive Effect of Traumagenic Dynamics and Current Stress on Physical Health

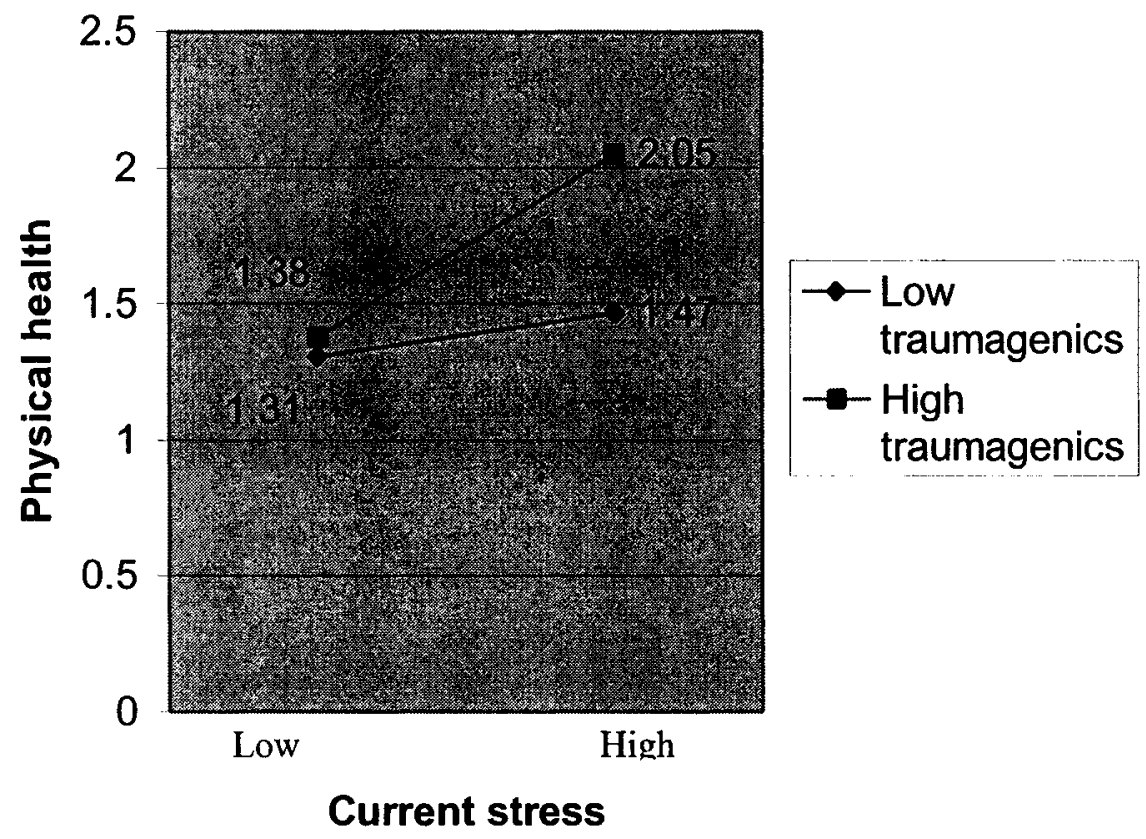

